\title{
UNDERSTANDING SPATIAL AND TEMPORAL PATTERNS IN MOVEMENT AND HABITAT USE OF BLACK-TAILED DEER IN NORTHERN CALIFORNIA, USA
}

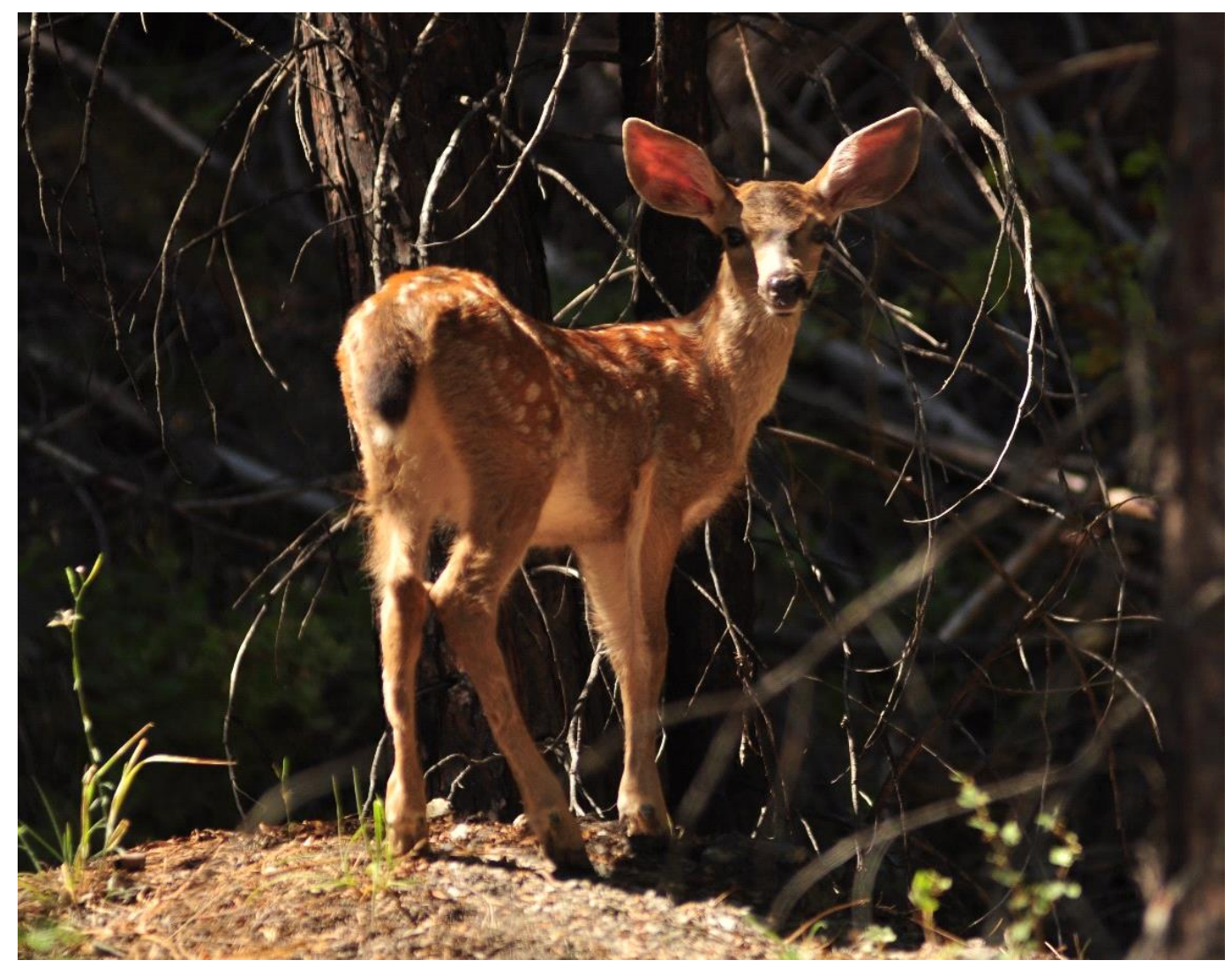

By

Samhita Bose

A dissertation submitted to the Victoria University of Wellington in fulfilment of the requirements for the degree of Doctor of Philosophy in Ecology and Biodiversity Victoria University of Wellington

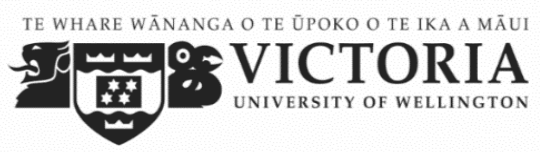




\section{Dissertation Abstract}

Black-tailed deer (BTD, Odocoileus hemionus columbianus), a socio-economically important deer species in western North America is steadily declining throughout much of its range over the last century. Though a large number of studies have been carried out on forage availability, predation pressure, and population dynamics of the species, there still remain broad gaps in current understanding of the underlying causes, mechanisms, and spatio-temporal patterns of habitat use which can affect the population dynamics and distribution of BTD. So, the central aim of my thesis was to identify the spatial and temporal scale that may affect habitat selection, movement and ultimately long-term persistence of the BTD population in the Mendocino National Forest, California.

Understanding population structuring in BTD is vital to underpin the spatial scale for conservation. So, I tested for presence of population sub-structuring among female BTD in the study area by analysing the combined effect of site fidelity and philopatry on the population. Fidelity analyses from radio-telemetry data revealed BTD to have extremely small seasonal home ranges $\left(0.71 \mathrm{~km}^{2}\right)$ and very high site fidelity to these ranges. Direct fitness benefits of fidelity were observed as individuals with decreased site fidelity to their ranges suffered elevated risks of mortality. Results from mtDNA sequencing revealed high genetic differentiation $\left(F_{\mathrm{ST}}>0.30\right)$ and low haplotype sharing even among geographic areas separated by as little as $4-10 \mathrm{~km}$. Combined, the results indicated prolonged period of philopatric behaviour resulting in demographic isolation and very small scale population sub-structuring that can impact the population dynamics at a finer spatial scale than previously assumed.

Next, I examined the effect of temporal scale on resource selection by BTD, through comparing habitat characteristics selected by BTD from a pooled model (all 
telemetry locations pooled across activity states) versus habitat characteristics associated with foraging (active state) and resting or ruminating (inactive state). The main factors that influenced resource selection in BTD were: 1) seasonal changes associated largely with variable selection towards slope, aspect, and elevation and 2) activity states influenced fine-scale selection towards vegetation type, edge density, and cover within the home-ranges. The comparative analysis also revealed that due to larger proportion of resting and ruminating locations, the pooled model frequently failed to identify critical foraging habitats and reflected habitats associated with resting. The frequent misidentification for important ecological covariates associated with foraging was a testimony that pooling data across activity states in BTD can negatively impact our understanding about habitat selection by the species.

Finally, I developed a movement model to understand the spatial and temporal patterns of risk-forage trade-offs by female BTD as a function of landscape familiarity. The results showed that familiarity affects the trade-off patterns by BTD in a heterogeneous landscape, with differential selection towards productivity and risk that also varied largely with habitat types. The results further revealed strong selection towards highly familiar areas by BTD during the night time and at dawn while stepping into less familiar areas during the daytime. The demonstrated preference for familiar locations within their home ranges when their primary predator (puma) is most active emphasizes that spatial familiarity is important not only for large scale processes like selection of home range, but also for striking fine-scale trade-offs between forage and risk within individual home ranges. The knowledge of this fine scale selection pattern is critical for maintaining habitat heterogeneity at a spatial scale comparable to the size of their home ranges, as they have vital consequences on fitness of BTD that ultimately affects the population dynamics of the species. 


\section{Acknowledgements}

Where to start...last four years had been a real test of endurance with many ups and downs but I was lucky to have a great circle of support people who helped me keep my sanity and kept me going through this phase. And I will like to take this opportunity to thank you all.

First and foremost, I will like to thank Dr. Heiko Wittmer for giving me this opportunity. Without his support this study would not have been possible. I also sincerely thank my secondary supervisor Dr. Stephen Hartley for his unwavering support. His door was always open whenever I needed his advice or help on any matter. I would also like to thank my advisory committee, Prof. Phil Lester, and Dr. Kevin C. Burns for their guidance and support.

I am grateful to Victoria University of Wellington for providing the platform to pursue my $\mathrm{PhD}$ study. I am especially thankful to the administrative staff at the School of Biological Sciences, Mary Murray, Mark Stephen, Sandra Taylor, Charlotte Ansell, Paul Marsden, and Lesley Thompson and Patricia Stein from the Faculty of Science, for facilitating my study at VUW. Financial support for my dissertation research was generously provided by Victoria University of Wellington $\mathrm{PhD}$ Scholarship and Victoria Doctoral Submission Scholarship. The funding helped me to exclusively focus on my study and finish it in time.

I thank all the members of the Wittmer lab, past and present, for their encouragement and collaboration. In particular, I owe special thanks to Dr. Tavis Forrester, Dr. Maximillian Allen and David Casady, who spent many years in the field 
painstakingly collecting all the data that I got to work on from the comfort of my office. I also thank Dr. Mark Elbroch and Dr. Bogdan Cristescu for providing unique perspective and advice with the predator data analysis. Dr. Lucile Marescot, had been a great company in early days of my $\mathrm{PhD}$ and helped me settle down in this foreign land. A very special thank you for Johannes Fischer, Victor Anton, and Michelle McLellan for being awesome lab mates and making this journey a little bit more fun and bearable. You guys have been amazing.

A number of people have supported me and provided me with valuable and much appreciated advice including statistical advice and comments on various chapters that largely increased the scientific rigour and clarity of the dissertation. I sincerely thank Dr. Stephen Hartley and Dr. Lisa Woods for helping me with statistical models whenever I needed. I would also like to acknowledge the useful comments and criticisms provided by Dr. Bogdan Cristescu, Dr. Tavis Forrester, Dr. Ben Sacks and David Casady on various chapters of my thesis. Furthermore, I am grateful to Johannes Fischer, Michelle McLellan, and Dr. Bibek Yumnam, for proofreading various manuscripts.

I am eternally indebted to my parents and sister who, even though far away, have been there for me in every step of the way and without whom none of these would have been possible. I am especially grateful to my parents for their unconditional love and faith in me. Thank you for letting me pursue my passion even though it meant being absent from all the family events for years together. And a special thanks to you Ma for voluntarily proof reading the thesis and going through all the references.

Most importantly, Bibek, you were my strongest pillar of support throughout this journey. You gave up on your dreams so that I can pursue mine. You moved 
country, worked long hours in often unrewarding jobs to help provide for us. You put up with all my mood swings, stress and anxiety without any complaints. You had been a great dad to our baby when I was busy working long hours. No amount of thank you is enough for what you did for us.

Finally, my little munchkin Aalekh. You endured long hours at the daycare from a very early age with a smile on your face. You accepted the fact that mommy is away all day but never failed to reward me with your innocent smiles and hugs even when I reached home late. You helped me relieve my stress in your own sweet way and the unwanted distractions you provided actually did good to me. Mommy loves you. 


\section{Table of Contents}

DISSERTATION ABSTRACT

ACKNOWLEDGEMENTS.

CHAPTER 1: GENERAL INTRODUCTION $\ldots \ldots \ldots \ldots \ldots \ldots \ldots \ldots \ldots \ldots \ldots \ldots$

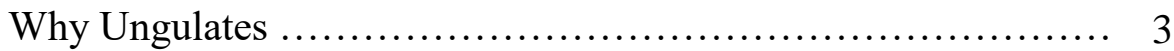

Ungulates and Scales....................................... 5

Black-tailed Deer Ecology and Research...................... 7

Dissertation Structure....................................... 9

Study Area ............................................... 11

Statement of Authorship..................................... 14

CHAPTER 2: FIDELITY AND PHILOPATRY IN BLACK-TAILED

DEER: IMPLICATIONS ON POPULATION STRUCTURE.................. 17

Acknowledgements....................................... 18

Abstract................................................ 19

Introduction........................................... 20

Materials and Methods................................... 23

Study Area.......................................... 23

Capture and Monitoring............................... 24

Home-range Estimation and Population Structure.......... 25

Site Fidelity Analysis................................ 26

Mitochondrial DNA and Philopatry................... 28

Results.............................................. 30

Home Ranges and Population Structure.................. 30

Site Fidelity........................................ 30

Philopatry and Genetic Population Structure............. 35

Discussion............................................... 36

CHAPTER 3: EFFECT OF ACTIVITY STATES ON HABITAT

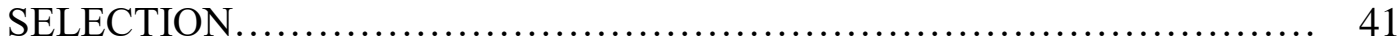

Acknowledgements ...................................... 42

Abstract................................................ 43

Introduction............................................. 44

Materials and Methods.................................... 46

Study Area....................................... 46

Capture and Monitoring............................... 48

Population and Home-range Estimation................ 50

Assigning Activity States............................ 50

Habitat Covariates................................... 51 
Statistical Analyses............................... 54

Results................................................ 56

Landscape Scale Selection......................... 57

Home-range Scale Selection........................ 67

Habitat Selection and Activity States............... 67

Discussion.............................................. 70

CHAPTER 4: NEGOTIATING LANDSCAPE OF FEAR: TRADE-OFFS BETWEEN FORAGE AND PREDATION RISK AS A FUNCTION OF LANDSCAPE FAMILIARITY AND PREDATOR BEHAVIOUR...

Acknowledgements...................................... 78

Abstract................................................ 79

Introduction............................................. 81

Materials and Methods................................... 84

Study Area....................................... 84

Capture and Monitoring.............................. 86

Space Use and Familiarity....................... 87

Puma Predation Risk................................ 88

Estimation of Forage Availability................... 90

Telemetry Data................................... 91

Statistical Analyses................................ 92

Results................................................ 95

Step Selection Patterns of Migratory BTD............. 95

Step Selection Patterns of Non-migratory BTD........ 112

Discussion.............................................. 116

Chapter 5: GENERAL DISCUSSION ................................ 125

Introduction............................................. 127

Chapter Overviews.................................... 127

Conclusions........................................... 131

Limitations................................................. 136

Directions for Future Research............................... 138

Management recommendations.............................. 139

LITERATURE CITED ............................................. 143

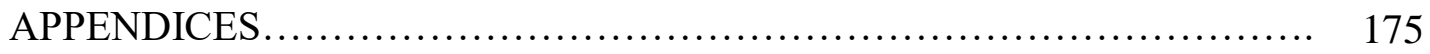

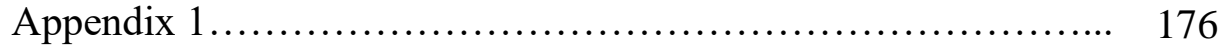

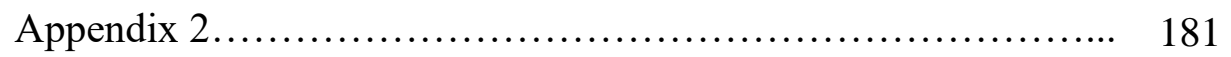


Chapter 1

General Introduction 


\subsection{Why ungulates?}

Large ungulates are fundamentally important components of ecosystems. By virtue of their actions, they modify nutrient cycling (McNaughton et al. 1997, Singer and Schoenecker 2003), influence primary ecosystem productivity (McNaughton 1979, Olofsson and Oksanen 2002), alter patch dynamics (Schreiner et al. 1996, Knapp et al. 1999), and play an important role in the transfer of primary production to higher trophic levels, including those of predators and scavengers (Hobbs 1996). Despite their profound roles to overall ecosystem functioning, many ungulate populations are facing stark declines globally. The roots of the decline lie in habitat fragmentation (Coulon et al. 2008), habitat shifts caused by climate change (Hansen et al. 2001, Brinkman et al. 2005, Robinson et al. 2009), depredation by exotic introduced predators (Fortin et al. 2005, Creel et al. 2005), unregulated hunting (Stankowich 2008), disease (MilnerGulland et al. 2001, Morgan et al. 2006) and irreversible land-use changes (Brinkman et al. 2005, Wittmer et al. 2007, Harris et al. 2009). Due to their roles as ecosystem engineers, the loss of ungulate populations will have a cascading effect on higher trophic levels of ecosystems.

Over the last two centuries, since European colonization of North America, many ungulate species have suffered from substantial range contractions and unabated population declines (Laliberte and Ripple 2004). Nowhere is the decline more evident than in the western United States, where since the late 1950's, populations of large and medium-sized ungulates including elk (Cervus elaphus spp.) and mule deer (Odocoileus hemionus spp.) have declined dramatically throughout much of their range (Forrester and Wittmer 2013, Vucetich et al. 2005). The steady decline in ungulate populations does not bode well for the ecology and conservation of the area, 
as they form the major prey base for apex predators such as pumas (Weaver et al. 1996, Knopff et al. 2010) and grizzly bears (Munro et al. 2006). Besides, it is also of concern for state wildlife agencies as ungulates are an important source of revenue through the issue of hunting licences (deVos et al. 2003). Decline in ungulate populations means shrinking net revenue for these agencies provided not only by hunters but also by groups such as wildlife enthusiasts and wildlife watchers. So, in the interests of conservation, hunting and revenue, the state wildlife agencies are actively spearheading efforts to maintain steady, sustainable populations of ungulates across North America, especially in the western half.

Conservation of ungulate populations in a rapidly changing environment comes with diverse set of challenges (Lindenmayer et al. 2008, Dzialak et al. 2011, Runge et al. 2014). The primary challenge is to maintain local populations of ungulates at a threshold level for long-term persistence. In doing so, park managers need to balance the conflicting needs of hunters (more deer to hunt), landowners (fewer deer to lessen crop damage), or other varied federal land uses. In such fragmented humaninfluenced habitats where there can be polarizing attitudes to conservation from local stakeholders, inherent complexity arises in terms of the threshold number of deer required to maintain viable local populations. Another important contributor to ungulate population dynamics is habitat management. Medium-sized ungulates such as elk and mule deer show tremendous plasticity in movements patterns (Ball et al. 2001, Cagnacci at al. 2011, Mueller et al. 2011). They can encompass resident individuals, which exhibit little or no migration, to individuals that disperse across a variety of habitats with varying human land-use activities (e.g., oil and gas extraction, residential subdivision, agriculture, transmission, roads, and forestry) to reach familiar seasonal ranges (Sawyer et al. 2005, Sawyer et al. 2012). Managing these landscapes 
for sustainable development activities and wildlife into the distant future represents an enormous challenge (Bolger et al. 2008, Berger et al. 2014). Conserving ungulates under these conditions require the integration of broad-scale landscape-based conservation strategies together with targeted management of localized populations.

\subsection{Ungulates and scale}

The definition of scale in ecology is vitally important for understanding ecological patterns and processes (Krebs 1985, Levin 1992, Schneider 1994, Peterson and Parker 1998). Broadly, "scale" can be defined as grain (smallest level spatial or temporal resolution) or extent (largest area or duration of investigation), and ecological investigation varies with different spatio-temporal scales and hierarchical levels (Pickett et al. 1994). Let us take the case of ungulate behaviours as an example. In ungulates, diverse components of population dynamics such as distribution, movements, dispersal, energetics, foraging, and diet, can all be regarded as diverse mechanisms of habitat selection operating at different scales (Orians 1991, Travis and Dytham 1999, Brown 2000). Hence, the sole reliance on a single level or scale of investigation severely weakens understanding of ecological processes.

The growth in concepts of scale (Hilden 1965) and hierarchy theory (Johnson 1980, Allen and Stan 1982) have spawned research into ecological processes at different hierarchical levels and interactions between them. Sparked by the ongoing decline in ungulate populations, the period since the $1980 \mathrm{~s}$ witnessed an unprecedented upsurge in ungulate ecology studies, especially on habitat selection at multiple spatial scales (Senft et al. 1987). Early telemetry studies on habitat selection in ungulates were targeted at spatial scales based on a hierarchical framework (following Johnson 1980), to investigate the observed variability in selection. The 
emphasis was on resolving the spatial scale to develop species-specific habitat management plans. Due to low accuracy of telemetry data, studies were typically carried out at two to four scales of resolution (Poizat and Pont 1996). In doing so, the likelihood that heterogeneity of habitat components may affect selection and ultimately fitness of ungulates was largely ignored. This facet, which plays an important role in ungulate ecology remained under represented until more recent times (Kie et al. 2002, Boyce et al. 2003, Frair et al. 2005, Mayor et al. 2009a).

Besides spatial scales, the decision rules, cues, and resources that influence habitat selection by animals is also a function of time (Orians and Wittenberger 1991, Fortin et al. 2002). Therefore, patterns of habitat selection can vary as much between temporal scales as between spatial scales (Mayor et al. 2009b). In the early days of telemetry due to the coarse resolution of GPS data, studies across different temporal scales were very limited in number (Forester et al. 2007, Bjørneraas et al. 2011). The only exception was seasonal variation, which remained the most frequently considered temporal scale in early habitat selection studies (Hanley 1982, Dardaillon 1986, Fryxell and Sinclair 1988), mostly because changes in environmental conditions are the largest between seasons and could also be assessed from coarse telemetry data. The ongoing telemetry revolution in the last decade, and advent of sophisticated techniques have finally permitted the rapid acquisition of fine-scale temporal data (Hebblewhite and Haydon 2010, Wilmers et al. 2015). Thus, recent studies are increasingly harnessing the technology to investigate temporal patterns of habitat selection, such as whether diurnal activity in ungulates can potentially influence habitat selection at different temporal scales (Owen-Smith et al. 2010). Current studies at fine temporal scales, have shown that behavioural decisions are governed by short-term responses to immediate stimuli, such as the circadian rhythm (Ensing et al. 2014, Prugh and Golden 
2014), rumination cycles in some herbivore species (Kamler et al. 2007, Godvik et al. 2009), behavioural states (Roever et al. 2014), weather (Ewald et al. 2014), risk of predation (Creel and Winnie 2005) or disturbance (Ciuti et al. 2012).

Ecological patterns are a function of multiple interacting processes operating at different spatial and temporal scales. Hence, a comprehensive understanding of ungulate behaviours at multiple scales is vital for testing hypotheses regarding forage acquisition, competition, and predator-prey interactions that can ultimately influence the population dynamics of ungulates (Gross et al. 1995). In doing so, any number of levels can be identified, but to understand the full suite of selective behaviours a continuum of scales is ideally suited (Mayor et al. 2009a). However, the levels of spatial, temporal and behavioural resolution also depend on the study at hand in relation to the quality and quantity of data sufficient to meet the objectives. A thorough understanding of the study species, particularly their behavioural adaptation specific to the environmental cues is thus essential to correctly define the scale as envisioned by the species.

\subsection{Black-tailed Deer Ecology and Research}

Mule deer (Odocoileus hemionus hemionus) and its ancestral form black-tailed deer (BTD, O. h. columbianus) are iconic North American ungulate species (Geist 1998). A subspecies of mule deer, inhabiting the complex forested habitats in coastal areas of the Pacific Northwest and northern California, BTD is among the least studied ungulate species in North America owing to its shy disposition. The first studies on BTD ecology date back to the 1950s (Taber 1953, Taber and Dasmann 1957). By the 1990s, the natural history of this species was studied both in California (Wallmo 1981, Geist 1981, Geist 1998) and in British Columbia (Bunnell 1990). The studies revealed 
that much like mule deer, BTD exhibited considerable plasticity in habitat use and movement patterns (Geist 1981, Garrott et al. 1987). However, BTD was found to occupy one of the smallest seasonal home ranges reported for any medium-sized ungulate (Taber and Dasmann 1957, Kelt and Van Vuren 2001), which is a testament to the high degree of site fidelity in the species. The high site fidelity was observed to be positively correlated with individual fitness in BTD (Forrester et al. 2015).

Another intriguing aspect of BTD ecology is the temporal variation in populations (Connolly 1981, Wallmo 1981, Ballard et al. 2001, deVos et al. 2003) which has so far remained unpredictable and poorly understood. The historic and recent spate of declines in BTD populations (Forrester and Wittmer 2013) has prompted state wildlife agencies to investigate the causes of decline and find ways to stabilize BTD populations across their distribution range. Previously, efforts to explain observed population fluctuations have mainly focused on habitat conditions including forage availability, with the effect of predation receiving considerable attention (Connolly 1981, Ballard et al. 2001). But, predicting the trajectory of decline is much more complicated than just understanding top-down and bottom-up effects. BTD occur across a wide range of environmental conditions, with their population density being driven by a blend of large-scale processes affecting life-history trade-offs and resource selection (Senft et al. 1987, Bowyer and Kie 2006). Moreover, the intensification of human-induced disturbances has accelerated the pace of fragmentation of hitherto large connected BTD populations.

The human-altered environment brings in added complexities, with the scenario of isolated populations, impaired connectivity, altered predator-prey dynamics, and reduced demographic and genetic viability, which can disrupt the 
trophic interactions at multiple levels. All these perturbations have important implications for conservation management of BTD, which is a generalist species and often try to adapt to a changing environment through shifting selection of habitats to maximize fitness (Belovsky 1986). As a result, researchers may fail to identify these adaptive habitat selection strategies because of intricate relationships among numerous ecological variables and associated fitness components affecting the local habitat management planning. Conversely, in other highly altered habitats, selection choices could become maladaptive and habitat cues can decouple from historic outcomes (Kokko and Sutherland 2001, Battin 2004, Bock and Jones 2004, Robertson and Hutto 2006), thus reducing their overall fitness. Given the uniqueness of each habitat, studies need to focus on each population separately to identify anthropogenic disturbances, forest management, land-use policies, and presence of predators in an area, and individually assess the habitat availability-use pattern of each population. A key area of investigation is to understand the association between the above drivers of habitat selection with fitness consequences in BTD, and their linkages to scales. This is especially important as effective implementation at the local level underpins current efforts at long-term conservation and recovery of range-wide BTD populations.

\subsection{Dissertation Structure}

I studied the spatial and temporal variation in habitat selection by BTD, to gain a mechanistic understanding of how BTD utilize resources in a multi-use landscape to increase individual fitness. Though my dissertation focuses on a declining BTD population in the Mendocino National Forest, my goal was to understand how the use of an interdisciplinary approach, combining both spatial and genetic data, can target the scale for effective management of ungulate populations. In particular, my 
dissertation aims at 1) understanding the spatial structuring of BTD to underpin the spatial scale for conservation, 2) understanding local and temporal patterns in habitat use, and 3) understanding the effect of spatial familiarity as a cause of observed spatial and temporal variation in resource use. For my studies, I used high-quality genetic, location, and activity data from over 50 female BTD collected over 9 years and backed up the field data with high-resolution spatial time series data. These large datasets allowed me to test my predictions that BTD habitat selection varies at a much finer spatial and temporal scale than previously presumed and that the variation is a function of familiarity.

In Chapter 2, I test the combined effect of site fidelity and philopatry on the BTD in the Mendocino National Forest for understanding spatial patterns in connectivity and population dynamics. My objectives are to quantify the extent of seasonal and annual site fidelity of female BTD and to then estimate levels of philopatry with the goal of ultimately assessing the combined effect of fidelity and philopatry on the genetic structuring of the population. To achieve my objectives, I use long-term location data from adult female BTD and mitochondrial DNA (mtDNA) data isolated from high quality tissue samples collected from the same population. Through this chapter I attempt to identify the spatial extent and also the cause and effect of BTD population structuring in a continuous multi-use landscape.

In Chapter 3, my primary goal is to test the fine-scale temporal variation in habitat selection by female BTD. I first hypothesize that due to the difference in climatic condition and forage availability the habitat selection by BTD will vary across the seasons. Additionally, I hypothesize that due to the feeding-resting-feeding cycle that medium-sized ungulates like BTD undergo, temporal variation in habitat selection 
will vary at a much finer scale and coincide with the activity states (active or feeding and inactive or ruminating and resting). I also assume that with the seasonal variation in predation pressure, climatic conditions, and forage quality, the individuals will show a differential preference towards forage and cover across seasons during active and inactive states. To test my hypotheses, I use high resolution telemetry data matched with activity data from the GPS collars of collared female BTD. Through this chapter I hope to gain an insight into the adaptive switching between different habitat types that coincide with the activity states in a ruminating ungulate.

In Chapter 4, by using fine-scale telemetry data, I develop movement model to understand the spatial and temporal patterns of risk- forage trade-offs by female BTD as a function of familiarity. I hypothesize that BTD will select areas with lower risk of puma predation and better forage availability, reflecting a trade-off between food acquisition and minimizing predation risk with variation in spatial familiarity. I also hypothesize that the use of familiar areas will vary with the time of the day, with BTD being more willing to venture into risky areas when pumas are less active. Finally, I hypothesize the trade-off pattern to vary between summer and winter due to seasonal variation in phenology, predation risk, and physiological conditions. Through this chapter I hope to gain a nuanced understanding of how female BTD handle food versus safety trade-offs across different levels of selection.

\subsection{Study Area}

The Mendocino National Forest is located in the Coastal Mountain Range in California, Northwest of Sacramento and includes portions of Mendocino, Tehama, Glenn, and Lake Counties (Figure 1.1). 


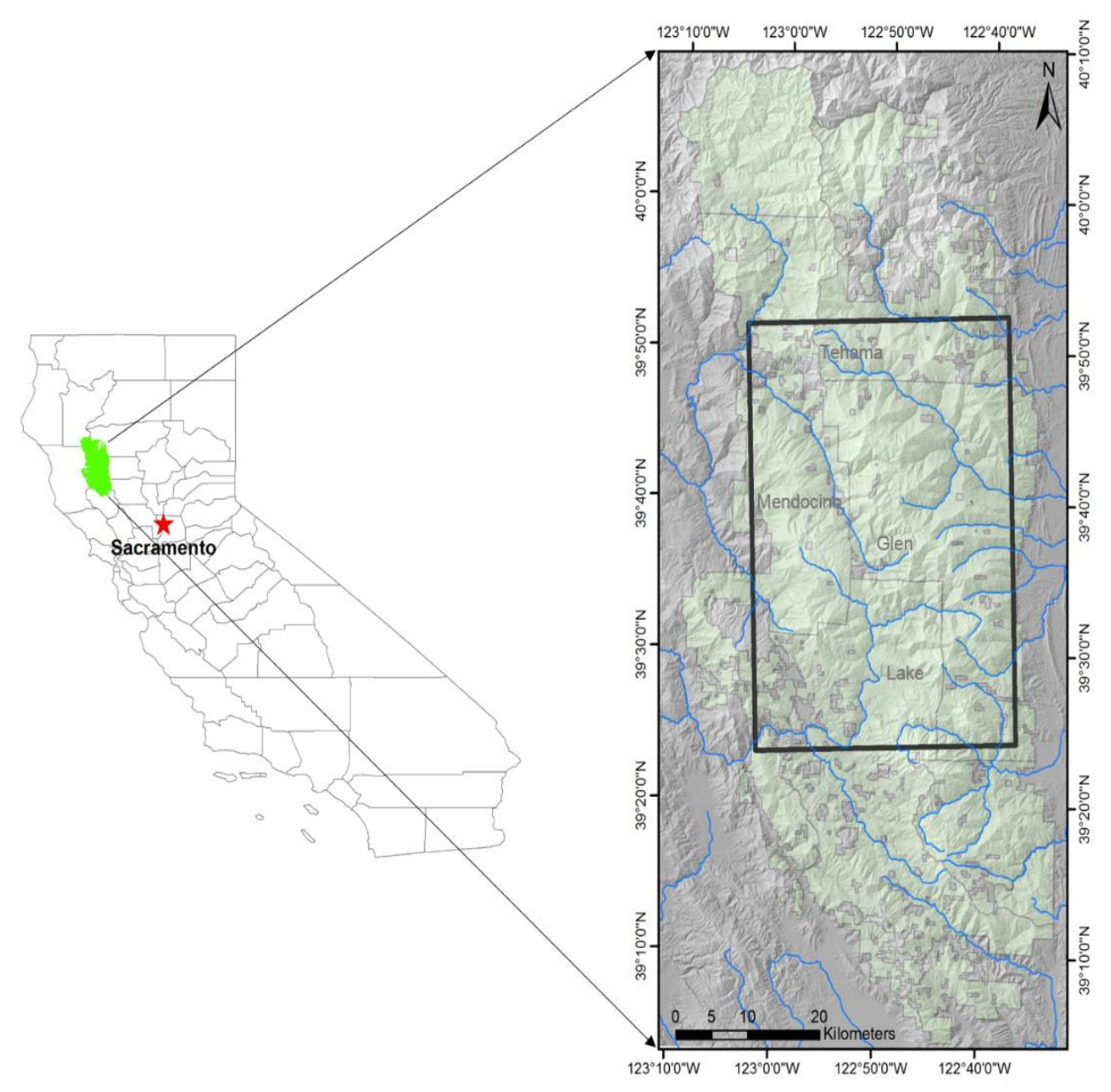

Figure 1.1: Map of the Mendocino National Forest in the context of state of California. The enlarged map shows the Mendocino National Forest (green) and adjacent private lands (grey) with the intensive study area outlined by the thick black line.

Approximate $1,000 \mathrm{~km}^{2}$ of intensive study area is characterized by rugged terrain, steep elevation gradients, and a range of habitat types. Elevations in the study area ranges approximately from $250 \mathrm{~m}$ to almost $2,500 \mathrm{~m}$ above sea level. Plant communities change from Oak woodlands (Quercus spp., Aesculus californicus, Arctostaphylos spp.), chaparral (Ceanothus spp., Adenostoma fasciculatum), and grasslands (Bromus spp., Avena spp.) at lower elevations, to pine (Pinus spp.) forests at mid-elevations, and mixed-coniferous hardwood forests (Pinus ponderosa, P. iambertiana, Abies concolor, A. magnifica, Pseudotsuga menziesii, Arbutus menziesii, Quercus spp.) dominating the higher elevations. 
Silviculture and intensive cattle grazing in the past have created a mosaic of even-aged conifers with occasional mature timber stands and openings dominated by non-native grasses mostly at lower elevations. But currently, there is relatively less anthropogenic disturbance in the area. Cattle grazing occurred at low intensity and was limited between May up to the second weekend of September when a buck-only deer hunting season started. There is no paved road in the study area and road access is limited to dirt roads and recreational activities focus on several campgrounds mostly at mid- and high-elevations.

Climate varied seasonally, with mean daily temperatures ranging from $-1^{\circ} \mathrm{C}$ to $24^{\circ} \mathrm{C}$ and extreme temperatures ranging from $-12^{\circ} \mathrm{C}$ to $45.5^{\circ} \mathrm{C}$ (NOAA-Mendocino Pass, CA Weather Station). Mean annual precipitation averaged $148.8 \mathrm{~cm}$; the majority of precipitation occurred from December through March with only trace precipitation from May through September (Mendocino Pass weather station; http://www.ncdc.noaa.gov/cdo-web, Accessed, $9^{\text {th }}$ September, 2014). Precipitation was predominantly in the form of rain below 1,000 m, while at higher elevations, snow was common.

The area supports one of the oldest and least interbred population of BTD likely because of its isolation from mule deer populations (Latch et al. 2009). BTD is the only abundant and resident ungulate in the study area. Other ungulates present in the study area included non-native wild pigs (Sus scrofa) at lower elevations and seasonally abundant domestic cattle (Bos taurus). There is also a reintroduced population of Tule elk (C.e. nannodes) to the extreme southern end of the study area. Mountain lions or pumas (Puma concolor) were the apex predator in the study area. The area supports a diversity of other predators, including black bears (Ursus 
americanus), bobcats (Lynx rufus), coyotes (Canis latrans), gray foxes (Urocyon cinereoargenteus), and fishers (Martes pennanti), which usually preys on smaller prey species including black-tailed jackrabbits (Lepus californicus), California ground squirrels (Otospermophilus beecheyi), and Microtus and Peromyscus rodent species.

Once identified as overpopulated deer range in the 1940's (Leopold et al. 1947) and the 1970's (Longhurst et al. 1976), this population of BTD has been steadily declining for decades, pointing to declining harvest rates since the 1980's (Booth et al.1982). However, recent declines in the BTD population despite reducing anthropogenic disturbances in the area have triggered interest in understanding scalebased habitat selection and resource use by the species to aid in developing effective management strategies.

\subsection{Statement of Authorship}

This study was conceived by me under the guidance of Dr. Heiko Wittmer, Associate Professor, Victoria University of Wellington. Chapter 2 through 4 presented in this thesis were written for publication in peer-reviewed journals. They have been or will be submitted with my supervisors and others as co-authors for their help during the research process. Contributions of collaborators who are co-authors on the manuscripts are outlined below.

Chapter 2 was conceived by Heiko Wittmer and myself. Telemetry data of BTD were provided by Heiko Wittmer and David Casady; data were collected by Dr. Tavis Forrester and a large team of field technicians. Genetic data were analysed by Dr. Benjamin Sacks and Jennifer Brazeal at the Veterinary Genetics Laboratory at the University of California, Davis. Statistical advice on telemetry data was provided by Heiko Wittmer. Statistical analyses and interpretation of results were solely done by 
me. I wrote the first draft of the chapter and Heiko Wittmer contributed significantly to the writing process. All co-authors provided additional helpful editorial feedback. A version of the chapter is now published as "Implications of fidelity and philopatry for the population structure of female black-tailed deer" in Behavioral Ecology.

Chapter 3 was conceived by Heiko Wittmer and myself. Telemetry data of BTD were provided by Heiko Wittmer and David Casady. All spatial data were obtained and processed by me. Statistical advice was provided by Heiko Wittmer. All statistical analyses were performed by me. I wrote the first draft of the chapter and Heiko Wittmer provided helpful feedback that significantly improved the manuscript. Other co-authors include David Casady and Tavis Forrester, both of whom provided additional editorial feedback. A version of the chapter is now accepted for publication in the Journal of Wildlife Management.

Chapter 4 was conceived by myself in consultation with Heiko Wittmer. Telemetry data of BTD were provided by Heiko Wittmer and David Casady. Collection of spatial data and subsequent spatial analyses were done by me. Statistical advice was provided by Drs. Stephen Hartley and Lisa Woods. I performed all statistical analyses and am the sole author of the chapter. Heiko Wittmer and Bogdan Cristescu provided editorial comments on the manuscript. 
Chapter 2

Site Fidelity and Philopatry in Black-tailed Deer: Implications on Population Structure 
A version of this chapter was published as:

Bose, S., Forrester, T. D., Brazeal, J. L., Sacks, B. N., Casady, D. S., \& Wittmer, H. U. (2017). Implications of fidelity and philopatry for the population structure of female black-tailed deer. Behavioral Ecology, 28(4), 983-990.

\section{Acknowledgements}

Funding for the research was generously provided by the California Department of Fish and Wildlife (\#P0880013) and the California Deer Association (\#08-001495, \#001-10, \#011-11). I am indebted to Dr. Tavis Forrester, David Casady and the numerous students and volunteers who helped with data collection in the field. Dr. Ben Sacks and Jennifer Brazeal did the genetic data analysis. J.M. Gaillard and an anonymous reviewer provided many helpful comments on a previous version of this manuscript. I also thank Dr. Bibek Yumnam and Johannes Fischer for proofreading the chapter. 


\section{Abstract}

Site fidelity and philopatry are behavioural adaptations found in many species and their fitness benefits are well documented. The combined population level consequences of site fidelity and philopatry, however, have received little attention despite their importance for understanding spatial patterns in connectivity and population dynamics. I used an integrative approach to explore consequences of fidelity and philopatry on the fine-scale genetic structure of black-tailed deer (Odocoileus hemionus columbianus). I assessed fidelity to seasonal home ranges based on location data from 64 female deer fitted with global positioning system (GPS) collars between 2004 and 2013 while philopatry was assessed from mitochondrial DNA (mtDNA) haplotypes using DNA extracted from 48 deer. Results based on location data revealed very small movements and seasonal home ranges together with high site fidelity. Fidelity improved survival; every $1 \mathrm{~km}$ increase in mean interlocation distances between consecutive summers increased the risk of mortality by $56.5 \%$. Results from mtDNA sequencing revealed high genetic differentiation $\left(F_{\mathrm{ST}}>0.30\right)$ and low haplotype sharing among geographic areas separated by as little as $4-10 \mathrm{~km}$. The high genetic differentiation indicated multigenerational periods of philopatric behaviour in the matrilineage of black-tailed deer. Combined, these results suggest that site fidelity together with strong sex-biased philopatry can create marked short- and long-term demographic isolation and trap matriarchal units as a subset of the larger population with locally-determined vital rates. Where such fine-scale population structuring as a consequence of fidelity and philopatry occurs, matrilineal groups might in some cases best serve as the basic units of conservation and management. 


\subsection{Introduction}

Animal populations are naturally predisposed to spatial structuring due to the generally non-random and clumped distribution of resources (Turner 1989). The degree of structuring varies among species and depends on life-history traits, social organization, ecological requirements, and mobility (e.g., Clutton-Brock and Coulson 2002, Coltman et al. 2003, Nussey et al. 2005). Highly mobile species are expected to show little spatial structuring at fine scales due to their ability to move longer distances to utilize dispersed resources. Individuals, including those of less mobile species, can also maximize resource utilization by either remaining within the same general area or by returning to previously occupied areas (Merkle et al. 2014). These behaviours have been defined as site fidelity and are well documented across many vertebrate taxa (Greenwood 1980). The most prevalent explanation as to the evolutionary benefits of site fidelity focuses on familiarity (Piper 2011), as prior knowledge of the distribution of resources and refugia from predators plays an important role in effective habitat use (Switzer 1993) thus enhancing survival (Forrester et al. 2015) and reproductive success (Beletsky and Orians 1991). Studies across different spatial and temporal scales have also linked fidelity behaviour to geographic structuring (Schaefer et al. 2000, van Beest et al. 2013) suggesting that fidelity at fine scales may affect demography and population dynamics (Morrison and Bolger 2012).

Dynamics and spatial distribution of animal population at large spatial scales are also affected by dispersal (Taylor and Taylor 1977, Kendall et al. 2000). Depending on social organization and ecological conditions, individuals of different species may either establish home ranges within their natal area (i.e., philopatry) or may disperse 
and subsequently establish fidelity to a new area (Pusey 1987). Dispersal in mammals is predominately male-biased with immature males dispersing and females more often exhibiting philopatry (Greenwood 1980). Long-term familiarity and use of natal sites by females has been predicted to result in genetic structuring (Chesser 1991) and studies involving different taxonomic groups have linked sex-biased philopatry to fine-scale genetic structuring over successive generations (e.g., Storz 1999, Miller et al. 2010).

Due to their large plasticity in movement and dispersal strategies, both site fidelity and philopatry have received considerable attention in ungulates. Previous studies assessing site fidelity in ungulates have highlighted the importance of different temporal scales (Schaefer et al. 2000, van Beest et al. 2013) in explaining spatial patterns of clustering and range use with respect to seasonal variation in forage quality (Garrott et al. 1987, Pettorelli et al. 2007) and predation risk (Wittmer et al. 2006). Many studies, however, have relied on relatively short-term data to investigate the effects of fidelity on geographic structuring of ungulate populations at different spatial scales. Specifically, the generally short duration of telemetry studies may have limited our ability to link an understanding of site fidelity and population structuring to population dynamics over longer times scales. Studies on philopatry on the other hand have often used mitochondrial DNA (mtDNA) data to evaluate genetic structuring at broader temporal scales and distances beyond the dispersal abilities of the species (e.g., Purdue et al. 2000, Latch et al. 2014). Fidelity and philopatry, however, are intrinsically related and by acting simultaneously can cause fine-scale genetic structuring within populations even in continuous landscapes without physical barriers to movement (Nussey et al. 2005, Bolger et al. 2008). Thus, the combined use of telemetry and genetic data provide opportunities to increase our ability to understand 
population-level consequences of site fidelity and philopatry, and use such an understanding for developing effective conservation and management plans.

Black-tailed deer (Odocoileus hemionus columbianus) provide an ideal model to study the combined effect of site fidelity and philopatry on the spatial extent of population structuring. Their social structure is based on matriarchal lineages with groups composed of adult females and several generations of female offspring (Kie and Czech 2000). While previous studies have reported plasticity in range use and movement patterns (Geist 1981, Garrott et al. 1987), non-migratory BTD occupy among the smallest reported home ranges of any medium-sized ungulate (Taber and Dasmann 1957, Kelt and Van Vuren 2001). Together, these socio-behavioural attributes should predispose BTD to genetic structuring even among neighbouring groups within a continuous population.

My objectives were to quantify the extent of seasonal and annual site fidelity of female black-tailed deer in northern California, USA and to then estimate levels of philopatry to ultimately assess the combined effect of fidelity and philopatry on the genetic structuring of the population. To achieve my objectives, I used location data from 64 adult females fitted with global positioning system (GPS) collars between 2004 and 2013 and mtDNA haplotypes isolated from high quality tissue samples obtained from 48 individuals ( 24 of the collared females and 24 unrelated fawns). The integrative approach of my study was particularly topical due to previously reported variability in vital rates at small spatial scales (Marescot et al. 2015) and thus the potential of demographic structuring of the population to affect meaningful assessments of its dynamics. 


\subsection{Materials and Methods}

\subsubsection{Study Area}

My study area was located within the Mendocino National Forest in the northwestern California Coast Ranges. The $1000 \mathrm{~km}^{2}$ study area is comprised of 2 major ridges (FH7 and M1) and 3 main watersheds (Figure 2.1). Elevation in the study area ranges from approximately 250 to almost 2,500 m above sea level, with moderately rolling terrain at lower elevations to steep and rugged terrain at higher elevations except on ridge tops.

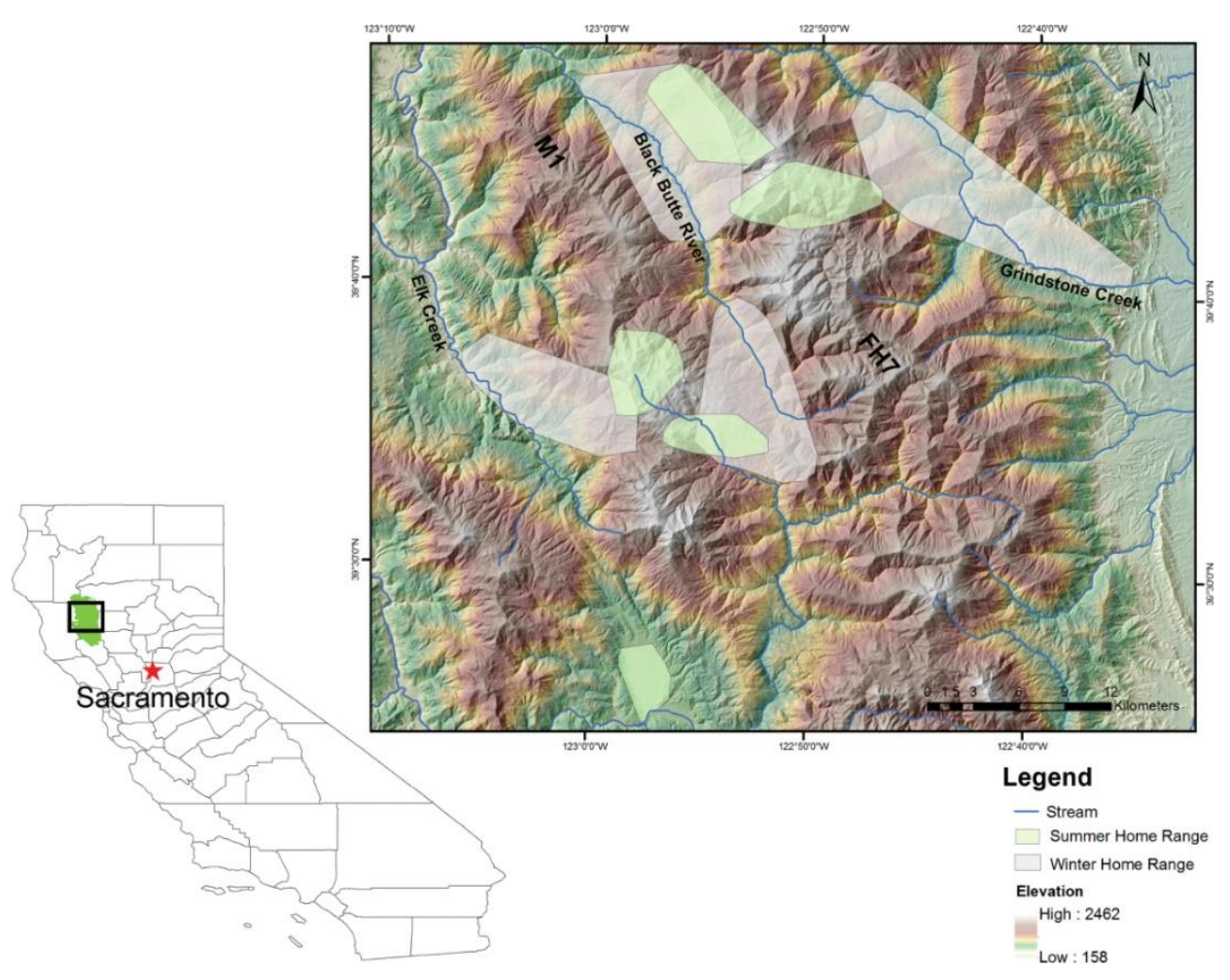

Figure 2.1: Location of the study area in California and intensive study area in the Mendocino National Forest covering 3 watersheds and 2 main ridges (M1 and FH7). Summer (5) and winter population ranges (4) were determined based on GPS location data of 64 adult female black-tailed deer monitored between 2004 and 2013.

Climate is considered Mediterranean with mean daily temperatures ranging from $5{ }^{\circ} \mathrm{C}$ during winter to $17{ }^{\circ} \mathrm{C}$ in summer (Mendocino Pass weather station; 
http://www.ncdc.noaa.gov/cdo-web, Accessed $9^{\text {th }}$ September, 2014). Temperatures reach extremes of $-11.5^{\circ} \mathrm{C}$ and $45.5^{\circ} \mathrm{C}$ in winter and summer, respectively. Mean annual precipitation over the study period averaged $148.8 \mathrm{~cm}$ with about $85 \%$ of the precipitation occurring from October through April. Snow cover was generally limited to elevations greater than $1000 \mathrm{~m}$ and was irregular, particularly during dry winters.

Major habitat types correlate with elevation and consist of (in order of increasing elevation): blue oak (Quercus douglasii) woodland, annual grassland, montane hardwood conifer, Douglas fir (Pseudotsuga menziesii), mixed chaparral, montane hardwood, ponderosa pine (Pinus ponderosa), Klamath mixed conifer, montane riparian, and montane chaparral (Mayer and Laudenslayer 1988). BTD were the only resident ungulate and coexisted with an abundant and diverse predator community that included pumas (Puma concolor), American black bears (Ursus americanus), coyotes (Canis latrans), and bobcats (Lynx rufus). Female BTD spent summer and winter aggregated in habitats that provided both high-quality and abundant forage (Wittmer et al. 2014, Lounsberry et al. 2015). Summer ranges were located on ridge tops where females also gave birth and winter ranges were in drainages at lower elevations. A majority of deer travelled the short distance (typically 5-10 km) between their seasonal ranges over the course of 1-2 days.

\subsubsection{Capture and Monitoring}

A total of 84 female BTD $\geq 1$-year old were captured over 2 separate time periods between September 2004 and August 2013 using free range darting. No deer were monitored between September 2008 and June 2009. One deer was captured and monitored during both time periods. Detailed capture and handling procedures are described in Casady and Allen (2013), and were approved by the Wildlife 
Investigations Laboratory of the California, Department of Fish and Wildlife and the Institutional Animal Care and Use Committee at University of California, Davis (Protocols 15341 and 16886). Captures occurred opportunistically, primarily from roads along the FH7 and M1 ridges at high elevations. All but 6 anesthetized deer had an incisiform canine tooth extracted for precise age determination based on cementum growth (Matson's Laboratory LLC, Missoula, MT); tooth eruption and wear patterns were used to determine age of individuals from whom teeth were not extracted. Deer were equipped with motion-sensitive, store-on-board GPS collars (Telonics, Mesa AZ and models 3300 and 4400M, Lotek Wireless, Inc., Newmarket, Ontario, Canada) that never exceeded $3 \%$ of their bodyweight. Collars were programmed to obtain a GPS location every 1 to $5 \mathrm{~h}$ and were deployed for a maximum period of 2 years after which they automatically dropped off. Collars switched to a mortality signal after $4 \mathrm{~h}$ of inactivity facilitating recovery and identification of mortality causes (Marescot et al. 2015). Of the 84 female deer captured, 3 died from capture related injuries and the collars of 4 individuals failed immediately. GPS location data from an additional 13 deer could not be retrieved leaving me with GPS location data from 64 individuals for the analyses.

\subsubsection{Home-range Estimation and Population Structure}

Summer and winter home ranges of individual deer were estimated separately using the $95 \%$ local convex hull $(\mathrm{LoCoH})$ method by applying the "minimum spurious hole covering" rule (Getz et al. 2007). Seasonal cut-off dates for each deer were identified from their GPS locations based on observed patterns in elevational movements and space use (D'Eon and Serrouya 2005). This allowed me to exclude GPS locations associated with elevational migrations from home range and fidelity analyses. Twelve 
deer did not show distinct elevational movements. For these deer, locations were assigned to either summer or winter based on the median date of migration of other deer on the same seasonal range and year. I tested for differences in mean seasonal home range sizes between the 2 ridges using an analysis of variance (ANOVA).

Available location and home range data were also used to assign deer to seasonal population ranges following an approach described by Forrester et al. (2015) Specifically, individual deer were allocated to distinct summer and winter population ranges based on spatial gaps in the GPS data that were greater than twice the size of the average diameter of a seasonal home range and geographic features that may have discouraged movement between ranges (e.g., steep drainages). The extent of these distinct seasonal population ranges were then determined using $95 \%$ minimum convex polygons from GPS locations of all collared deer within each seasonal range.

\subsubsection{Site Fidelity Analysis}

My assessment of site fidelity was based on interlocation distances within seasons and between years because approaches based on animal locations are generally considered more accurate than those based on home range overlap (Garrott et al. 1987, Conner and Leopold 2001). To avoid spurious statistical significance arising from nonindependent GPS locations obtained for each individual deer, I subsampled the dataset by randomly choosing one location per week.

Within season fidelity was estimated by calculating linear distances between all possible pairs of weekly locations for each collared individual within their individual seasonal ranges. To quantify between year fidelity to seasonal ranges, I used an approach similar to multiresponse permutation procedure (Mielke et al. 1976, Zimmerman et al. 1985) where linear distances between all locations within an 
individual's seasonal range were calculated pairwise across different years. If the mean within-year interlocation distances were equal or near equal to the mean interlocation distances between years, then the animal was considered to show a high degree of fidelity to its seasonal home range from one year to the next (Wittmer et al. 2006).

I examined variation in mean interlocation distances of female BTD as a function of temporal and spatial covariates using linear mixed effect (LME) models contained in the nlme package (Pinheiro et al. 2014). Interlocation distances were logtransformed and treated as the response variable. Explanatory variables included fidelity type (within year, between years), season (summer, winter), and area (FH7 ridge, $\mathrm{M} 1$ ridge). I included season and area as covariates in my site fidelity analysis because previous research highlighted both temporal and spatial variation in survival of deer in the study population (Forrester et al. 2015, Marescot et al. 2015). All 3 explanatory variables and their first order interactions were included in the full model. To account for repeated measurements from the same individual, animal ID was included as a random intercept. The full model thus took the following form: Interlocation distances $\sim$ fidelity type + season + area + fidelity type $\times$ season + season $\times$ area + fidelity type $\times$ area + fidelity type $\times$ season $\times$ area $+(1 \mid$ ID). The statistical significance of each variable and their interactions was assessed by sequential backward elimination from the full model (Crawley 1993) followed by comparisons using likelihood ratio tests. Finally, I used least squares regression models with the mean intra- and inter-year location distances of individual deer as the dependent variable to test for the effect of age of female deer on fidelity.

I used Cox Proportional Hazards $(\mathrm{CPH})$ model to assess the mortality risks associated with decreasing site fidelity (Cox 1972, Therneau and Grambsch 2000). 
The $\mathrm{CPH}$ framework allows the baseline mortality hazards to vary freely over time, thus removing any confounding effects due to seasonal or annual variation in mortality. As the seasonal ranges were spatially separated, I derived distinct models for each variable group. The number of deer monitored each year across the 8-year study period averaged $14.89 \pm 2.71$ (range from 4 to 29 ). I modelled their survival as a function of days since capture and estimated the time to "event" (i.e., mortality) for each individual that died $(n=28)$. Individuals were censored upon collar failure or at the end of study $(n=36)$. I assessed the proportional hazard assumption (Winterstein et al. 2001) for my models by testing for nonzero slopes of Schoenfeld residuals (Schoenfeld 1982) and by inspecting plots of logarithmic estimates of the cumulative hazard functions (Cleves et al. 2004).

Unless otherwise noted, I assessed significance based on $\alpha=0.05$ and report variables as mean \pm SE. All statistical analyses were performed in R Studio ( $R$ Development Core Team 2014).

\subsubsection{Mitochondrial DNA and Philopatry}

To assess whether female site fidelity behaviour occurred over long enough periods of time (i.e., multigenerational) to translate to matrilineal population structure, I analysed mitochondrial DNA, which is transferred along female lineages. Because females gave birth on high-elevation summer ranges, I chose to look at genetic differences of individuals from the 2 main ridges where these ranges were located. Ridges were on average separated by $10.2 \pm 0.2 \mathrm{~km}(\min =7.2 \mathrm{~km}$, $\max =13.9 \mathrm{~km}$; Figure 2.1$)$.

Ear punches collected from 24 adult females during collaring as well as tissue samples from 24 unrelated fawns captured during the same time period (i.e., 20112012; Marescot et al. 2015) were used for the genetic analyses. DNA from all 48 
samples were extracted using Qiagen DNeasy blood and tissue kits (Qiagen Inc.) following manufacturer's instructions. Polymerase chain reaction (PCR) was performed to amplify a 451 base pair (bp, including primers) portion of mitochondrial D loop using primers, HV1Deer-F (CTATTTAAACTATTCCCTGACG) and HV1Deer-R (GATCTAGGGGACGGGATA). PCR were $23 \mu$ l total volume and consisted of $2 \mu \mathrm{l}$ of DNA extract, $1 \mathrm{U}$ taq polymerase and other reagents at the following reaction concentrations: PCR buffer $(1 \times), \mathrm{MgCl}(2.5 \mathrm{mM})$, dNTPs $(0.2$ $\mathrm{mM})$, Bovine Serum Albumin $(0.1 \mathrm{mg} / \mathrm{ml})$, primers $(0.5 \mu \mathrm{M})$. The PCR cycle conditions were $94{ }^{\circ} \mathrm{C}$ for $3 \mathrm{~min}, 33$ cycles of $94{ }^{\circ} \mathrm{C}$ for $30 \mathrm{~s}, 50{ }^{\circ} \mathrm{C}$ for $30 \mathrm{~s}$, and 72 ${ }^{\circ} \mathrm{C}$ for $45 \mathrm{~s}$, followed by $10 \mathrm{~min}$ at $72{ }^{\circ} \mathrm{C}$. Dye terminator sequencing reactions for each PCR product was used from each primer using Applied Biosystems (Foster City, CA) reagents with products sequenced on an ABI 3730 capillary sequencer. After trimming primers (22 bp, 18 bp) and an additional 130 bp (78 bp 5', 52 bp 3'), 279 bp fragment was obtained that was unambiguously sequenced for all 48 individuals for analysis (Genbank Accession Nos. KX254554-KX254563).

To assess potential genetic structuring of females giving birth on different ridges, a median joining network of mitochondrial DNA haplotypes was constructed using the program Networks 4.613 (Bandelt et al. 1999). Haplotype and nucleotide diversity was estimated in DNAsp (Librado and Rozas 2009) and tested for population genetic subdivision using the frequency-based $F_{\mathrm{ST}}$ approach implemented in Arlequin 3.5 (Excoffier and Lischer 2010). The value of $F_{\mathrm{ST}}$ indicates the magnitude of genetic structure, with $F_{\mathrm{ST}}=0$ (the null hypothesis) implying no genetic structure and $F_{\mathrm{ST}}>0$ implying impeded gene flow between ridges. Theoritically, $F_{\mathrm{ST}}=1 /(2 m N f+1)$, implying that exchange of a single female migrant $(m N f)$ per generation corresponds to $F_{\mathrm{ST}}=0.33$. 


\subsection{Results}

\subsubsection{Home Ranges and Population Structure Based on Telemetry Data}

Average adult female home range sizes varied between the $\mathrm{M} 1$ and $\mathrm{FH} 7$ ridges during both summer $\left(\mathrm{M} 1=0.98 \mathrm{~km}^{2} \pm 0.09\right.$ vs. $\mathrm{FH} 7=0.56 \mathrm{~km}^{2} \pm 0.05 ; F_{2,51}=9.179, P=$ $0.004)$ and winter $\left(\mathrm{M} 1=1.19 \mathrm{~km}^{2} \pm 0.17 \mathrm{vs} . \mathrm{FH} 7=0.79 \mathrm{~km}^{2} \pm 0.10 ; F_{2,51}=2.247, P=\right.$ 0.036). In general, individuals associated with the M1 ridge had between 50-70\% larger seasonal home ranges than individuals associated with the $\mathrm{FH} 7$ ridge. Based on available telemetry data, collared female deer associated with 1 of 5 distinct summer ranges $\left(\min =12.0 \mathrm{~km}^{2} ; \max =30.7 \mathrm{~km}^{2}\right)$ and 1 of 4 distinct winter ranges $(\min =55.2$ $\left.\mathrm{km}^{2} ; \max =100.5 \mathrm{~km}^{2}\right)($ Figure 2.1).

\subsubsection{Site Fidelity}

Annual sample sizes of deer and locations used to estimate fidelity within and between seasons are shown in Table 2.1.

Table 2.1: Number of individuals $\left(\mathrm{n}_{\mathrm{A}}\right)$ and number of weekly GPS locations $\left(\mathrm{n}_{\mathrm{L}}\right)$ of black-tailed deer by year, season, and area (M1 or FH7 ridge) between 2004-2014 in the Mendocino National Forest, California

\begin{tabular}{|c|c|c|c|c|c|c|c|c|}
\hline \multirow{3}{*}{ Year } & \multicolumn{4}{|c|}{ Summer } & \multicolumn{4}{|c|}{ Winter } \\
\hline & \multicolumn{2}{|c|}{ M1 } & \multicolumn{2}{|c|}{ FH7 } & \multicolumn{2}{|c|}{ M1 } & \multicolumn{2}{|c|}{ FH7 } \\
\hline & $\mathrm{n}_{\mathrm{A}}$ & $\mathrm{n}_{\mathrm{L}}$ & $\mathrm{n}_{\mathrm{A}}$ & $\mathrm{n}_{\mathrm{L}}$ & $\mathrm{n}_{\mathrm{A}}$ & $\mathrm{n}_{\mathrm{L}}$ & $\mathrm{n}_{\mathrm{A}}$ & $\mathrm{n}_{\mathrm{L}}$ \\
\hline 2004-2005 & 4 & 39 & - & - & 5 & 51 & - & - \\
\hline $2005-2006$ & 9 & 209 & - & - & 5 & 152 & - & - \\
\hline 2006-2007 & 5 & 119 & - & - & 5 & 133 & - & - \\
\hline 2007-2008 & 6 & 130 & - & - & - & - & - & - \\
\hline
\end{tabular}




\begin{tabular}{|l|cc|cc|cc|cc|}
$2008-2009$ & - & - & 4 & 51 & - & - & 3 & 76 \\
$2009-2010$ & 6 & 79 & 3 & 39 & 5 & 88 & 2 & 64 \\
$2010-2011$ & 4 & 83 & 6 & 98 & 2 & 44 & 3 & 66 \\
$2011-2012$ & 5 & 80 & 3 & 103 & 4 & 101 & 3 & 54 \\
$2012-2013$ & 8 & 93 & 12 & 215 & 5 & 115 & 11 & 287 \\
$2013-2014$ & 3 & 50 & 11 & 197 & - & - & - & - \\
\hline
\end{tabular}

Linear mixed effect model indicated no statistically significant interaction or main effect of fidelity type, season, or area on mean interlocation distances of individual deer (Table 2.2).

Table 2.2: Variation in mean interlocation distances of female black-tailed deer as a function of fidelity type (within and between years), season (summer and winter), and area (FH7 vs. M1 ridge) based on linear mixed effect (LME) models. The statistical significance of each variable and their interactions was assessed by backward elimination from the full model. Model comparison based on AIC, log likelihood (LL) and outcomes likelihood ratio (L. Ratio) test.

\begin{tabular}{|l|cccccc|}
\hline \multicolumn{1}{|c|}{ Model } & df & AIC & LL & Test & L.Ratio & $\begin{array}{c}p \\
\text { value }\end{array}$ \\
\hline 1) Null model & 5 & 210408.9 & -105199.4 & & & \\
2) Fidelity Type & 6 & 210409.5 & -105198.8 & 1 vs 2 & 1.36 & 0.243 \\
3) Season & 7 & 210411.4 & -105198.7 & 2 vs 3 & 0.12 & 0.730 \\
4) Area & 8 & 210411.3 & -105197.7 & 3 vs 4 & 2.03 & 0.154 \\
5) Fidelity type $\times$ Season & 9 & 210413.0 & -105197.5 & 4 vs 5 & 0.40 & 0.528 \\
6) Area $\times$ Season & 10 & 210413.2 & -105196.6 & 5 vs 6 & 1.73 & 0.189 \\
\hline
\end{tabular}


7) Fidelity type $\times$ Area

8) Full Model
$11 \quad 210415.2 \quad-105196.6 \quad 6$ vs $7 \quad 0.01$

0.944

$\begin{array}{lllll}12 & 210417.0 & -105196.5 & 7 \text { vs } 8 & 0.20\end{array}$

0.653

None of the explanatory variables improved model fit (Table 2.3). Differences in mean interlocation distances among individuals (Figure 2.2) explained $13 \%$ of the observed variation. I also found no effect of age on within and between year fidelity to seasonal ranges (summer within: $F_{1,49}=0.097, P=0.757$; summer between: $F_{1,31}=$ $0.721, P=0.402 ;$ winter within: $F_{1,42}=1.231, P=0.274 ;$ winter between: $F_{1,8}=$ $0.152, P=0.707)$. The lack of differences in interlocation distances within and between years during both summer and winter indicated that female deer returned to the same areas in consecutive years (Table 2.4).

Table 2.3: Summary statistics full model conducted to assess the significance of main (fixed) effects and interactions on mean interlocation distances (log-transformed) of female black-tailed deer.

\begin{tabular}{|l|ccccc|}
\hline Covariates & Value & SE & df & $\begin{array}{c}t \\
\text { value }\end{array}$ & $\begin{array}{c}p \\
\text { value }\end{array}$ \\
\hline Fidelity type & -0.12 & 0.23 & 31 & -0.53 & 0.597 \\
Season & -0.16 & 0.40 & 49 & -0.40 & 0.692 \\
Area & 0.04 & 0.26 & 51 & 0.15 & 0.883 \\
Fidelity type $\times$ Season & -0.07 & 0.45 & 49 & -0.16 & 0.873 \\
Fidelity type $\times$ Area & 0.09 & 0.31 & 31 & 0.29 & 0.772 \\
Season $\times$ Area & & & & & \\
Fidelity type $\times$ Season $\times$ Area & -0.26 & 0.59 & 49 & -0.45 & 0.658 \\
\hline
\end{tabular}



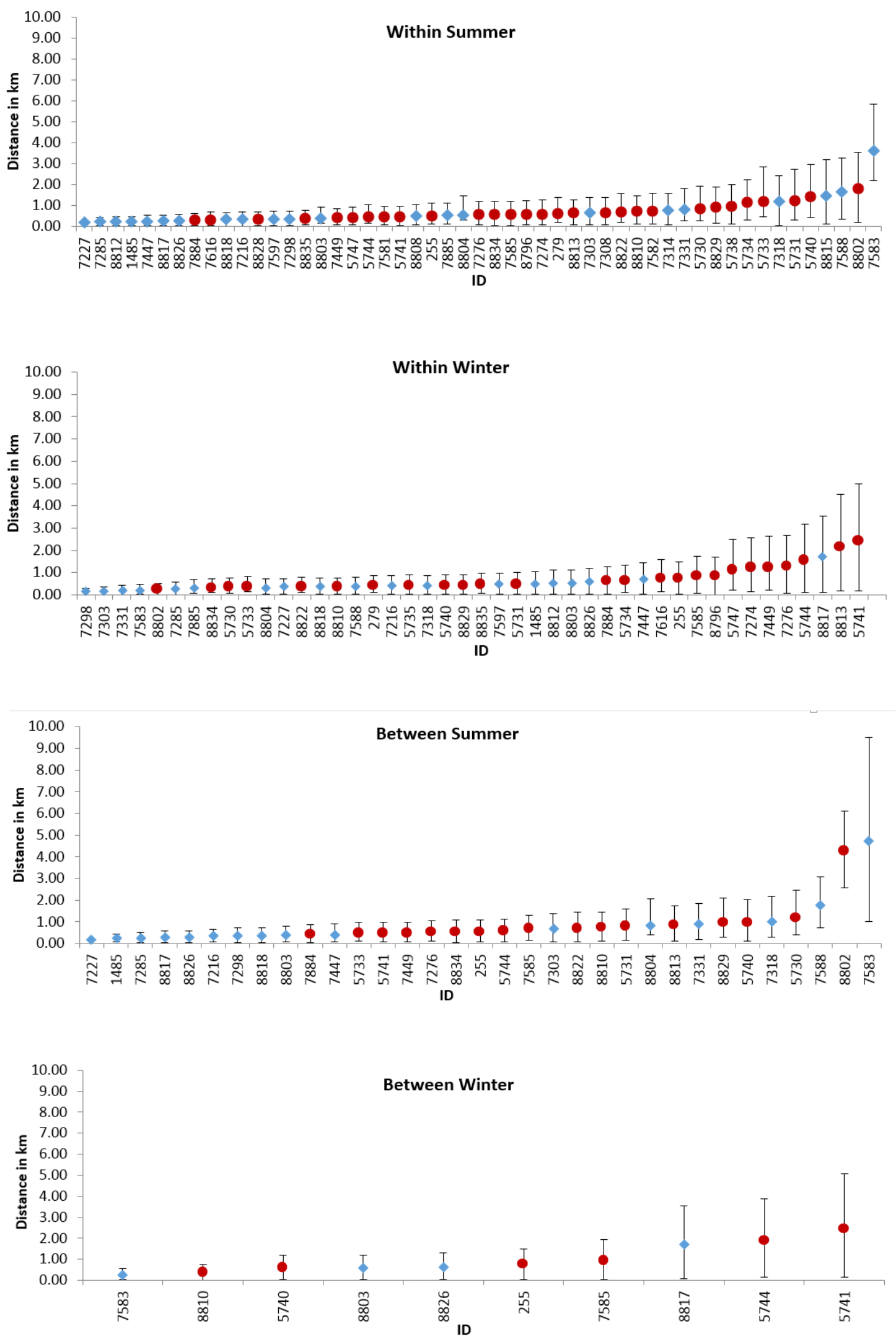

Figure 2.2: Mean interlocation distances of 64 female black-tailed deer in the Mendocino National Forest. The interlocation distances are grouped by within and between seasons. The red circle represents individuals from M1 ridge and the blue diamond represents individuals from $\mathrm{FH} 7$ ridge. 
Table 2.4: Mean seasonal interlocation distances for female black-tailed deer within and between years and their corresponding sample sizes $\left(n_{\mathrm{A}}\right)$

\begin{tabular}{|l|lcc|}
\hline Season & Group & $n_{\mathrm{A}}$ & Mean distance $(\mathrm{km})$ \\
\hline Summer & Within & 51 & $0.81 \pm 0.12$ \\
& Between & 33 & $0.90 \pm 0.21$ \\
\hline Winter & Within & 44 & $0.65 \pm 0.08$ \\
& Between & 9 & $1.01 \pm 0.23$ \\
\hline
\end{tabular}

Annual survival probabilities for female deer averaged $0.76 \pm 0.03$ across all years. Fidelity to seasonal ranges appeared to be correlated with mortality risk. Increase in mean interlocation distances between consecutive summers are found to significantly increase the risk of mortality $(\beta=0.448, P=0.046)$. Specifically, summer survival probabilities of deer averaged $0.92 \pm 0.07$ for individuals with interlocation distances of $\leq 1 \mathrm{~km}$ between consecutive summers. For every additional kilometre in interlocation distances between consecutive summers, survival decreased by $56.5 \%$ (Figure 2.3). The nonsignificant Schoenfeld residuals $(\sigma=-0.154, P=0.690)$ suggested that the assumptions for the model were adequately met. No other significant effects on mortality were apparent from my data. 


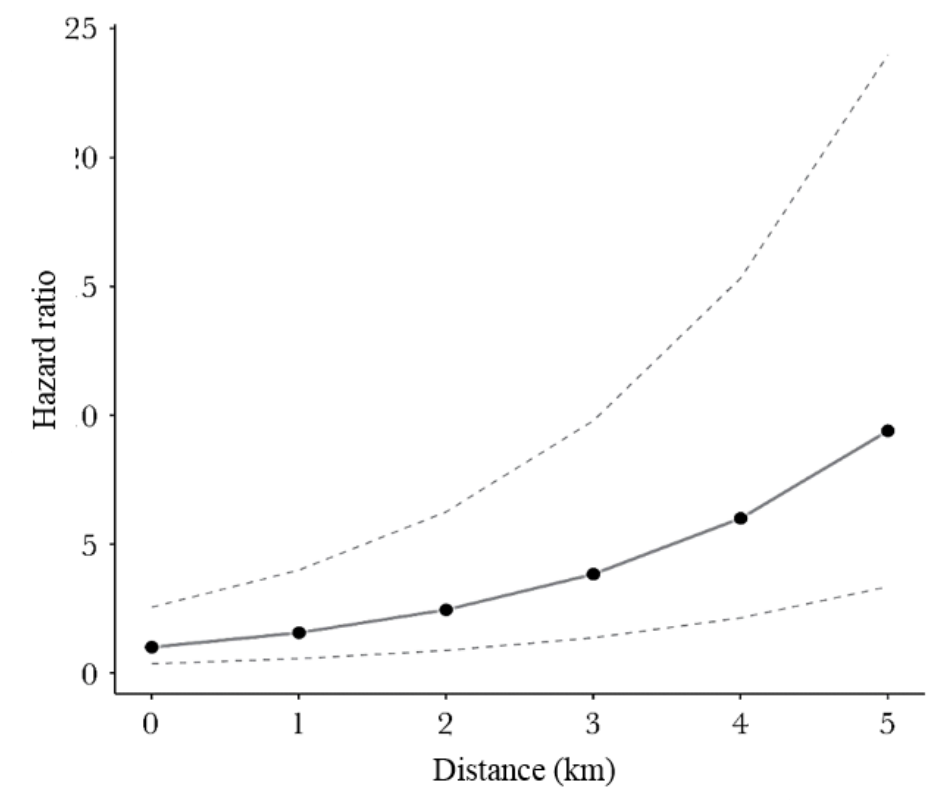

Figure 2.3: Estimated Hazard ratio with $95 \%$ confidence intervals of female blacktailed deer in the Mendocino National Forest as a function of between-year interlocation distances during summer.

\subsubsection{Philopatry and Genetic Population Structure}

I observed a total of 10 haplotypes, corresponding to a gene diversity of $0.75 \pm 0.06$ and a nucleotide diversity of $0.013 \pm 0.002$. The haplotype diversity was $48 \%$ higher on the M1 ridge $(0.89 \pm 0.04, n=19)$ than on the FH7 ridge $(0.43 \pm 0.11, n=29)$. However, the nucleotide diversity was similar between the ridges $(\mathrm{M} 1=0.013 \pm 0.002$; FH7 $=0.010 \pm 0.004)$. Overall, haplotype sharing was low (Figure 2.4), corresponding to a marked genetic subdivision between the $\mathrm{M} 1$ and $\mathrm{FH} 7$ ridges $\left(F_{\mathrm{ST}}=0.36, P<\right.$ $0.001)$. By rearranging the formula $F_{\mathrm{ST}} \approx 1 /(2 m N f+1)$, where $m N f$ is the number of female migrants per generation, I obtained an estimate of $\approx 0.89$ female deer moving between ridges per generation. The haplotype network revealed visible genetic structuring between $\mathrm{M} 1$ and FH7 ridges. Of the 10 total haplotypes, 5 were restricted to $\mathrm{M} 1,2$ to $\mathrm{FH} 7$, and the remaining 3 haplotypes were shared across both localities (Figure 2.4). 


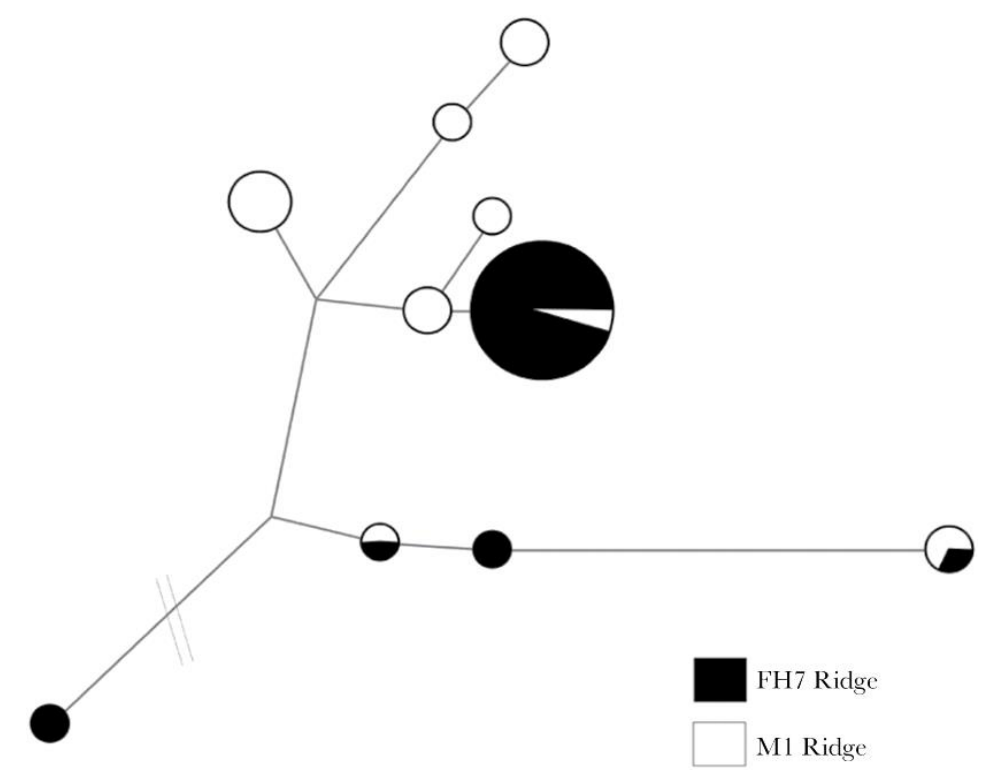

Figure 2.4: Mitochondrial haplotype network illustrating the low sharing of haplotypes between ridges based on 48 individuals ( 24 adult females and 24 unrelated fawns) captured on the FH7 $(n=29)$ and M1 $(n=19)$ ridges, Mendocino National Forest, 2011-2012.

\subsection{Discussion}

This approach differed from most previous studies in that I combined detailed spatial data from GPS collared individuals with mtDNA samples to simultaneously assess the effects of fidelity and philopatry. Results based on the telemetry data revealed very small seasonal home ranges together with high site fidelity in female BTD, which did not vary spatially (i.e., between ridges) or with age. Plasticity in movement behaviour among individuals was low but linked to improved survival of adult female deer with higher site fidelity, demonstrating a possible mechanism to explain the prevalence of female philopatry in the population. Results from mtDNA sequencing revealed a range of locality-specific haplotypes with low level of interpopulation mixing and very high genetic differentiation $\left(F_{\mathrm{ST}}>0.30\right)$ between the $\mathrm{M} 1$ and $\mathrm{FH} 7$ ridges, even though wintering ranges where mating occurred were separated by as little as $4 \mathrm{~km}$. The high genetic differentiation indicated multigenerational philopatric behaviour in the 
matrilineage. Combined, these findings improve our understanding of the short- and long-term population level consequences of animal movements and fidelity in species with sex-biased dispersal.

The high $F_{\text {ST }}$ value and low level of shared haplotypes observed among individuals on the 2 ridges were indicative of population subdivision and genetic drift, which can over time lead to population isolation and thus locally disjunct subpopulations (Greenwood 1980, Robertson and Cooke 1999). As measures of $F_{\mathrm{ST}}$ are based on an idealized population at equilibrium between the opposing forces of genetic drift, mutation and migration, the very high $F_{\mathrm{ST}}$ estimate suggests that genetic divergence and therefore philopatry of females was not limited to just a few generations but over a relatively longer time scale. Populations are said to be isolated if the dynamics are entirely dependent on local birth and death rates and not on migration events (Turchin 2003). Isolation can either be genetic (no immigrants of either gender), demographic (immigrants of one gender only), or both (local isolation). Although genetic differentiation among individuals on the different ridges was high, it is unlikely that the population was genetically isolated as 1) only female deer and, more importantly, maternally inherited markers, were sampled in this study, 2) male BTD were continuously distributed throughout the study area, and 3) females from both ridges seasonally migrated to the same low elevation winter ranges where mating occurred and thus shared the same male mating pool. Rather, it appears that BTD may be experiencing small-scale demographic isolation due to strong philopatry, where, similar to white-tailed deer (O. viginianus; Porter et al. 1991), females are predominantly recruited into existing family groups. This isolation persists despite the lack of barriers to movement in my study area. Identifying such demographic isolation is important, given that population dynamics in polygynous cervids including BTD are 
typically based on estimates of vital rates of females only (Gaillard et al. 2000, Forrester and Wittmer 2013).

Low movement rates combined with high fidelity to seasonal ranges across successive years resulted in extremely small home ranges for my study animals. Mean seasonal home range sizes of $0.71 \mathrm{~km}^{2}$ in summer and $0.99 \mathrm{~km}^{2}$ in winter were smaller than previously reported home range estimates for BTD (Geist 1981, Garrott et al. 1987) and most other ungulates of comparable size (Kelt and Van Vuren 2001). The slightly larger size of winter ranges is consistent with previous findings (Lesage et al. 2000, Wittmer et al. 2006) and likely a consequence of either reduced availability or quality of forage during the colder months or increased mobility associated with the mating season. Larger seasonal home ranges on the M1 ridge may have been related to forage availability and population density. For example, results from vegetation surveys indicated lower forage availability and quality on the M1 ridge (Wittmer et al. 2014). At the same time, density of female BTD was lower on the M1 than the FH7 ridge (Lounsberry et al. 2015) and smaller home range sizes have been hypothesized to reduce competition at high densities in cervids (Larson et al. 1978, Lesage et al. 2000).

Importantly, I found that site fidelity was positively linked to increased survival in female BTD, a possible mechanism explaining high levels of philopatry. Evidence for a link between movement behaviour including site fidelity and survival is still rare (Morales et al. 2010) and might have been due to benefits associated with site familiarity (Piper 2011). For example, individuals living within small, familiar home ranges have been shown to reduce the time they spend searching for forage and thus encounters with predators (Wolf et al. 2009). In my system, annual survival 
probabilities of adult female deer were low $(0.76 \pm 0.06)$ compared to previous estimates reported across the distribution of mule deer and BTD $(0.84 \pm 0.04$; Forrester and Wittmer 2013). In addition, predation from pumas accounted for $86 \%$ of known mortalities of adult females in my study area and primarily occurred during summer (Allen et al. 2014, Marescot et al. 2015). Returning to small but highly familiar home ranges during consecutive summers thus apparently lowered mortality risks including from predation, highlighting fitness benefits of both familiarity and reduced movements. This finding also matches earlier research that found a higher predation risk for female deer in my study area when they strayed outside their 95\% summer home ranges (Forrester et al. 2015).

Prevalence of philopatry and fidelity is expected to vary with population density and trends. Specifically, individuals should be more compelled to disperse when the costs of competition for forage at high population density outweigh the fitness benefits of staying put (Matthysen 2005, Morales et al. 2010). Site fidelity behaviour is expected to be more pronounced at low population densities and in declining populations when associated interference competition is low (Merkle et al. 2015). However, I found evidence for philopatry over multiple generations and high site fidelity despite high BTD densities on summer ranges in the study area (male density ranged from $7.80 \pm 2.60$ to $18.20 \pm 6.88$ per $\mathrm{km}^{2}$, female density ranged from $24.58 \pm 3.48$ to $52.45 \pm 10.75$ per $\mathrm{km}^{2}$; Lounsberry et al. 2015 ). These results suggest that benefits of philopatry and site fidelity seem to have outweighed costs from competition with conspecifics. Over time, this may lead to high local densities and potential population increases beyond carrying capacity, increasing the likelihood of a population decline due to over-utilization of resources (Leopold et al. 1947, Forrester and Wittmer 2013, Merkle et al. 2015). Demographic recovery following population 
declines will then either depend on immigrants from expanding populations in the vicinity that did not suffer a decline or on local births rates (Porter et al. 1991, Duckworth 2008, Bitume et al. 2013). My observed pattern of genetic structuring hints at a trend of historic demographic fluctuations with infrequent immigration. If true, then local birth rates will be more important than founding females for re-establishing populations with high philopatry that experience population declines.

I have shown that strong site fidelity and sex-biased philopatry cause population structuring and likely dynamics at a much finer scale than previously established in BTD or other species with strong matrilineal groups. Low maternal gene flow, as evidenced by the occurrence of few representative mtDNA haplotypes on each ridge, reveals that high levels of philopatry and low female movement between adjacent family groups can lead to demographic isolation with potentially localized vital rates (Monteith et al. 2014, Marescot et al. 2015) and result in small-scale differences in estimates of population growth. In populations with high site fidelity and philopatry among females, consideration should thus be given to matrilineal groups as the basic unit of genetic structuring and the potential to effect their conservation and management. 
Chapter 3

\section{Effect of Activity States on Habitat Selection Pattern by Black-tailed deer}


This paper is now accepted for publication in Journal of Wildlife Management as:

Bose S., Forrester T.D., Casady D.S. and Wittmer H.U. Effect of activity states on habitat selection by black-tailed deer

\section{Acknowledgements}

The project was generously funded by the California Department of Fish and Wildlife (\#P0880013) and the California Deer Association (\#08-001495, \#001-10,\#011-11). I thank Dr. Tavis Forrester, David Casady, all students, volunteers, and agency personnel who helped with deer captures and collecting data in the field. J. Fischer provided helpful comments on a previous version of the manuscript. 


\section{Abstract}

Habitat selection is a complex hierarchical process and in ungulates typically varies at broad spatial and temporal scales as well as among individuals. Recent advancements in the ability of GPS collars to collect activity data provide opportunities to understand underlying mechanisms or trade-offs responsible for fine-scale variation in habitat selection. Based on data from 64 female black-tailed deer (BTD; Odocoileus hemionus columbianus) fitted with GPS collars in northern California between 2004 and 2013, I estimated selection for topographic and vegetation covariates at two spatial scales (i.e., landscape and home range scales). I then used data from a subset of 27 individuals to determine if habitat selection within home ranges was influenced by activity states (active/inactive). At the landscape scale, habitat selection by BTD varied between summer and winter, and was mostly explained by differences in elevation, terrain, and vegetation. Within their home ranges, BTD showed fine-scale selection for habitats that varied with activity states. In summer, selection for slope and forest types varied across activity states highlighting important fine-scale selection patterns. Activity state also affected conclusions about the selection of habitats including edge density, canopy cover, and forest types by BTD in winter. During both seasons, deer selected for apparently secure habitat when inactive, likely to minimise risk of predation. My results highlight the importance of considering activity states when evaluating habitat selection from animal location data. This is particularly important in multi-use landscapes such as National Forests where habitat needs of ungulates are important considerations in management decisions, including logging. 


\subsection{Introduction:}

Habitat selection by animals is influenced by a range of conflicting demands associated with foraging (Hanley 1982), predator avoidance (Pierce et al. 2004, DeCesare et al. 2014), competition for mates and resources (Kie and Bowyer 1999), and rearing young (Van Moorter et al. 2009a). Habitats needed to meet these diverse requirements are often distributed heterogeneously in space and time. Selection of habitats by individual animals thus varies temporally to optimally utilize disjunct and clumped resources (Rosenzweig 1991, Morris 2003, Gaillard et al. 2010). The temporal variation in habitat selection can be short-term due to differences in circadian patterns (Ager et al. 2003, Prugh and Golden 2014), medium-term (e.g., seasonal) to account for variability in environmental conditions and physiological requirements (Long et al. 2009a, Monteith et al. 2011), or long-term (e.g., annual or even decadal) due to directional changes in demographic population structure and environmental parameters (Fryxell et al. 2008).

Ungulates in temperate environments, including mule deer (Odocoileus hemionus; D'Eon and Serrouya 2005, Sawyer et al. 2006), elk (Cervus elaphus; Anderson et al. 2005, Sawyer et al. 2007) and caribou (Rangifer tarandus; Rettie and Messier 2000, Leblond et al. 2011), have been repeatedly shown to select different habitats across seasons. Consequently, estimating habitat selection at different temporal scales has been strongly advocated for ungulates (Ager et al. 2003, van Beest et al. 2010). However, until recently, we lacked technology linking location data used to quantify habitat selection to activity information (Wilmers et al. 2015). The hypothesis that habitat selection also depends on short-term differences in behavioural 
states of individuals (Johnson 1980, Senft et al. 1987) has therefore largely been overlooked (Roever et al. 2014).

Activity patterns of ruminating ungulates are composed of alternating foraging (active states) and resting bouts used for mastication and digestion (inactive states; Gillingham et al. 1997). Although locational data can be used to estimate patterns of habitat selection, without a behavioural context these data may fail to capture changes in selection associated with daily foraging and resting patterns (Godvik et al. 2009, Roever et al. 2014). Overlooking activity states associated with habitat selection may lead to oversimplification of specific habitat requirements, thus reducing the predictive power of pooled resource selection models and diminishing the ability of resource managers to develop effective habitat management strategies (Garshelis 2000, Roever et al. 2014). The use of habitat during active foraging bouts and resting periods can also be affected differently by changing energetic demands, predation risk, and competition (Krebs 1980, DeCesare et al. 2014). Accounting for activity state in selection models may allow greater insights into the effects of these processes on ungulates.

Black-tailed deer (BTD, O. h. columbianus) are among the subspecies of mule deer that inhabit complex forested habitats in coastal areas from northern California into the Pacific Northwest and British Columbia. They, being an important social and economic species in western USA, have been extensively studied across their distribution (e.g., Heffelfinger and Messmer 2003). However, recent declines in both BTD and mule deer populations throughout much of their ranges (Forrester and Wittmer 2013) have led to renewed interest in understanding habitat selection and resource use by the species to aid in developing effective management strategies. 
The overall objective of this chapter was to understand fine-scale habitat selection by BTD in northern California. Only females were included in this study because in deer, the adult female segment disproportionally drives population dynamics (Gaillard et al. 2000) and therefore management actions primarily target this segment of the population. To achieve my objective, resource selection functions (RSFs; Manly et al. 2002) were developed based on location data from 64 adult female BTD fitted with GPS collars between 2004 and 2013 at two spatial scales (i.e., landscape and home range scales). Using data from a subset of 27 individuals (Appendix 1), activity specific RSFs were then compared with general RSFs to assess how activity states influenced seasonal habitat selection by BTD.

\subsection{Materials and Methods}

\subsubsection{Study Area}

The Mendocino National Forest covers approximately $3,700 \mathrm{~km}^{2}$ of the interior Coast Range of California, USA. Within the Mendocino National Forest, intensive study area covered approximately $1,000 \mathrm{~km}^{2}$ and included 2 major mountain ridges (M1 and FH7) and 3 main watersheds (Figure 3.1). Elevation in the study area ranges from 158 $\mathrm{m}$ to $2,462 \mathrm{~m}$ above sea level. The topography varies from moderately rolling terrain at lower elevations to steep and rugged terrain at higher elevations except on ridge tops. Climate is Mediterranean; mean daily temperatures ranged from $5^{\circ} \mathrm{C}$ during winter to $17^{\circ} \mathrm{C}$ in summer (Mendocino Pass weather station; http://www.ncdc.noaa.gov/cdo-web, Accessed $9^{\text {th }}$ September, 2014). However, temperatures reached extremes of below $-10^{\circ} \mathrm{C}$ and above $40^{\circ} \mathrm{C}$ in winter and summer, respectively. Precipitation over the study period averaged $148.8 \mathrm{~cm}$ per year and was highly seasonal, with about $85 \%$ of the precipitation occurring from October through 
April. Snow cover was generally limited to elevations $>1000 \mathrm{~m}$ and was irregular, particularly during dry winters.

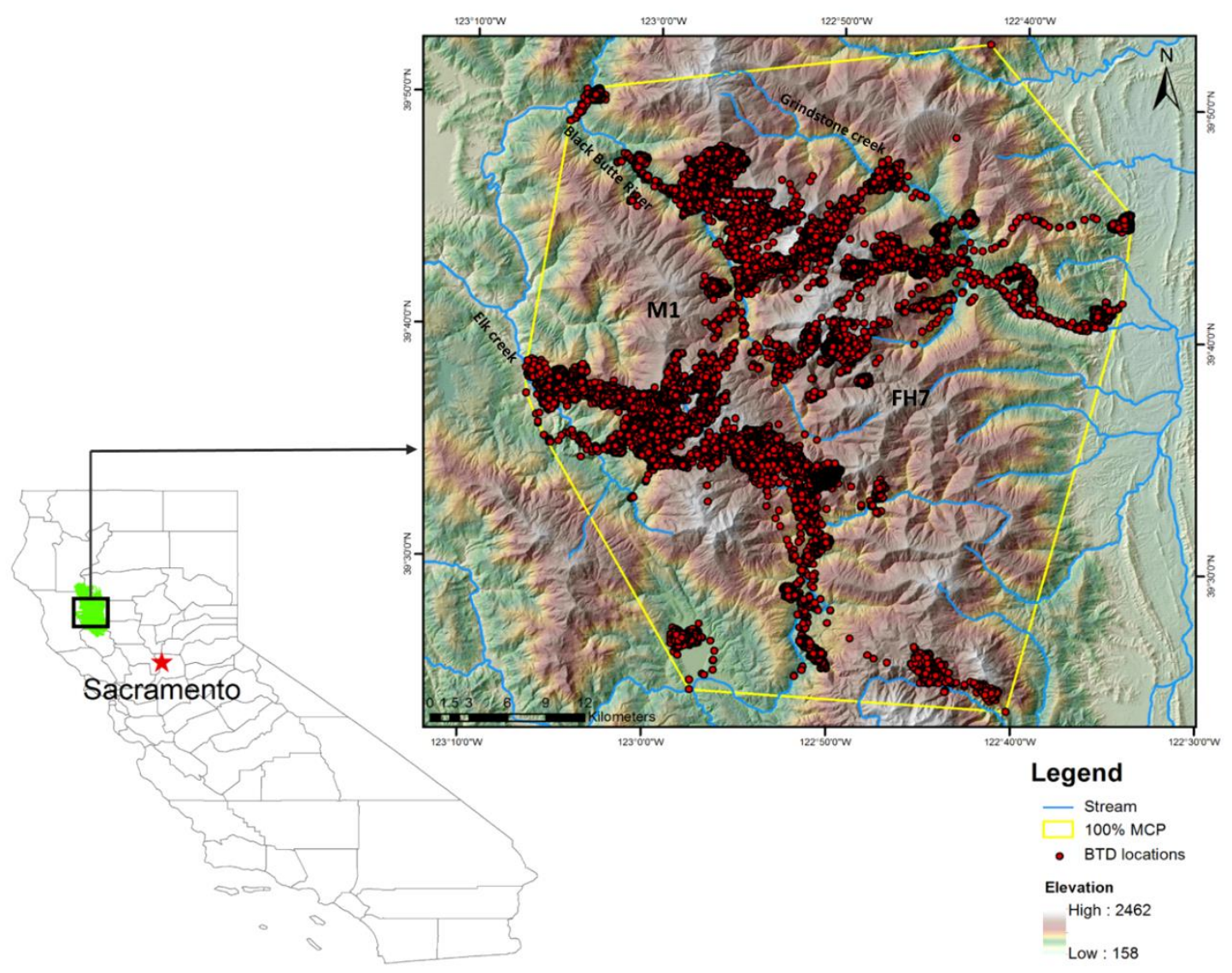

Figure 3.1: Location of the study area in the Mendocino National Forest, California, including 2 main ridges (M1 and FH7) and 3 main watersheds. The 100\% minimum convex polygon shown is based on all locations of 64 GPS collared adult female blacktailed deer monitored between 2004 and 2013 and was used to determine available habitats at the landscape scale.

Vegetation in the study area varied with elevation and aspect. Oak woodlands (Quercus spp., Aesculus californicus, Arctostaphylos spp.), chaparral (Ceanothus spp., Adenostoma fasciculatum), and grasslands (Bromus spp., Avena spp.) dominated lower elevations and southerly slopes while mixed-coniferous hardwood forests (Pinus ponderosa, P. iambertiana, Abies concolor, A. magnifica, Pseudotsuga menziesii, Arbutus menziesii, Quercus spp.) dominated higher elevations and northerly slopes. 
Silviculture and cattle grazing were the primary land management activities in the past and left a mosaic of even-aged conifers with occasional mature timber stands and openings dominated by non-native grasses.

BTD were the only resident and abundant ungulate in the intensive study area. Other ungulates present in the study area included non-native wild pigs (Sus scrofa) at lower elevations and seasonally abundant domestic cattle (Bos taurus). Tule elk (C. e. nannodes), observed twice during the study period, were likely dispersing individuals from a population reintroduced to the extreme southern end of the study area. Pumas (Puma concolor) were the primary predator of adult female deer; fawns were also killed by American black bears (Ursus americanus), coyotes (Canis latrans) and bobcats (Lynx rufus) (Marescot et al. 2015).

\subsubsection{Capture and Monitoring}

Between September 2004 and August 2013, a total of 84 female BTD $\geq 1$ year old was captured. No deer were captured or monitored between September 2008 and June 2009. Deer were captured opportunistically while driving along unpaved logging roads using chemical immobilization via free range darting. Captures primarily occurred on high elevation summer ranges on the M1 and FH7 ridges. Detailed capture and handling procedures are described in Casady and Allen (2013). All procedures were approved by the Wildlife Investigations Laboratory of the California Department of Fish and Wildlife and the Institutional Animal Care and Use Committee at the University of California, Davis (Protocols 15341 and 16886).

Anaesthetized deer were fitted with numbered ear tags and motion-sensitive, store-on-board GPS collars (Telonics, Mesa Arizona, USA and models 3300 and 4400M, Lotek Wireless, Inc., Newmarket, Ontario, Canada) that never exceeded 3\% 
of their bodyweight. Collars were programmed to obtain a GPS location every 1-5 hours . In addition to recording locations, Lotek 4400M collars were also programmed to obtain activity data every 5 minutes. Collars were deployed on deer for a maximum of 2 years after which they dropped off. All collars were programmed to emit VHF mortality signals after 4 hours of inactivity, facilitating collar recovery and identification of mortality causes (Marescot et al. 2015). Of the 84 female deer captured, 3 died from capture related injuries and the collars of 4 individuals failed immediately. GPS location data from an additional 13 individuals could not be retrieved due to collar malfunction leaving me with GPS location data from 64 deer for the preliminary habitat selection analyses. Twenty-seven of these 64 individuals had activity data recorded that was used for activity-specific selection models (Table 3.1).

Table 3.1: Total number of female deer $\left(\mathrm{n}_{\mathrm{D}}\right)$, deer with activity data $\left(\mathrm{n}_{\mathrm{A}}\right)$, and number of pooled (telemetry locations pooled across activity states), active, and inactive GPS locations used in models to estimate habitat selection by black-tailed deer in the Mendocino National Forest, California, USA, 2004-2013.

\begin{tabular}{|c|c|ccc|}
\hline & & \multicolumn{3}{|c|}{ Number of GPS locations } \\
\cline { 3 - 5 } Season & $\mathrm{n}_{\mathrm{D}}\left(\mathrm{n}_{\mathrm{A}}\right)$ & Pooled & Active & Inactive \\
\cline { 3 - 5 } Summer & $51(22)$ & 79110 & 2439 & 23603 \\
Winter & $45(20)$ & 63132 & 2370 & 21945 \\
Non-migratory & $12(5)$ & 20699 & 778 & 6446 \\
\hline
\end{tabular}




\subsubsection{Population and Home-range Estimation}

The population range to be used for the RSFs was first defined by creating a $100 \%$ minimum convex polygon (MCP) with locations from all 64 collared deer. The $100 \%$ MCP was then considered as the "landscape scale" for the second order RSF analysis (Johnson 1980). Similar to D’Eon and Serrouya (2005), GPS locations of individual deer were then assigned to summer, winter, or migration "seasons" based on observed patterns in elevational movements and space use. Based on the seasonal locations, summer and winter home ranges of individual migratory deer were subsequently derived using a 95\% MCP. Twelve deer did not show distinct elevational migrations across years. For these non-migratory deer 95\% MCPs were derived based on all acquired locations for each individual and created annual home ranges.

\subsubsection{Assigning Activity State}

Active or inactive states were assigned to the GPS locations of the 27 individuals fitted with Lotek 4400M collars equipped with activity sensors. Activity sensors are made of 2 accelerometers that record changes in acceleration associated with animal motion along the $\mathrm{x}$ and $\mathrm{y}$ axes of the body 4 times per second. Motion data from each accelerometer were averaged over the duration of 5 minutes and resulted in assignment of a single activity monitor value (AMV) ranging from 0 to 255 for each axis. The $\mathrm{x}$ and y AMVs were log transformed and classified based on discriminant function models developed by Gaylord (2013) for classifying activity states of mule deer. The activity states to GPS locations were assigned based on average values for the 5-minute interval that overlapped the time a GPS location was taken. I chose to use a two-state model that differentiated between active and inactive only, as models considering a greater number of activity states (e.g., differentiating among inactive, walking and 
running behaviours) resulted in lower accuracy and greater variability of the classification (Gaylord 2013).

\subsubsection{Habitat Covariates}

Covariates known to influence patterns of habitat selection and habitat use by female BTD (e.g., Bunnell 1990, Gillingham 2004) were included for the RSF analyses. I obtained $30 \mathrm{~m}$ x $30 \mathrm{~m}$ resolution raster data layers for the study area and prepared a suite of Geographic Information System (GIS) layers of selected variables for the analyses (Table 3.2). Elevation data were obtained from the Advanced Spaceborne Thermal Emission and Reflection radiometer (ASTER) global digital elevation model (GDEM; www.gdem.aster.ersdac.or.jp, Accessed 12 ${ }^{\text {th }}$ December, 2013). Topographic variables including slope $(\%)$ and aspect (sine and cosine transformed) were derived from the ASTER GDEM layer using Spatial Analyst surface tools in ArcGIS 10.2 (ESRI, Redlands, CA, USA). Vector ruggedness measure (VRM) was derived from ASTER GDEM in ArcGIS following Sappington et al. (2007).

Vegetation layers including type, succession class (i.e., stand age), canopy cover and height, and canopy at base height (i.e. vertical cover) were acquired from Landscape Fire and Resource Management Planning databases (LandFire; www.landfire.gov, Accessed $20^{\text {th }}$ February, 2015) for the study area (Table 3.2). Based on proposed ecological importance for BTD (e.g., Dasmann and Taber 1956, Wallmo 1981) vegetation was reclassified into 7 distinct habitat categories: oak forest, oak shrub, conifer, grassland, riparian, non-oak shrub, and other (water, barren, developed upland forests and agricultural land). Conifer was used as the reference class for comparison among vegetation types, as it was the most abundant form of vegetation in both summer and winter ranges. 
Table 3.2: Habitat covariates used in models to estimate habitat selection by 64 female black-tailed deer in the Mendocino National Forest, California, between 2004 and 2013.

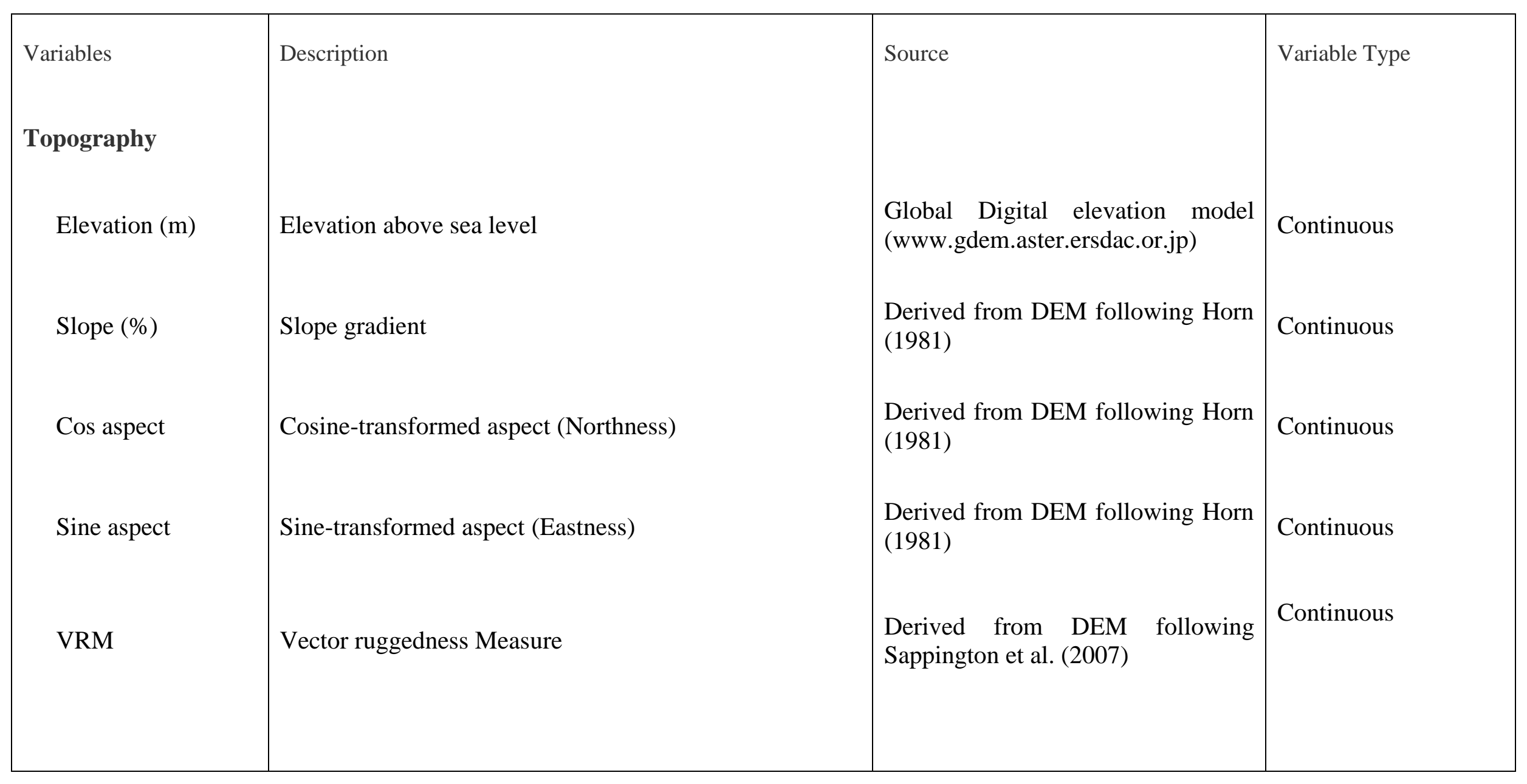




\begin{tabular}{|c|c|c|c|}
\hline Type & Complexes of plant communities & http://www.landfire.gov/ & Categorical \\
\hline Succession class & $\begin{array}{l}\text { Current vegetation conditions with respect to species } \\
\text { composition, cover, and height ranges of successional } \\
\text { states within each biophysical setting }\end{array}$ & http://www.landfire.gov/ & Categorical \\
\hline Cover $(\%)$ & $\begin{array}{l}\text { Proportion of the forest floor covered by the vertical } \\
\text { projection of the tree crowns }\end{array}$ & http://www.landfire.gov/ & Continuous \\
\hline Canopy height (m) & Average height of the top of the canopy & http://www.landfire.gov/ & Continuous \\
\hline $\begin{array}{l}\text { Canopy at base } \\
\text { height }(\mathrm{m})\end{array}$ & $\begin{array}{l}\text { Average height from ground to a forest stand's canopy } \\
\text { bottom }\end{array}$ & http://www.landfire.gov/ & Continuous \\
\hline
\end{tabular}


Stand age is considered an important ecological covariate for most ungulates, including BTD, as younger forest stands generally provide opportunities for foraging, while older forest stands facilitate thermoregulation (Bunnell 1990). Successional classes included in the analysis were thus based on the age of the forest stands and broadly classified into 5 classes: regenerative or very young (0-19 years), young (2039 years), intermediate ( $40-79$ years), mature ( $80-120$ years), and old (> 120 years). A sixth class contained all other vegetation types (uncharacteristic native, exotic, barren, and water). Edge density was also used as a predictor variable in my analyses, where edge was defined as the interface between open (herbaceous, shrubs, grassland) and closed-canopy (forested) vegetation and between river/stream/road edges. The density of these linear features per pixel was calculated using Spatial Analyst density tools in ArcGIS 10.2.

\subsubsection{Statistical Analyses}

A use-availability design (Manly et al. 2002) was implemented to evaluate the influence of environmental variables on habitat selection by female BTD across seasons and activity states. For the behaviourally pooled data, hierarchical resource selection functions were considered at two scales: the landscape scale (second order selection) and within individual (seasonal) home ranges (third order selection; Johnson 1980). Resource availability at the landscape scale was estimated by plotting 1,000 random points per individual within the population range. Resource availability at the seasonal home range scale was estimated by drawing 1,000 random points from within each individual's winter and summer MCP home range. The same set of random locations from within seasonal home ranges was used for the pooled and activity specific RSFs. I estimated RSFs using logistic regression of the form 


$$
g(\mathrm{x})=\ln \left[\frac{\pi(X)}{1-\pi(x)}\right]=\beta_{0}+\beta_{1} x_{l i j}+\ldots+\beta_{n} x_{n i j}+\gamma_{0 j}
$$

where, $\beta_{n}$ is the estimated coefficient for covariate $x_{n}$, and $\gamma_{0 j}$ is the random per-subject intercept (Gillies et al. 2006). This method effectively controls for variation due to unbalanced individual sampling (Gillies et al. 2006, Hebblewhite and Merrill 2008).

My objectives were to understand how RSFs vary with scales and to compare pooled RSFs (across activity states) with activity specific RSFs (active and inactive) within home ranges. I thus chose to keep the number of competing models low and built a set of 3 a priori candidate models (Table 3.3).

Table 3.3: Candidate models and respective number of parameters $(K)$ used to determine habitat selection by 64 female black-tailed deer across activity states in the Mendocino National Forest, California, between 2004 and 2013. Models were fit to activity-specific and pooled location datasets at 2 spatial scales (landscape scale and home ranges scale).

\begin{tabular}{|c|c|c|}
\hline Name & Candidate Model & $K$ \\
\hline $\begin{array}{l}\text { 1.Food } 1 \\
\text { (interaction with early seral } \\
\text { vegetation class) }\end{array}$ & $\begin{array}{l}\text { Elevation }+\cos (\text { aspect })+\sin (\text { aspect })+\text { edge } \\
\text { density }+ \text { vegetation type } \times \text { S-class } 1+ \\
\text { ruggedness }+ \text { slope }\end{array}$ & 20 \\
\hline $\begin{array}{l}\text { 2. Food } 2 \\
\text { (interaction with early to } \\
\text { mid-seral vegetation class) }\end{array}$ & $\begin{array}{l}\text { Elevation }+\cos (\text { aspect })+\sin (\text { aspect })+\text { edge } \\
\text { density }+ \text { vegetation type } \times \text { S-class } 2+ \\
\text { ruggedness }+ \text { slope }\end{array}$ & 20 \\
\hline 3. Cover & $\begin{array}{l}\text { Elevation }+\cos (\text { aspect })+\sin (\text { aspect })+\text { edge } \\
\text { density }+ \text { vegetation type } \times \text { S-class } 5+\text { canopy } \\
\text { cover }+ \text { canopy at base height }+ \text { slope }\end{array}$ & 17 \\
\hline
\end{tabular}

The candidate models were based on the hypothesis that deer will select for nutrient rich habitat (food models) while active (foraging), and for secure habitat (cover model) while inactive (resting/ruminating), and fitted models across all scales and states. I included topographic variables and vegetation types known to affect BTD 
habitat selection and varied forest stand age, cover and ruggedness to test between food and cover models. I tested for multicollinearity among the predictor variables used in each model and the variables with correlation coefficients $\geq 0.6$ were not used together in any model (Graham 2003). As canopy height and canopy cover were correlated, only canopy cover and canopy at base height were retained in the cover model as proxy for thermal and security cover. All continuous variables were standardized to allow direct comparisons of parameter estimates. Generalized linear mixed models (GLMMs) were fitted using the library 'Ime4' (Bates et al. 2015) in program R (R Development Core Team 2014). I used an information-theoretic approach based on Akaike's Information Criterion (AIC) (Burnham and Anderson 2003) to identify the best performing models for the pooled and the two activity state datasets.

I assessed model fit using a k-fold cross-validation method (Boyce et al. 2002, Long et al. 2009b). The data were randomly partitioned by individuals within seasonal models to construct a training set ( $80 \%$ of data) and test set (20\% of data). Model averaged estimates from the training models were then used to calculate predicted RSF values for the random locations. Subsequently, I ranked the random locations based on predicted values and binned them into 10 equal groups (Boyce et al. 2002). The fit was then quantified using the Spearman rank correlation coefficient based on the frequency of used points in each of 10 equal bins of predicted values (Boyce et al. 2002).

\subsection{Results}

A total of 168,599 GPS locations were retrieved via remote download or collar retrieval from 64 female BTD. Of 57,581 fixes from the 27 individuals fitted with 
activity collars, $10 \%$ were classified active and $90 \%$ as inactive (Table 3.1 ). I excluded 5,658 locations associated with elevational migrations from RSF models. Fix success rates averaged $83.81 \pm 1.4 \%($ mean $\pm \mathrm{SE})$ for all 64 individuals and $83.46 \pm 1.56 \%$ for the 27 individuals with activity collars.

\subsubsection{Landscape Scale Selection}

Selection or avoidance of specific land-cover classes and landscape features by female BTD in the Mendocino National Forest changed with spatial scale, season and migration behaviour (Table 3.4). At the landscape scale, cover models performed better across seasons for migratory deer showing elevational movements, whereas for non-migratory deer, food models performed better (Table 3.5). Despite the coarse scale of selection, migratory BTD showed difference in seasonal selection patterns towards more localized habitat characteristics (Tables 3.4 and 3.6). During summer, habitat selection by migratory BTD at the landscape level was driven by higher elevation $(\beta$ $=2.092 ;$ CI: $2.060-2.124)$, eastern aspects $(\beta=0.060 ;$ CI: $0.042-0.077)$, oak forests $(\beta$

$=0.542$; CI: 0.422-0.663) (Figure 3.2), and gentler slopes $(\beta=-0.534$; CI: $-0.554-(-$ 0.514). During winter, habitat selection by migratory BTD was associated with lower elevation ( $\beta=-1.024$; CI: $-1.046-(-) 1.001)$, sheltered western aspects $(\beta=-0.473$; CI: $-0.490-(-) 0.456)$ and old oak forests $(\beta=2.049$; CI: 1.935-2.164) (Figure 3.2). Nonmigratory BTD selected for higher elevations ( $\beta=1.069$; CI: 1.028-1.111), southern and western aspects $(\cos \beta=-0.007$; CI: $-0.043-0.028 ; \sin \beta=-0.225$; CI: $-0.258-(-$ 0.192) with gentler slopes $(\beta=-0.042$; CI: $-0.073-(-) 0.012)$ and regenerative forest stands $(\beta=0.598$; CI: 0.453-0.743) year-round (Figure 3.2). 
Table 3.4: Summary of significance level of estimated parameters of all models. If a p-value is less than 0.1 it is flagged with one dot (.). If a pvalue is less than 0.05 it is flagged with one star $\left(^{*}\right)$. If a p-value is less than 0.01 it is flagged with two stars $(* *)$. If a p-value is less than 0.001 it is flagged with three stars $(* * *)$.The colour green or red denotes the slope of selection; green for positive slope and red for negative slope of selection. The shaded column signifies the best models.

\begin{tabular}{|c|c|c|c|c|c|c|c|c|c|c|c|c|c|}
\hline \multirow[t]{2}{*}{ Type } & \multirow[t]{2}{*}{ Covariates } & \multicolumn{4}{|c|}{ Summer } & \multicolumn{4}{|c|}{ Winter } & \multicolumn{4}{|c|}{ Non-migratory } \\
\hline & & Landscape & $\begin{array}{l}\text { Home } \\
\text { range }\end{array}$ & Active & Inactive & Landscape & $\begin{array}{l}\text { Home } \\
\text { Range }\end{array}$ & Active & Inactive & Landscape & $\begin{array}{l}\text { Home } \\
\text { Range }\end{array}$ & Active & Inactive \\
\hline \multirow{11}{*}{ Food 1} & Elevation & $* * *$ & $* * *$ & $* * *$ & $* * *$ & $* * *$ & $* * *$ & $* * *$ & $* * *$ & $* * *$ & $* * *$ & **** & *** \\
\hline & Cos Aspect (N) & $* * *$ & $* * *$ & $* * *$ & $* * *$ & *** $*$ & & & & & $* * *$ & *** $*$ & $* * *$ \\
\hline & Sin Aspect (E) & $* * *$ & *** $*$ & *** $*$ & *** $*$ & $* * *$ & \multirow[t]{2}{*}{$* * *$} & \multirow{2}{*}{$\begin{array}{l}* * * \\
* * *\end{array}$} & $* * *$ & \multirow[t]{2}{*}{$* * *$} & \multirow{2}{*}{$\begin{array}{l}* * * \\
* * * \\
\end{array}$} & $* * *$ & \multirow{2}{*}{$\begin{array}{l}* * \\
* * * \\
\text { * }\end{array}$} \\
\hline & Slope & $* * *$ & $*$ & $*$ & & $* * *$ & & & $* * *$ & & & $* *$ & \\
\hline & Ruggedness & $* * *$ & $* * *$ & $* * *$ & $* * *$ & $* * *$ & $* * *$ & $* * *$ & $* * *$ & $* * *$ & $* * *$ & $* * *$ & $* * *$ \\
\hline & Edge density & $* * *$ & $* * *$ & $* * *$ & $* * *$ & $* * *$ & $* * *$ & $* * *$ & $* * *$ & $* * *$ & $* * *$ & & $* * *$ \\
\hline & Oak Forest & $* * *$ & $* * *$ & . & $* * *$ & $* * *$ & $* * *$ & $* * *$ & $* * *$ & $* *$ & & & $* * *$ \\
\hline & Oak Shrub & $* * *$ & $* * *$ & $*$ & $* * *$ & $* * *$ & \multirow[t]{2}{*}{$* * *$} & \multirow{2}{*}{$\begin{array}{l}* * * \\
* * * \\
\end{array}$} & $* * *$ & \multirow[b]{2}{*}{ *** $*$} & \multirow{2}{*}{$\begin{array}{l}* * \\
* * * \\
\end{array}$} & & \\
\hline & Grassland & & $*$ & & & $* * *$ & & & $* * *$ & & & $*$ & \\
\hline & Riparian & $* * *$ & $* * *$ & & $*$ & $* *$ & \multirow[t]{2}{*}{$* * *$} & & $* * *$ & \multirow[t]{2}{*}{$* * *$} & \multirow[t]{2}{*}{$* * *$} & $* * *$ & \multirow[t]{2}{*}{$* * *$} \\
\hline & Shrub & $* * *$ & $* * *$ & $* * *$ & $* * *$ & $* * *$ & & $* * *$ & $* * *$ & & & & \\
\hline
\end{tabular}




\begin{tabular}{|c|c|c|c|c|c|c|c|c|c|c|c|c|c|}
\hline & Other & $* * *$ & $* * *$ & $* * *$ & $* * *$ & $* * *$ & $* * *$ & $* * *$ & $* * *$ & $* * *$ & $* * *$ & $* * *$ & $* * *$ \\
\hline & S-class 1 & $* * *$ & $* * *$ & & $* * *$ & $* * *$ & $* * *$ & $* * *$ & $* * *$ & $* * *$ & $* * *$ & & $* * *$ \\
\hline & Oak Forest $\times 1$ & & & $*$ & & & $*$ & & & & & $*$ & \\
\hline & Oak Shrub×1 & & & & $* * *$ & $* * *$ & $* * *$ & $* * *$ & $* *$ & $* * *$ & $* *$ & & \\
\hline & Grassland $\times 1$ & $*$ & $* * *$ & $*$ & $*$ & $* * *$ & $* * *$ & $* * *$ & $* * *$ & $* * *$ & $* * *$ & & \\
\hline & Riparian×1 & & & & & & & & & & & & \\
\hline & Shrub $\times 1$ & $* * *$ & $* * *$ & & $* * *$ & $* * *$ & $* * *$ & $* * *$ & $* * *$ & . & & & . \\
\hline & Other $\times 1$ & $* * *$ & $* * *$ & $* * *$ & $* * *$ & $* * *$ & $* * *$ & $* *$ & $* * *$ & $* *$ & $*$ & & \\
\hline \multirow{8}{*}{ Food2 } & Elevation & $* * *$ & $* * *$ & $* * *$ & $* * *$ & $* * *$ & $* * *$ & *** & $* * *$ & $* * *$ & $* * *$ & $* * *$ & $* * *$ \\
\hline & Cos Aspect (N) & $* * *$ & *** & $* * *$ & *** & $* * *$ & & & & & $* * *$ & $* * *$ & $* * *$ \\
\hline & Sin Aspect (E) & $* * *$ & *** & \multirow[t]{2}{*}{$* * *$} & *** & $* * *$ & *** $*$ & *** $*$ & $* * *$ & $* * *$ & $* * *$ & **** & ** \\
\hline & Slope & $* * *$ & & & & $* * *$ & $* * *$ & $* * *$ & $* * *$ & $* *$ & $* * *$ & $* *$ & $* * *$ \\
\hline & Ruggedness & $* * *$ & $* * *$ & $* * *$ & $* * *$ & $* * *$ & $* * *$ & $* * *$ & $* * *$ & $* * *$ & $* * *$ & $* * *$ & $* * *$ \\
\hline & Edge density & $* * *$ & $* * *$ & \multirow[t]{2}{*}{$* * *$} & $* * *$ & $* * *$ & $* * *$ & $* * *$ & $* * *$ & $* * *$ & $* * *$ & & $* * *$ \\
\hline & Oak Forest & $* * *$ & $* * *$ & & $* * *$ & *** $*$ & $* * *$ & *** $*$ & **** & * & & & **** \\
\hline & Oak Shrub & $* * *$ & $* * *$ & & $* * *$ & $* * *$ & $* * *$ & $* * *$ & $* * *$ & & & & \\
\hline
\end{tabular}




\begin{tabular}{|c|c|c|c|c|c|c|c|c|c|c|c|c|c|}
\hline & Grassland & $* * *$ & $* * *$ & $* * *$ & $* * *$ & $* * *$ & $* * *$ & $* * *$ & $* * *$ & $* * *$ & $* * *$ & $* * *$ & $* * *$ \\
\hline & Riparian & $* * *$ & $* *$ & & & $* * *$ & $* * *$ & & $* * *$ & $* *$ & $* * *$ & $* * *$ & $*$ \\
\hline & Shrub & *** $*$ & $* * *$ & *** $*$ & $* * *$ & $* * *$ & $* * *$ & $* * *$ & $* * *$ & $* * *$ & $* * *$ & & $* *$ \\
\hline & Other & $* * *$ & $* * *$ & *** $*$ & $* * *$ & $* * *$ & $* * *$ & $* * *$ & *** $*$ & **** & $* * *$ & $* * *$ & *** $*$ \\
\hline & S-class2 & $* * *$ & $* * *$ & $* * *$ & **** & $* * *$ & & & . & & $*$ & & \\
\hline & Oak Forest×2 & & . & $*$ & & $* * *$ & $* * *$ & & *** & $* * *$ & & & \\
\hline & Oak Shrub×2 & & $* * *$ & $* * *$ & & $* * *$ & & $* * *$ & $*$ & & $*$ & & $*$ \\
\hline & Grassland $\times 2$ & $* * *$ & $* * *$ & $* *$ & $* * *$ & $* * *$ & $*$ & $* *$ & & . & & & $*$ \\
\hline & Riparian×2 & & & & & $* * *$ & $* * *$ & & $*$ & . & & $* *$ & \\
\hline & Shrub $\times 2$ & $* * *$ & $* *$ & . & & $* *$ & $* * *$ & & & $* * *$ & $*$ & & \\
\hline & Other $\times 2$ & & & & & & & & & & & & \\
\hline \multirow{5}{*}{ Cover } & Elevation & $* * *$ & $* * *$ & $* * *$ & $* * *$ & $* * *$ & $* * *$ & $* * *$ & $* * *$ & $* * *$ & $* * *$ & $* * *$ & $* * *$ \\
\hline & Cos Aspect (N) & $* * *$ & $* * *$ & $* * *$ & $* * *$ & $* * *$ & & & & $* *$ & $* * *$ & & $* * *$ \\
\hline & Sin Aspect (E) & $* * *$ & $* * *$ & $* * *$ & $* * *$ & $* * *$ & $* * *$ & *** & $* * *$ & $* * *$ & $* * *$ & \multirow[t]{2}{*}{$* * *$} & *** \\
\hline & Slope & $* * *$ & **** & & * & ** $*$ & **** & & *** $*$ & $* * *$ & $* * *$ & & $* * *$ \\
\hline & Canopy cover & $* * *$ & $* * *$ & $* * *$ & $* * *$ & $* * *$ & $* * *$ & & $* * *$ & & $* * *$ & $* * *$ & $* * *$ \\
\hline
\end{tabular}




\begin{tabular}{|c|c|c|c|c|c|c|c|c|c|c|c|c|}
\hline $\begin{array}{l}\text { Canopy at base } \\
\text { height }\end{array}$ & \multirow{2}{*}{$\begin{array}{l}* * * \\
* * *\end{array}$} & \multirow{2}{*}{$\begin{array}{l}* * * \\
* * *\end{array}$} & \multirow{2}{*}{$* * *$} & \multirow[b]{2}{*}{$* * *$} & \multirow{2}{*}{$\begin{array}{l}* * * \\
* * * \\
* *\end{array}$} & \multirow{2}{*}{$\begin{array}{l}* * * \\
* * *\end{array}$} & \multirow{2}{*}{$\begin{array}{l}* * * \\
* * * \\
* * *\end{array}$} & \multirow{2}{*}{$\begin{array}{l}* * * \\
* * * \\
* *\end{array}$} & \multirow[b]{2}{*}{$* * *$} & \multirow{2}{*}{$\begin{array}{c}* \\
* * * \\
* *\end{array}$} & \multirow[t]{2}{*}{$* * *$} & \multirow[b]{2}{*}{$* * *$} \\
\hline Edge density & & & & & & & & & & & & \\
\hline Oak Forest & $* * *$ & $* * *$ & & $* * *$ & $* * *$ & $* * *$ & $* * *$ & $* *$ & $* *$ & & $*$ & $*$ \\
\hline Oak Shrub & \multirow[b]{2}{*}{$* * *$} & \multirow[t]{2}{*}{$* *$} & & \multirow[t]{2}{*}{$* * *$} & \multirow{2}{*}{$\begin{array}{c}* \\
* * * \\
*\end{array}$} & $* * *$ & $* * *$ & \multirow{2}{*}{$\begin{array}{l}* * * \\
* * * \\
*\end{array}$} & & $* *$ & \multirow{2}{*}{$\begin{array}{l}* * * \\
* * *\end{array}$} & \\
\hline Grassland & & & $* *$ & & & $* * *$ & $* * *$ & & $* * *$ & $* * *$ & & $* * *$ \\
\hline Riparian & $* * *$ & $* *$ & & $*$ & $* * *$ & $* * *$ & . & $* * *$ & $*$ & $* * *$ & $* * *$ & $*$ \\
\hline Shrub & $* * *$ & $* * *$ & & $* *$ & $* * *$ & & $* * *$ & $* * *$ & $* * *$ & $* * *$ & $* * *$ & \\
\hline Other & \multirow{2}{*}{$\begin{array}{l}* * \\
* * *\end{array}$} & \multirow{2}{*}{$\begin{array}{l}* * * \\
* * *\end{array}$} & $* * *$ & \multirow{2}{*}{$\begin{array}{c}* * * \\
*\end{array}$} & \multirow{2}{*}{$\begin{array}{l}* * * \\
* * *\end{array}$} & $* * *$ & $* * *$ & \multirow{2}{*}{$\begin{array}{l}* * * \\
* * *\end{array}$} & $* * *$ & $* * *$ & \multirow{2}{*}{$\begin{array}{l}* * * \\
* *\end{array}$} & $* * *$ \\
\hline S-class5 & & & $* * *$ & & & $* * *$ & $* * *$ & & $* * *$ & $* * *$ & & \\
\hline Oak Forest $\times 5$ & & $* *$ & & & $* * *$ & & $* *$ & $* * *$ & $* * *$ & $* * *$ & $* *$ & \\
\hline Oak Shrub×5 & & & & & & & & & & & & \\
\hline Grassland $\times 5$ & & & & & & & & & & & & \\
\hline Riparian $\times 5$ & & & & & & & & & & & & \\
\hline Shrub $\times 5$ & & & & & & & & & & & & \\
\hline Other $\times 5$ & & & & & & & & & & & & \\
\hline
\end{tabular}


Table 3.5: Habitat selection model results for migratory and non-migratory female black-tailed deer in the Mendocino National forest, California, 2004-2013. Results are shown for 2 spatial scales (landscape scale and home range scale) and 2 activity states (active and inactive). Selection for migratory deer further delineated for 2 distinct seasons (summer and winter) based on observed elevational migrations.

\begin{tabular}{|c|c|c|c|c|c|c|c|}
\hline Type & Scale/State & Model & $K^{\mathrm{a}}$ & $\mathrm{AIC}^{\mathrm{b}}$ & $\Delta \mathrm{AIC}$ & $w_{i}^{\mathrm{c}}$ & $r_{\mathrm{s}}^{\mathrm{d}}$ \\
\hline \multirow{12}{*}{$\begin{array}{l}\text { Migratory: } \\
\text { Summer }\end{array}$} & \multirow{3}{*}{ Landscape } & Cover & 17 & 90174.97 & 0 & 1 & 0.85 \\
\hline & & Food2 & 20 & 90632.00 & 457.03 & 0 & 0.88 \\
\hline & & Food1 & 20 & 90666.97 & 492 & 0 & 0.87 \\
\hline & \multirow{3}{*}{$\begin{array}{l}\text { Home } \\
\text { Range }\end{array}$} & Cover & 17 & 89097.71 & 0 & 1 & 0.81 \\
\hline & & Food1 & 20 & 89244.75 & 147.04 & 0 & 0.83 \\
\hline & & Food2 & 20 & 89441.00 & 343.29 & 0 & 0.84 \\
\hline & \multirow{3}{*}{ Active } & Food2 & 20 & 8629.13 & 0 & 0.98 & 0.74 \\
\hline & & Food1 & 20 & 8637.01 & 7.884 & 0.02 & 0.73 \\
\hline & & Cover & 17 & 8684.73 & 55.602 & 0 & 0.71 \\
\hline & \multirow{3}{*}{ Inactive } & Cover & 17 & 31779.40 & 0 & 1 & 0.76 \\
\hline & & Food1 & 20 & 31809.66 & 30.26 & 0 & 0.73 \\
\hline & & Food2 & 20 & 31889.94 & 110.54 & 0 & 0.75 \\
\hline \multirow{6}{*}{$\begin{array}{l}\text { Migratory: } \\
\text { Winter }\end{array}$} & \multirow{3}{*}{ Landscape } & Cover & 17 & 99490.38 & 0 & 1 & 0.84 \\
\hline & & Food1 & 20 & 100131.64 & 641.26 & 0 & 0.86 \\
\hline & & Food2 & 20 & 100361.58 & 871.2 & 0 & 0.83 \\
\hline & \multirow{3}{*}{$\begin{array}{l}\text { Home } \\
\text { Range }\end{array}$} & Food1 & 20 & 94970.36 & 0 & 1 & 0.92 \\
\hline & & Food2 & 20 & 95069.14 & 98.78 & 0 & 0.9 \\
\hline & & Cover & 17 & 95481.09 & 510.73 & 0 & 0.87 \\
\hline
\end{tabular}




\begin{tabular}{|c|c|c|c|c|c|c|c|}
\hline & \multirow{3}{*}{ Active } & Food1 & 20 & 9718.86 & 0 & 1 & 0.78 \\
\hline & & Food 2 & 20 & 9812.30 & 93.44 & 0 & 0.75 \\
\hline & & Cover & 17 & 10105.04 & 386.18 & 0 & 0.76 \\
\hline & \multirow{3}{*}{ Inactive } & Cover & 17 & 36133.37 & 0 & 1 & 0.77 \\
\hline & & Food1 & 20 & 37040.42 & 907.05 & 0 & 0.78 \\
\hline & & Food2 & 20 & 37153.33 & 1019.96 & 0 & 0.76 \\
\hline \multirow{12}{*}{$\begin{array}{l}\text { Non- } \\
\text { migratory }\end{array}$} & \multirow{3}{*}{ Landscape } & Food1 & 20 & 30971.16 & 0 & 1 & 0.81 \\
\hline & & Food2 & 20 & 31110.25 & 139.09 & 0 & 0.83 \\
\hline & & Cover & 17 & 31488.34 & 517.18 & 0 & 0.79 \\
\hline & & Food1 & 20 & 35812.45 & 0 & 1 & 0.78 \\
\hline & $\begin{array}{l}\text { Home } \\
\text { Range }\end{array}$ & Food2 & 20 & 35875.20 & 61.19 & 0 & 0.78 \\
\hline & & Cover & 17 & 35936.39 & 123.94 & 0 & 0.76 \\
\hline & & Cover & 17 & 3246.24 & 0 & 1 & - \\
\hline & Active & Food 2 & 20 & 3462.44 & 216.203 & 0 & - \\
\hline & & Food1 & 20 & 3469.22 & 222.981 & 0 & - \\
\hline & & Food1 & 20 & 10457.50 & 0 & 1 & - \\
\hline & Inactive & Food2 & 20 & 10477.02 & 19.52 & 0 & - \\
\hline & & Cover & 17 & 10548.13 & 90.63 & 0 & - \\
\hline
\end{tabular}


Table 3.6: Coefficient estimates ( $\beta$ ) from the top pooled (landscape and home range scale) and state-specific (active and inactive) resource selection function models for migratory and non-migratory female black-tailed deer in the Mendocino National Forest, California, between 2004 and 2013. Selection for migratory deer further delineated for 2 distinct seasons (summer and winter) based on observed elevational migrations.

\begin{tabular}{|c|c|c|c|c|c|c|c|c|c|c|c|c|}
\hline \multirow[b]{2}{*}{ Covariates } & \multicolumn{4}{|c|}{ Migratory Summer } & \multicolumn{4}{|c|}{ Migratory Winter } & \multicolumn{4}{|c|}{ Non-migratory } \\
\hline & $\begin{array}{c}\text { Landscape } \\
\text { Scale }\end{array}$ & $\begin{array}{l}\text { Home- } \\
\text { range } \\
\text { Scale }\end{array}$ & Active & Inactive & $\begin{array}{c}\text { Landscape } \\
\text { Scale }\end{array}$ & $\begin{array}{c}\text { Home- } \\
\text { range } \\
\text { Scale }\end{array}$ & Active & Inactive & $\begin{array}{c}\text { Landscape } \\
\text { Scale }\end{array}$ & $\begin{array}{l}\text { Home- } \\
\text { range } \\
\text { Scale }\end{array}$ & Active & Inactive \\
\hline Elevation & 2.092 & 3.431 & 3.333 & 3.107 & -1.024 & -1.748 & -1.459 & -1.583 & 1.069 & 0.910 & 1.933 & 1.001 \\
\hline Cos Aspect (N) & -0.147 & -0.316 & -0.590 & -0.419 & 0.172 & 0.008 & -0.018 & 0.000 & -0.007 & -0.181 & 0.059 & -0.283 \\
\hline Sin Aspect (E) & 0.060 & 0.205 & 0.185 & 0.161 & -0.473 & -0.156 & -0.416 & -0.324 & -0.225 & 0.119 & -0.443 & -0.085 \\
\hline Slope & -0.534 & 0.070 & -0.106 & 0.033 & 0.023 & 0.183 & 0.315 & 0.237 & -0.042 & 0.723 & 0.030 & 0.184 \\
\hline Ruggedness & & & -0.304 & & & -0.328 & -0.614 & & -0.409 & -0.216 & & -0.270 \\
\hline Canopy Cover & -0.545 & -0.480 & & -0.350 & -0.492 & & & 0.746 & & & 1.126 & \\
\hline Canopy at Base Height & -0.110 & 0.093 & & -0.030 & -0.099 & & & -0.136 & & & -0.519 & \\
\hline Edge Density & 0.226 & 1.015 & 0.308 & 0.463 & -0.160 & -0.489 & 0.423 & -0.206 & 0.976 & 0.325 & 0.108 & -2.497 \\
\hline Oak Forest & 0.542 & 0.372 & 0.518 & 0.509 & 0.369 & 0.346 & 0.483 & 0.154 & -0.178 & 0.078 & 0.801 & 0.548 \\
\hline
\end{tabular}




\begin{tabular}{|c|c|c|c|c|c|c|c|c|c|c|c|c|}
\hline Oak Shrub & -0.196 & 0.382 & 0.858 & 1.044 & 0.140 & 0.879 & 1.601 & 2.484 & 0.685 & 0.624 & 3.099 & 0.297 \\
\hline Grassland & -0.369 & -0.024 & 0.917 & 0.051 & 0.281 & 1.723 & 2.551 & 2.034 & 1.577 & 1.223 & 2.323 & 0.212 \\
\hline Riparian & -0.949 & -0.438 & 0.203 & -0.749 & -1.273 & -0.777 & 0.061 & -1.663 & 1.232 & 1.257 & 3.947 & 1.070 \\
\hline Shrub & -0.535 & -0.337 & 0.469 & -0.169 & -0.230 & 0.441 & 1.164 & 1.655 & -0.026 & 0.158 & 1.621 & 0.155 \\
\hline Other & 0.110 & 0.501 & 1.254 & 0.575 & 0.376 & 1.430 & 1.964 & 2.433 & 1.192 & 1.356 & 2.307 & 1.125 \\
\hline S-class & -0.227 & 0.339 & 0.746 & 0.151 & -0.796 & 0.312 & 0.763 & 0.440 & 0.598 & 0.512 & -3.412 & 0.686 \\
\hline Oak Forest $\times$ S-class & 0.143 & -0.351 & -1.051 & -0.016 & 2.049 & -0.282 & -0.298 & 0.900 & 0.459 & -0.354 & 3.914 & -0.588 \\
\hline Oak Shrub $\times$ S-class & & & 5.288 & & & -0.328 & 1.192 & & -3.363 & -2.483 & & -12.147 \\
\hline Grassland $\times$ S-class & & & -2.111 & & & -0.891 & -2.512 & & -1.194 & -0.673 & & 0.031 \\
\hline Riparian $\times$ S-class & & & -0.402 & & & & & & & & & \\
\hline Shrub $\times$ S-class & & & -0.667 & & & -0.568 & -0.925 & & 0.221 & -0.075 & & -0.499 \\
\hline Other $\times$ S-class & & & & & & -1.871 & -1.766 & & -1.212 & -0.787 & & -0.971 \\
\hline
\end{tabular}



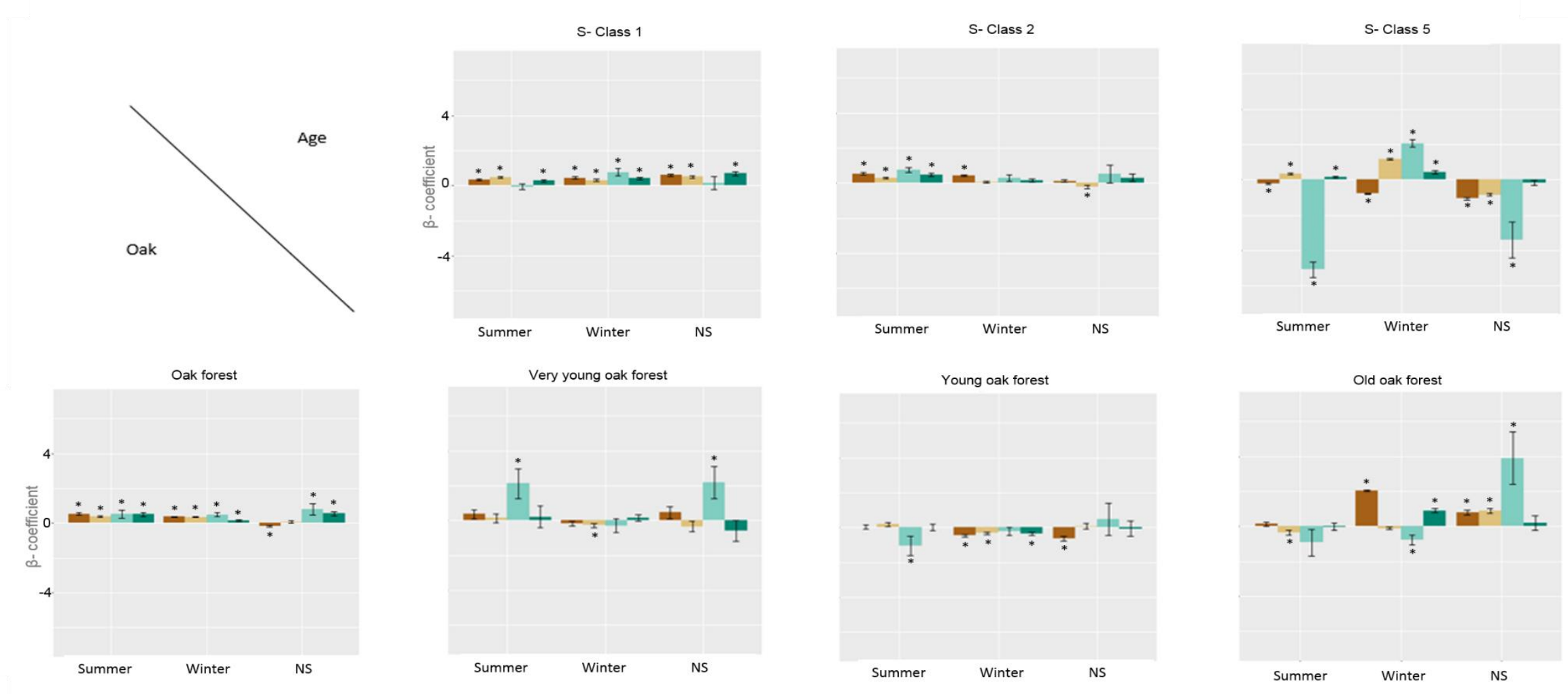

Scale Landscape $\square$ Home range

State Active

Figure 3.2: Selection indices for forest age (succession classes: S-class1 = very young, S-class2 = young and S-class5 = old) as well as oak forests and their interactions, based on standardized parameter estimates obtained from hierarchical resource selection function models for female blacktailed deer in Mendocino National Forest, California, between 2004 and 2013. Selection indices were estimated by season (summer and winter) for migratory deer, and pooled locations across year for non-migratory deer (no seasonality or NS) and show how selection differed among the models pooled across activity states (landscape and home range scale) and activity specific models (active and inactive state). Error bars represent 95\% confidence intervals and asterisks show significant parameter estimates. 


\subsubsection{Home-range Scale Selection}

At the home-range scale, BTD exhibited pronounced changes between seasons in overall habitat selection for a number of variables (Table 3.4). In summer, migratory BTD selected for old forest stands $(\beta=0.339$; CI: $0.254-0.424)$, oak forests $(\beta=0.372$; CI: 0.275-0.470) (Figure 3.2) and oak shrubs $(\beta=0.382$; CI: 0.110-0.653). They also selected for significantly higher edge density ( $\beta=1.015$; CI: $0.982-1.048)$ and southeast and east-facing slopes ( $\cos \beta=-0.316$; CI: $-0.344-(-) 0.288 ; \sin \beta=0.205$; CI: 0.187-0.223). In winter, migratory BTD mostly selected for western aspects $(\beta=-$ 0.156; CI: -0.175- (-)0.138) with regenerative age classes $(\beta=0.312$; CI: 0.204-0.421) (Figure 3.2) and open vegetation including oak shrub ( $\beta=0.879$; CI: 0.760-0.999) and grassland $(\beta=1.723 \mathrm{CI}: 1.596-1.851)$. Habitat selection by non-migratory deer approximated selection patterns of migratory deer exhibited during winter but with a greater affinity for higher elevation $(\beta=0.910$; CI: 0.861-0.958) and south and east facing slopes $(\cos \beta=-0.181$; CI: $-0.228-(-) 0.134 ; \sin \beta=0.119$; CI: 0.075-0.163). The selection for flatter and less complex terrain were consistent across seasons for both migratory and non-migratory BTD (Tables 3.4 and 3.6).

\subsubsection{Habitat Selection and Activity States}

At the home range scale, habitat selection by female BTD varied with activity state (active vs. inactive; Tables 3.4, 3.5 and 3.6). The selection patterns for habitat covariates including slope, edge density and vegetation types differed markedly between the state-specific and pooled models (Figure 3.3). 

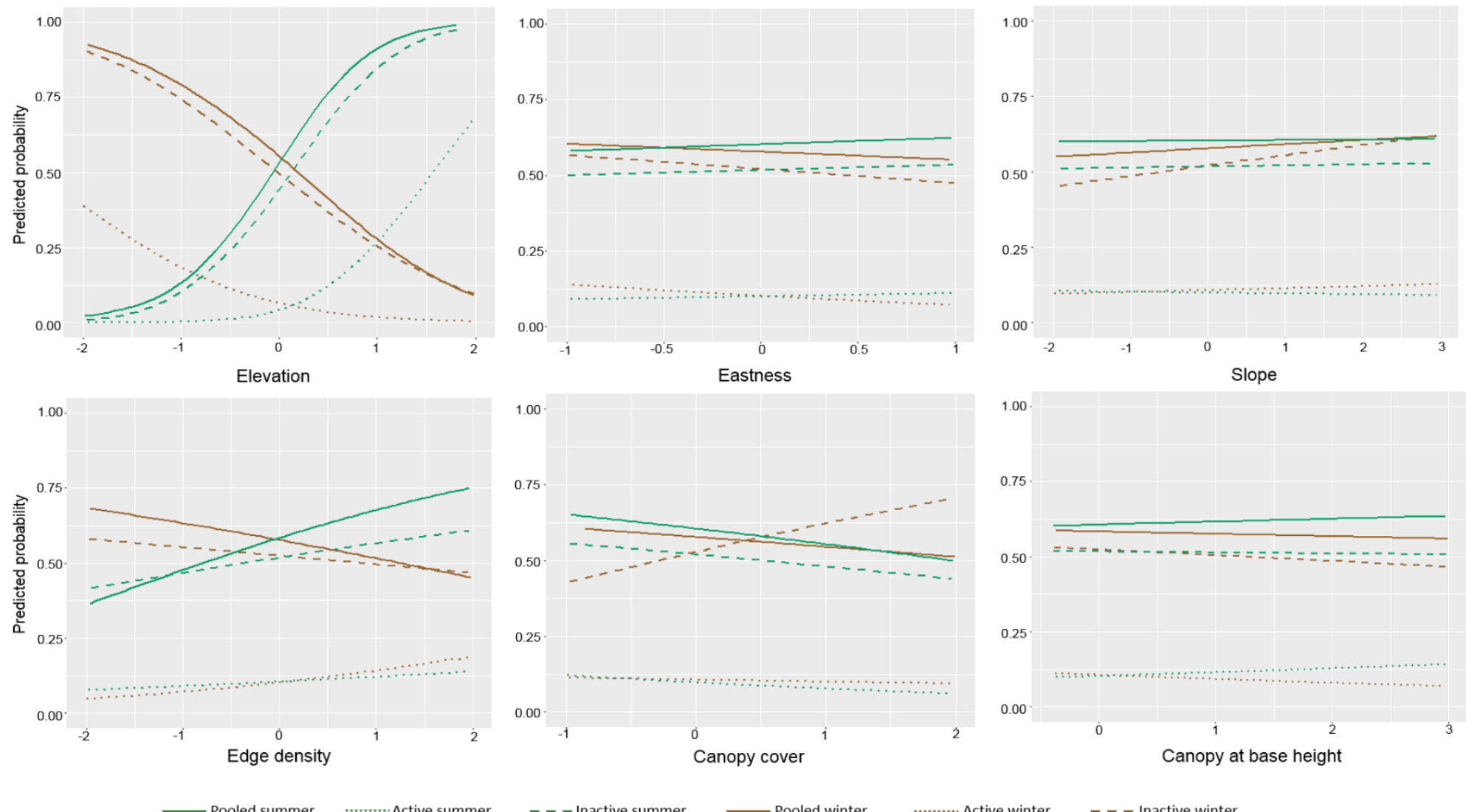

Figure 3.3: Predicted probability of selection for elevation, aspect (eastness), slope, edge density, canopy cover and canopy at base height as a function of seasons (summer and winter) and activity states (locations pooled across activity states, active, and inactive). Results based on hierarchical resource selection function models at the home range scale using location data from female black-tailed deer in the Mendocino National Forest, California, collared between 2004 and 2013. Note that for canopy at base height negative slope of selection indicates selection for hiding cover or canopy cover closer to the ground. 
In summer, the patterns of selection for land-use and land cover types across activity states mostly differed in strength (i.e. slope of the curve) and significance but did not affect selection patterns (Figure 3.3; Tables 3.4 and 3.6). However, there was a difference in selection of the age class of habitats between activity states. When active, migratory BTD commonly selected oak forests $(\beta=0.518$; CI: 0.075-0.961) and oak shrubs in young age classes $(\beta=5.288$; CI: 2.876-7.700) (Figure 3.2) and preferred gentle slopes $(\beta=-0.106$; CI: $-0.177-(-) 0.035)$ with south to south-east facing aspects $(\cos \beta=-0.590 ; \mathrm{CI}:-0.653-(-) 0.527 ; \sin \beta=0.185 ; \mathrm{CI}: 0.123-0.247)$ and flat terrain $(\beta=-0.304$; CI: $-0.372-(-) 0.237)$. In contrast, migratory BTD showed clear preference for old forest stands $(\beta=0.151$; CI: 0.022-0.281) (Figure 3.2) and steeper slopes $(\beta=0.033$; CI: $-0.001-0.068)$ when inactive. BTD selected for opencanopy forests in summer, independent of their activity state (Tables 3.4 and 3.6). BTD were also close to edges during both active and inactive states (Tables 3.4 and 3.6).

In winter, patterns of selection changed markedly with activity states. When active, migratory BTD selected for regenerative forest stands $(\beta=0.763$; CI: 0.3391.186) (Figure 3.2) with preference for younger oak shrubs $(\beta=1.192$; CI: 0.568 1.817) and open vegetation including grasslands $(\beta=2.551$; CI: $2.147-2.955)$ and shrubs $(\beta=1.164$; CI: $0.934-1.393)$. When resting, BTD selected for vegetation and cover types providing thermal cover, and showed significant preference for old forests stands $(\beta=0.440$; CI: $0.254-0.627)$ especially old oak forests $(\beta=0.900$; CI: 0.661 1.139) (Figure 3.2) and dense canopy cover ( $\beta=0.746$; CI: 0.708-0.784). In addition to choosing dense canopy forest, individuals also selected for areas with vertical cover $(\beta=-0.136$; CI: -0.173- (-)0.099). Female BTD switched from selecting habitats close to edges $(\beta=0.423$; CI: $0.271-0.576)$ when active to more sheltered habitats $(\beta=-$ 
0.206; CI: -0.263- (-)0.148) when inactive. Parameter estimates for slope across both states showed a consistent preference for steeper slopes in winter (Figure 3.3; Table 3.4 and 3.6).

Non-migratory BTD selected for habitat with dense canopy $(\beta=1.126$; CI: 0.971-1.281), good vertical cover $(\beta=-0.519 ; \mathrm{CI}:-0.808-(-) 0.229)$ and old oak forests $(\beta=3.914$; CI: 0.978-6.850) (Figure 3.2) when active. When inactive, non-migratory BTD showed contrasting selection patterns towards physical features like aspect (Tables 3.4 and 3.6) and preferred locations away from edges $(\beta=-2.497$; CI: -2.628 (-)2.367) inside regenerating forests ( $\beta=0.686$; CI: 0.424-0.947) (Figure 3.2).

The top-ranked resource selection models provided good to medium fit to the data using k-fold cross-validation tested with the Spearman rank correlation coefficient $\left(r_{s} \geq 0.71, P<0.05\right)$ for all models (Tables 3.4). However, I could not test the fit of activity specific models for the non-migratory deer due to low sample size ( $n$ $=5)$.

\subsection{Discussion}

My results support the hypotheses that: 1) patterns of habitat selection by BTD in the study area are scale dependent (Senft et al. 1987, Gaillard et al. 2010) and that 2) finescale habitat selection is affected by the variation in selection between activity states (Roever et al. 2014). Selection of habitats was dependent upon availability on the landscape and spatial heterogeneity. At the landscape scale, habitat selection by female BTD varied between summer and winter, and was mostly explained by differences in elevation, terrain, and vegetation. However, within their seasonal home ranges, BTD selected habitats that varied according to their specific activity states. For instance, during summer deer preferred oak communities and gentle slopes when active and 
mature conifer forests and steeper slopes when inactive. During winter, deer primarily used oak and other shrub communities when active, and old forests when inactive. During both seasons, deer thus selected for apparently secure habitat when inactive, likely to minimise risk of predation.

Comparing models that included information about the activity state of individuals to pooled models influenced conclusions regarding the selection of ecological covariates including edge density, slope, canopy cover and forest age during both summer and winter. These habitat characteristics are central to our understanding of ungulate ecology, and accurate understanding of selection of these habitat types provided insight into key habitat characteristics that are used for short but critical foraging periods. These results are also likely indicative of fine-scale trade-offs between meeting energetic requirements while spending as little time as possible foraging in habitats with high vulnerability to predation (Pierce et al. 2004). The results thus offer important understanding for testing ecological theory and the effective management of ungulates in multi-use landscapes.

Topographic variables including elevation, slope, and aspect are primary determinants of broad-scale distribution patterns for BTD (Bunnell 1990, Bailey et al. 1996). They play a significant role in habitat selection in BTD, as individuals attempt to balance the energetic costs of foraging and thermal regulation in often rugged elevated terrain (Bunnell 1990). Consistent with previous habitat selection studies (Bunnell 1990, Gillingham 2004), I found BTD to select for relatively high elevation, south and southeast facing aspects at the landscape scale in summer, likely as a consequence of early green-up of forage in these habitats (Xie et al. 2015). In winter, BTD descended to lower elevations and selected the warmer, western aspects. Due to 
the low interspersion of these variables in space, and very small home ranges of the study individuals (Forrester et al. 2015), the pattern of selection remained consistent across all hierarchical scales. Selection patterns for slope by BTD, however, showed opposing patterns across activity states that affected the outcome of the pooled models at the home range scale. The pooled summer model detected positive selection of individuals towards steeper slopes which contradicts predictions based on optimal foraging theory (Krebs 1980, Bergman et al. 2001). Substantially higher energetic costs of locomotion would be incurred when traversing steep slopes and consistent use of steeper terrain within their home ranges could significantly increase the energy expended on movement during each foraging bout (Parker et al. 1984). When I considered selection based on active and inactive states, I found that individuals only selected for steeper slopes during inactive states while resting, likely as an effective anti-predator strategy (Riley and Dood 1984, Apps et al. 2013). During active states individuals selected for gentler slopes, consistent with optimal foraging theory. These results illustrate how considering activity state can correctly identify the use of important habitat types while pooled models may lead to erroneous inferences.

Canopy cover is an important determinant for habitat selection in many ungulates and influences vital factors like thermoregulation, concealment and forage (Bunnell 1990, Mysterud and Ostbye 1999). A forest stand with dense canopy can reduce energetic costs of thermoregulation by providing shade, but often has reduced quantity of available browse (Lorimer et al.1994, Frost et al. 1997). Canopy closer to ground, can provide better quality browse and concealment (Bunnell 1990, Camp et al. 2013), but can also conceal predators (Camp et al. 2013). Thus, the selection towards cover exemplifies energetics vs. fitness trade-offs (Mysterud and Ostbye 1999). As expected due to temporal shift in trade-offs, I found selection towards 
vertical and canopy cover to vary across seasons and activity states. In summer, female BTD chose areas with better visibility within their home ranges and avoided areas with dense canopy cover across activity states (Figure 3.3). In winter, BTD consistently selected for canopies closer to ground, but only selected for dense canopy cover when inactive. I hypothesize that due to higher predation risks during summer (Allen et al. 2014) BTD preferred higher, open areas without dense, concealing vegetation as it provided visual advantage over predators (Smith at al. 1986) while foraging and resting. Conversely, during winter months, when pumas in the study area suffered less kleptoparasitism from black bears (Elbroch et al. 2014), kill rates of BTD were lower (Allen et al. 2014), and need for quality forage and thermal cover outweighed predation risk. Hence, deer in my study area chose canopies closer to ground which provide them with sufficient forage and security cover when active and dense canopy cover provide thermal cover when resting (Bunnell 1990, Mysterud and Ostbye 1999).

BTD are known to select edge habitats (Chang et al.1995, Doerr et al. 2005) as individuals can utilize relatively high quality forage in these habitats, while being close to protective cover (Leopold 1933). However, in the pooled winter model for resource selection at home range scale I observed clear avoidance towards edge density unlike some previous studies (Hanley 1983, Kremsater and Bunnell 1992, Kie et al. 2002). The result was particularly notable as selection towards dense canopy cover away from the edges implies selection of areas with poor understory growth and low browse availability (Lorimer et al.1994). I expected activity state to influence these results and indeed found that during active states, BTD showed strong positive selection towards high edge density, whereas significant avoidance was observed during inactive states. In winter, BTD spend more time ruminating as available forage has higher lignin content and takes longer to digest (Bunnell 1990). During the longer resting period, 
the energy saved by thermoregulation in a covered habitat offsets the energy needed to travel to cover. I thus observed a clear switch from habitat near edges while foraging to habitat away from edges during resting periods in winter. Given that deer spend less time actively foraging during winter (Bunnell 1990), the selection pattern of proportionately larger number of inactive used locations was thus reflected in the pooled model, leading to an erroneous conclusion for an important ecological covariate.

Previous studies on ungulates have shown the importance of both quality and quantity of forage on reproduction (Taillon et al. 2006), growth (Fryxell 1991) and survival (Forrester et al. 2015). BTD at higher latitudes generally prefer herbaceous vegetation and other high energy forage when available, due to their higher energy content (Bunnell and Gillingham 1985, Cook et al. 2016). As nutrient content and digestibility of the plant parts vary with season (Maufette and Oechel 1989; Salminen et al. 2004) and age (van Soest 1994), I tried to determine if the activity state of BTD affected selection of the age classes of particular vegetation types. In summer, I found deer selected nutrient rich, young oak shrubs and oak forest during active states, consistent with previous studies (Dasmann and Taber 1956, Forrester et al. 2015). However, BTD selected for old coniferous forest when inactive as it provided optimal shade from higher ambient temperatures (Renaud et al. 2011, Bobek et al. 2016). In winter, I suspect female BTD preferred regenerating oak shrub and coniferous forest to get maximum nutrition from their forage, and chose mature oak forest with understory growth during inactive state for better thermal and security cover (Bowyer and Kie 2009). As expected, the pooled models failed to identify the variation in selection towards age specific vegetation types with changing activity states (Figure 3.2). The misidentification and non-detection of BTD selection of specific vegetation 
types and age classes are of particular concern in managed landscapes such as National Forests, where large-scale habitat conversion (e.g., logging and grazing) may result in homogenous habitats. Homogeneous habitat will likely not meet all requirements for individual BTD, thus prompting individuals to venture out of their familiar homeranges and increase the risk of mortality (Forrester et al. 2015).

The results from this chapter support the findings from a small, but rapidly growing body of literature (Ager et al. 2003, Godvik et al. 2009, Roever et al. 2014) that highlight the importance of considering activity states and behaviour when determining habitat selection. This study clearly demonstrates the shortcomings of making assumptions on habitat use from resource selection models based on pooled data across activity states. As observed by Roever et al. (2014), I found the assessment of the importance of habitat covariates based on strength of selection from the pooled model to be inaccurate and sometimes misleading. I also observed opposing selection patterns between activity states for parameters that are highly interspersed in space. This frequently led to misidentification of selection patterns for important ecological covariates in the pooled model. I suggest that this may have arisen from the highfrequency feeding-resting-feeding cycles of ruminants, such as BTD, leading to pronounced differences in selection patterns across different activity states in a very short period of time. Ungulates have evolved strategies to minimize foraging time (rumination, selecting high quality forage), and to accurately test prediction of foraging and energetic theory it is important to use selection models that measure selection for all activity states. Further use of these models have the potential to generate insight into the consumptive and non-consumptive effects of both predation risk and competition as we can measure selection differences related to activity state. 
Chapter 4

Negotiating Landscape of Fear: Trade-offs Between Forage and Predation Risk as a Function of Landscape Familiarity 
This paper will be submitted for publication as:

Bose S., Casady D. S., \& Wittmer H. U. Negotiating landscape of fear: trade-offs between forage and predation risk as a function of landscape familiarity in Movement Ecology

\section{Acknowledgements}

The project was funded by the California Department of Fish and Wildlife (\#P0880013) and the California Deer Association (\#08-001495,\#001-10,\#011-11). I sincerely thank D. Casady, all students, volunteers, and agency personnel who helped with deer captures and collecting data in the field. I also thank Dr. Stephen Hartley and Dr. Lisa woods for their help with statistical analysis of the movement data. Dr. Bibek Yumnam provided helpful comments in an earlier version of the manuscript. 


\section{Abstract}

Availability of forage and predator avoidance are traditionally considered as primary drivers of animal movements. Efficient movement choices that reflect trade-offs between forage and risk have thus been long acknowledged as the adaptive mechanism to optimise energy intake that ultimately increase individual fitness. Recent advances in animal ecology have identified more fundamental mechanisms like memory and familiarity as integral parameters in driving animal movements, although very few studies have examined the variation in risk-forage trade-offs with varying spatial familiarity. In this study, I used a movement model to examine how spatial familiarity affects risk-forage trade-off in a medium-sized ungulate while navigating a heterogeneous landscape. Specifically, I used step selection functions to assess how productivity (normalized difference vegetation Index; NDVI), predation risk, and vegetation type feature in movement step selection with respect to familiarity and time of the day from 64 GPS-collared female black-tailed deer (BTD, Odocoileus hemionus columbianus) in Mendocino National Forest, California. The analyses revealed that the movements of female BTD are directed towards areas with lower NDVI and lower probability of being killed by pumas (Puma concolor). However, on inclusion of familiarity in the model, BTD showed a positive selection towards NDVI and risk in highly familiar areas. The selection towards risk and NDVI also varied with vegetation type as BTD selected higher NDVI and risk in open vegetation type such as grassland. Time of day had a strong influence over selection of familiar areas. At night time and at dawn, BTD selected areas with higher familiarity and during the day BTD stepped out into areas with lower spatial familiarity. Combined, the analyses demonstrate that familiarity affects the trade-off pattern of an ungulate in a heterogeneous landscape and the complex nature of trade-offs is likely an adaptive response to avoid predation 
by an ambush nocturnal predator like puma, their only predator in the study area. Understanding the antipredator responses and effect of site familiarity on habitat selection of an ungulate in a heterogeneous landscape is critical to understand how prey species balance trade-off across multiple levels of selection to improve fitness. Such knowledge is crucial to the study of distribution and population dynamics of the species, and can help direct conservation and wildlife management efforts with greater efficiency. 


\subsection{Introduction}

Understanding the causes and consequences of movements are primary (Nathan et al. 2008) and long-standing (Elton 1950) paradigms in animal ecology. Animals move to access spatially (i.e., clumped) and temporally dispersed resources (Johnson et al. 2002a, Fryxell et al. 2004); to avoid predators (Fortin et al. 2005); to mitigate negative effects from intra- and interspecific competition (Greenwood 1980, Stewart et al. 2002, Debeffe et al. 2012); and to locate conspecifics for mating and other social interactions (Greenwood 1980, Guttal and Couzin 2010). The ability to move across space thus enhances individual fitness and survival, and poor movement choices increase the risk of mortality (Mennechez et al. 2004). Given the often significant energetic costs associated with movements (Parker et al. 1984, Johnson et al. 2002b), animals need to carefully balance the potential costs and benefits associated with movements (Fahrig 2007) to maximize overall fitness.

Access to forage and avoidance of predators are the two most important factors that drive movement choices in prey species (Schoener 1971, Mangel and Clark 1986, Fryxell 1995, Frair et al. 2005) and influence fitness in fundamentally different ways. While access to forage exerts a direct positive effect on the fitness of an individual (e.g., Newman et al. 1995), presence of predators imposes both direct and indirect fitness costs on the prey (Lima 2002, Sih 2005). Mortality resulting from successful predation is the lethal and direct cost on an individual's fitness. But the more complex and indirect cost of presence of a predator is the perceived sense of risk (i.e., landscape of fear; Laundré et al. 2001) that affects most aspect of prey ecology (Thomson et al. 2006, Laundré et al. 2010). Behaviourally complex prey species inhabiting the 
landscape of fear adjust their space use according to the spatial and temporal variation in actual and perceived predation risk (Lima and Dill 1990, Cresswell 2008, Willems and Hill 2009). For example, previous studies have shown that prey species retreat to relatively safe habitats when predators are active (Bergerud et al. 1983, Formanowicz and Bobka 1989, Blumstein and Daniel 2002), and show increased movement and an increase in foraging time in more risky habitats when the predators are less active (Sih and McCarthy 2002, McCain 2008, Valeix et al. 2009).

Recent empirical and theoretical studies have recognized the importance of cognition and spatial memory to understand how animals navigate heterogeneous landscapes (Nathan et al. 2008, van Moorter et al. 2009b, Boyer and Walsh 2010, Fagan et al. 2013, Moorter et al. 2013, Merkle et al. 2014). Results from these studies suggest that when prey is familiar with site-specific resources and mortality risks (experience gained through site fidelity; Wolf et al. 2009), the optimal space use strategy to maximize individual fitness remains movement-directed towards richer food patches (Mitchell and Lima 2002). This implies that in a familiar area, prey species are more likely to revisit profitable foraging locations even in high-risk areas, as the spatial memory of resources and physical habitat features enable a higher chance to escape predators (Clarke et al. 1993). Thus, with access to better quality forage and greater chance of escaping predators, the fitness of prey species is likely to improve with increasing spatial familiarity (Fagan et al. 2013, Forrester et al. 2015).

Despite the recognition that spatial familiarity may influence overall fitness of prey species by altering patterns of space use by animals, very few studies have investigated the effect of familiarity on movement choices for large, free ranging herbivores (Wolf et al. 2009, van Beest et al. 2011). The paucity of studies is primarily 
due to the difficulties in acquiring long-term location data with sufficient accuracy and intensity to quantify familiarity of free ranging ungulates, which move across a mosaic of habitats. However, recent advancements in GPS technology enable collection of long-term location data with high accuracy at appropriate temporal and spatial scales (Hebblewhite and Haydon 2010). Efforts to use these data to understand the underlying mechanisms of movements and the role of spatial memory have also proven challenging due to numerous methodological difficulties. However, recent modelling techniques of time-series data have increasingly helped to unravel activity patterns (Boyce et al. 2010) and thus the complex behavioural motivation behind animal spaceuse (e.g., Gautestad et al. 2013).

Based on high-resolution location data from 64 GPS-collared female blacktailed deer (BTD; Odocoileus hemionus columbianus) in northern California, I examined how spatial familiarity and time of day may enable deer to navigate complex landscape of fear from puma (Puma concolor) predation. I expected (i) BTD to select areas with lower risk of puma predation and better forage availability, reflecting a trade-off between food acquisitions and minimizing predation risk with variation in spatial familiarity. Moreover, because of seasonal variation in physiological conditions of female BTD, plant phenology and predation risk, I predicted (ii) BTD to show difference in trade-off pattern between summer and winter. I also expected (iii) the use of familiar areas to vary with the time of the day, with BTD being more willing to venture into risky areas when pumas were less active. Lastly, as the resource selection patterns of the monitored migratory and non-migratory individuals were largely different at both landscape scale and home range scale (see Chapter 3), I expected (iv) migratory and non-migratory BTD to have different risk-forage trade-off strategies too. 


\subsection{Materials and Methods}

\subsubsection{Study area}

The Mendocino National Forest is located in north-western California and covers 3,696 $\mathrm{km}^{2}$ along the inner North Coast Ranges (Figure 4.1).

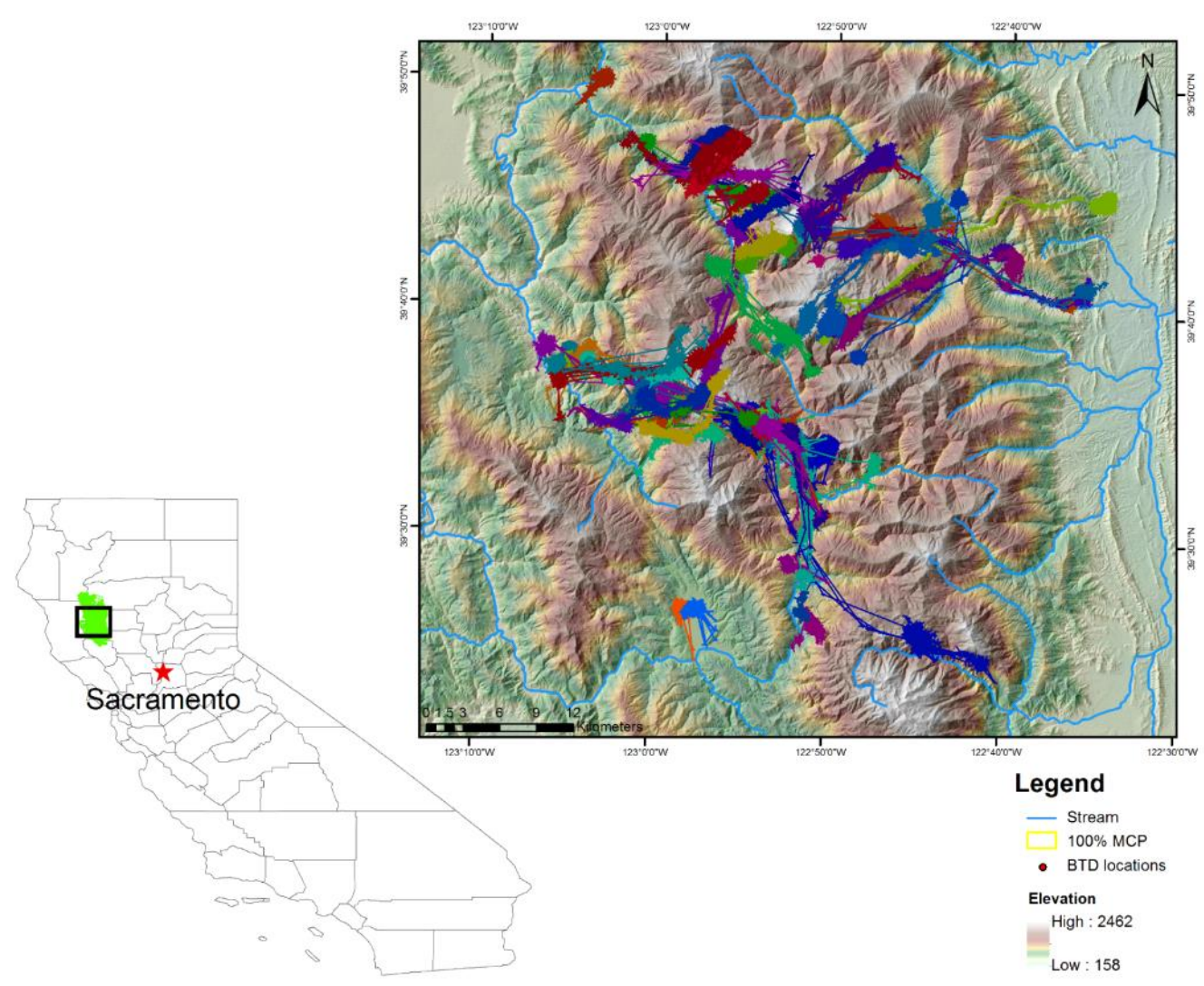

Figure 4.1: Location of the study area in the Mendocino National Forest, California, including 2 main ridges (M1 and FH7) and 3 main watersheds. The individual tracks show movement pathway of each of 64 GPS collared adult female black-tailed deer monitored between 2004 and 2013.

The study occurred completely within the National Forest boundaries and covered approximately $1,000 \mathrm{~km}^{2}$. The study area was bisected by two major ridges (M1 and FH7) and three main watersheds. Elevations in the study area range from 300 
$\mathrm{m}$ to $2,500 \mathrm{~m}$ asl. Terrain is highly variable from flat valley bottoms to steep and rugged slopes at higher elevations except on ridge tops.

In the study area, average daily temperatures range from approximately $5^{\circ} \mathrm{C}$ during winter to $17^{\circ} \mathrm{C}$ in summer (Mendocino Pass weather station; http://www.ncdc.noaa.gov/cdo-web, Accessed $9^{\text {th }}$ September, 2014). During the study, temperatures reached extremes of $-11.5^{\circ} \mathrm{C}$ and $45.5^{\circ} \mathrm{C}$. Annual precipitation over the study period averaged $148.8 \mathrm{~cm}$. Precipitation is typically highly seasonal, with about $85 \%$ of the precipitation occurring from October through April. Snow cover is generally limited to elevations $>1,000 \mathrm{~m}$ and is irregular, particularly during dry winters.

The study area is characterised by diverse vegetation types which vary with elevation and aspect. Oak woodlands (Quercus spp., Aesculus californicus, Arctostaphylos spp.), chaparral (Ceanothus spp., Adenostoma fasciculatum), and grasslands (Bromus spp., Avena spp.) dominate lower elevations and southerly slopes, while mixed-coniferous hardwood forests (Pinus ponderosa, P. iambertiana, Abies concolor, A. magnifica, Pseudotsuga menziesii, Arbutus menziesii, Quercus spp.) dominate higher elevations and northerly slopes. There is relatively little current anthropogenic disturbance in the area. Road access is limited to dirt roads, and recreational activities focus on several campgrounds, mostly at mid and high elevations. Domestic cattle (Bos taurus) grazing occurred every year at low intensity from May up to the second weekend of September when a buck only deer hunting season started. Past logging and more intensive cattle grazing have created a mosaic of even-aged conifers with occasional mature timber stands and openings dominated by non-native grasses, particularly at lower elevations. 
BTD were the only ungulate in the study area present year-around. Adult BTD were preyed upon almost entirely by pumas (Allen et al. 2014, Marescot et al. 2015). Pumas, American black bears (Ursus americanus), coyotes (Canis latrans) and bobcats (Lynx rufus) all preyed on BTD fawns (Marescot et al. 2015). Other ungulates in the study area included non-native wild pigs (Sus scrofa) at lower elevations and seasonally abundant domestic cattle. Tule elk (Cervus elaphus nannodes) were observed migrating through the study area, but had no established populations inside the study area.

\subsubsection{Capture and monitoring}

A total of 84 adult female BTD ( $\geq 1$ year old) were captured using free range darting primarily while driving along the M1 and FH7 ridges at high elevations. Detailed capture and handling procedures are described in Casady and Allen (2013) and were approved by both the Wildlife Investigations Laboratory of the California Department of Fish and Wildlife, and the Institutional Animal Care and Use Committee at the University of California, Davis (Protocols 15341 and 16886). Captures occurred between September 2004 and August 2013 with no deer captured or monitored between September 2008 and June 2009.

Anaesthetized deer were fitted with numbered ear tags and motion-sensitive, store-on-board GPS collars (Telonics, Mesa Arizona, USA and models 3300 and 4400M, Lotek Wireless, Inc., Newmarket, Ontario, Canada) that never exceeded 3\% of body weight. Collars were programmed to obtain a GPS location every 1 to 7 hours and retrieved location data either via UHF technology or once the collars had automatically dropped off (Table 4.1). 
Table 4.1: Number of individuals of black-tailed deer by season for different categories of fix intervals captured and monitored between 2004-2013 in the Mendocino National Forest, California

\begin{tabular}{|c|cccc|}
\hline \multirow{2}{*}{$\begin{array}{c}\text { Collar fix interval } \\
\text { (in hr) }\end{array}$} & Summer & Winter & $\begin{array}{c}\text { Non- } \\
\text { migratory }\end{array}$ & Total \\
\cline { 2 - 5 } & 15 & 15 & 0 & 15 \\
\hline 5 & 23 & 18 & 11 & 34 \\
7 & 13 & 14 & 1 & 15 \\
\hline Total & 51 & 47 & 12 & 64 \\
\hline
\end{tabular}

Collars were deployed for a maximum period of two years but one individual was subsequently re-collared. All collars were programmed to emit mortality signals of increased pulse rates after 4 hours of inactivity to facilitate recovery and identification of mortality causes (Marescot et al. 2015). Of the 84 female BTD captured, 3 died from capture related injuries and 4 had immediate collar failure. GPS location data from an additional 13 individuals could not be retrieved. The effective sample size thus consisted of 64 BTD.

\subsubsection{Space use and familiarity}

I used location data retrieved for individual deer to estimate their respective home ranges. Due to pronounced seasonal migrations of the majority of deer $(n=52)$, I estimated home ranges separately for summer and winter using the fixed-kernel home utilization distribution method (Worton 1989) in the R-package adehabitat (Calenge 2006). For non-migratory deer $(n=12)$, deer that did not migrate seasonally between distinct low elevation winter ranges and high elevation summer ranges, I estimated 
home ranges for summer and winter locations combined. I applied an ad hoc smoothing parameter $\left(\mathrm{h}_{a d h o c}\right)$ and determined home range boundaries based on $95 \%$ isopleths (Seaman and Powell 1996). I also determined 75\% isopleths within all home ranges using the same methods as described above. I then defined areas encompassed by the $75 \%$ isopleths as highly familiar, areas falling between the $75 \%$ and $95 \%$ isopleth as moderately familiar (Morse et al. 2009, Tumenta et al 2013), and based on Forrester et al. (2015), areas outside the 95\% isopleths as unfamiliar to deer.

\subsubsection{Puma predation risk}

Between June 2010 and November 2012, 7 pumas were also captured within the study area (2 males, 5 females) and fitted with Argos-linked GPS collars (Lotek 7000SAW). Puma capture and handling procedures are detailed in Allen et al. (2015) and were covered by animal care protocols and permits mentioned for deer above. Puma collars were programmed to acquire GPS locations at 2-hr intervals and downloaded data via the Argos satellite every 3 days. All 609 known GPS clusters, defined as $\geq 5$ locations (or a minimum of 8 hours between first and last location) within $150 \mathrm{~m}$ of each other that contained at least one crepuscular or nocturnal location (Elbroch and Wittmer 2013), were then searched within $6.8 \pm 8.2$ (SD; range 0-60) days of their initiation for possible prey remains (Allen et al. 2014). Based on the cluster investigations 288 BTD killed by pumas, 75 of which were fawns $\leq 6$ months old (Allen et al. 2014), were identified.

Habitat characteristics associated with known deer kill sites were then used to model the probability of puma kill success across the landscape (Appendix 2). This is one possible method to establish the spatial configuration of predation risk/landscapes of fear (Hebblewhite et al. 2005, Moll et al. 2017). I modelled predation risk using 
mixed-effect Resource Selection Functions (RSFs; Manly et al. 2002, Gillies et al. 2006) allowing for individual heterogeneity in puma kill site selection. I partitioned the puma kill data into winter (November-May) and summer (June-October), and modelled risk separately to account for known differences in seasonal kill rates and elevational migrations of pumas in response to deer migrations (Allen et al. 2014). Using the Raster Calculator in ArcMap 10.2, the $\beta$-coefficients from the top summer and winter models were entered into the equation $w(x)=\beta_{1} x_{1}+\beta_{2} x_{2} \ldots+\beta_{n} x_{n}$ and projected across the landscape to generate a $30 \mathrm{~m}$ resolution seasonal predation risk layers for adult BTD. The resulting raster pixel values were then scaled to range between 0 and 1 and thus equal to the relative probability of a pixel being a kill site (Figure 4.2).
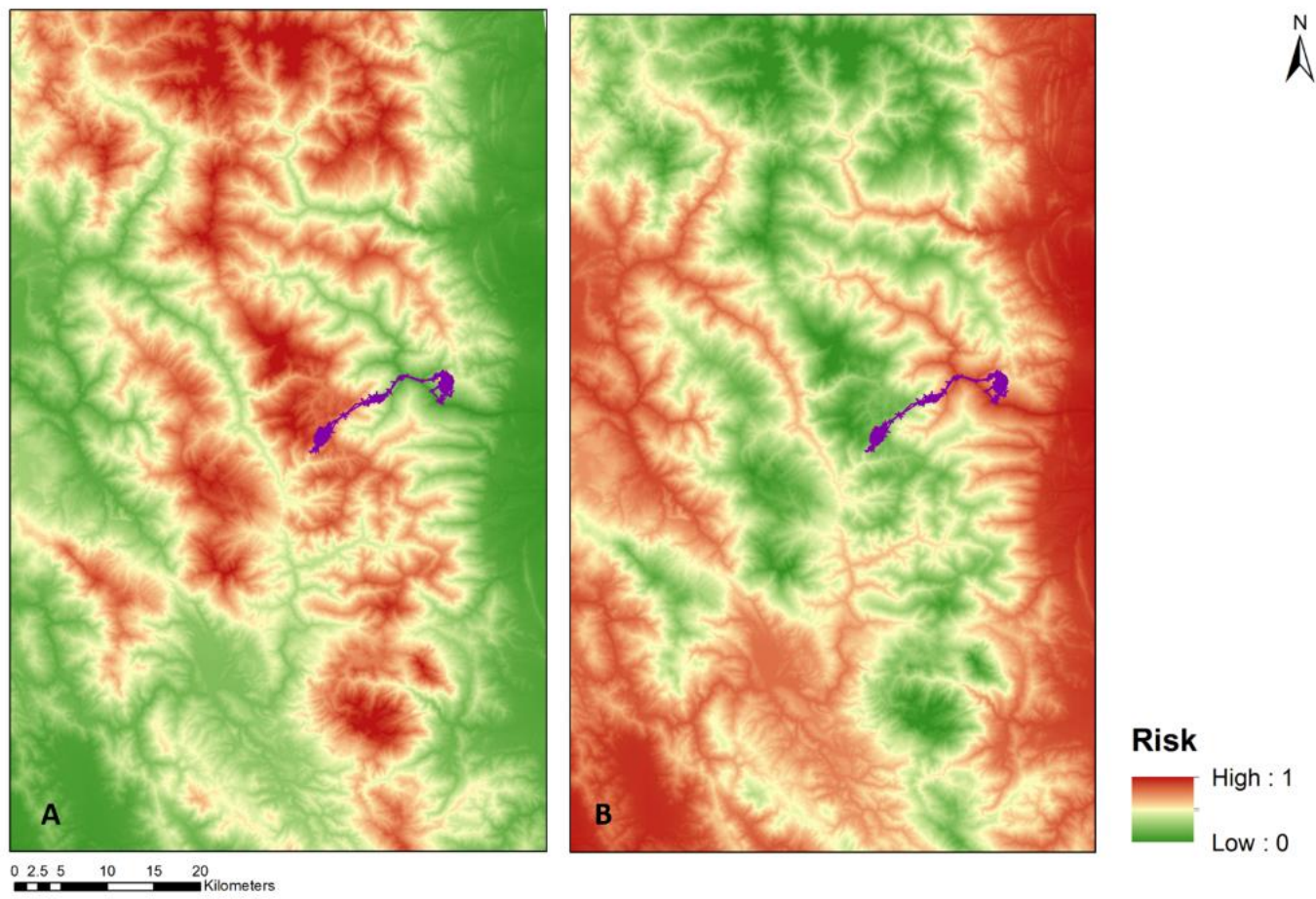

Figure 4.2: Predicted probability of risk of BTD being killed by pumas by season (A: Summer and B: Winter) in the Mendocino National Forest. The colours categorize risk by pixel (30-meter resolution) such that red denotes high probability of getting killed, yellow denotes medium risk areas and green denotes areas with low probability of getting killed by pumas. The purple track shows the movement pathway of a collared migratory BTD (\# 7216). 


\subsubsection{Estimation of forage availability}

The normalized difference vegetation index (NDVI) is one of the most commonly used vegetation indices in ecological studies (Pettorelli et al. 2005, Pettorelli et al. 2011). It has been widely used as a proxy for forage quality (Hamel et al. 2009, Sawyer and Kauffman 2011), primary productivity or phytomass (Hebblewhite et al. 2008) and plant phenology (Boone et. al. 2006). I used NDVI to assess productivity or phytomass in a pixel across the study area and also its spatiotemporal dynamics. To capture the temporal shift in productivity, I generated a NDVI time series from September 2004 to August 2013. Because BTD in the study area use very small home ranges and move very short distances within seasonal home ranges (Bose et al. 2017), high resolution NDVI layers were a requisite for the study. I thus downloaded Landsat satellite images with a spatial resolution of $30 \mathrm{~m}$ x $30 \mathrm{~m}$ for every month between September 2004 to August 2013 (EarthExplorer; https://earthexplorer.usgs.gov/, Accessed 23 ${ }^{\text {rd }}$ March 2017). From those, I selected images with less than 5\% cloud cover over the study area that had been further processed to remove haze and cloud contaminated pixels. The final images were then used to calculate the NDVI using the formula

$$
N D V I=\frac{N I R-V R}{N I R+V R}
$$

where, NIR is the near infrared light and VR is the visible red spectrum reflected by the vegetation. For months which did not have at least one cloud free image (less than $5 \%$ cloud cover over the study area), the mean NDVI values from the month before and after were used instead. While satellite-derived NDVIs of forested areas typically measure photosynthetic activity (productivity) of the topmost canopy layer, ground estimates of productivity and forage biomass or phytomass are correlated with the satellite-derived NDVI in moderately tree-covered habitat (Hebblewhite et al. 2008). 
Different vegetation types have been shown to exhibit different NDVI signatures over the course of a year, as nutrient content and digestibility of plants and plant parts vary with season (Gamon et al. 1995, Pettorelli et al. 2005, Pang et al. 2017). They also provide differential cover, and with the varying physiological demand across the year, BTD thus show a shift in preference for different vegetation types round the year (Bunnell 1990). Vegetation type was thus included as an additional layer in the movement analyses models as a proxy for forage quality. I acquired vegetation type layers from Landscape Fire and Resource Management Planning databases (LandFire; www.landfire.gov, Accessed $19^{\text {th }}$ January 2017) available for the study area. Based on proposed ecological importance for BTD (e.g., Dasmann and Taber 1956, Wallmo 1981), I re-classified vegetation into 6 distinct habitat categories: hardwood, conifer, grassland, shrub, riparian, and others (water, barren, developed upland forests and agricultural land). Conifer was used as the reference class for comparison among vegetation types, as it was the most abundant form of vegetation in both summer and winter ranges.

\subsubsection{Telemetry data}

I used GPS locations from all 64 female BTD for the movement analysis. Depending on individual fate and the lifespan of collar batteries, monitoring of individuals ranged from between 45 days to 903 days, with a mean of 400 days. To reduce error, I discarded GPS locations obtained within 48 hours of collaring the individual. Additionally, to decrease the risk of including fixes with high locational errors, GPS locations with dilution of precision (DOP) values $>10$ were deleted from the dataset (Lewis et al. 2007). Finally, apparently aberrant fixes (i.e. very far away) were also deleted from the final dataset. 


\subsubsection{Statistical analyses}

\subsubsection{Generation of random steps}

I considered consecutive telemetry locations as used steps for the study. For every used step retained in the dataset, 10 random steps were generated in Geospatial Modelling Environment (GME; Beyer 2012). In order to generate random steps, an angular-linear correlation coefficient (Fisher and Lee 1983) for each individual was first calculated to determine if step length and turning angles could be sampled independently. The very low correlation coefficient $\left(\mathrm{R}^{2}<0.001\right)$ indicated that these two parameters could be sampled independently. The step lengths and turning angles (i.e., the angle between subsequent locations) of random steps were drawn from two separate distributions established from observations on 15-34 individuals (Figure 4.3).
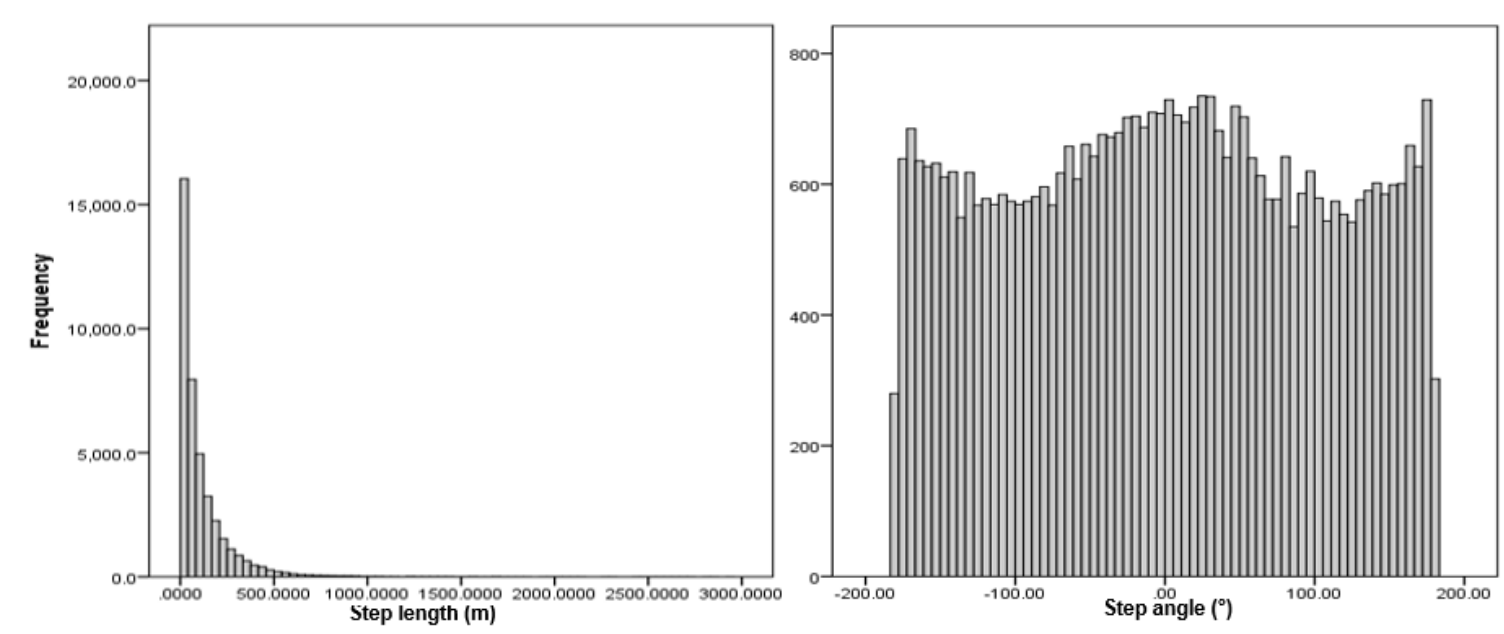

Figure 4.3: Distribution of average step lengths and turning angles for radio-collared BTD relocated every 1 hour in the Mendocino National Forest between 2004-2013. These average distributions were used to assign random steps to radio-collared BTD \# 7227; hence the means were calculated excluding the said individual.

As collars were programmed to collect location data at different intervals (1, 5, or $7 \mathrm{hrs}$ ), separate distributions for step length and turning angle were calculated for 
each interval. To characterize step lengths, observed step lengths were binned into bins of $50 \mathrm{~m}$ increments and observed turning angles were grouped into 10-degree bins. Potential step length and turning angle distributions for each deer were then sampled from the mean (sub) distributions matching the fix interval for the deer, which did not include its own data (Figure 4.3).

\subsubsection{Step selection functions}

Step Selection Functions (SSFs; Fortin et al. 2005) from the observed and random steps were estimated using mixed effect conditional logistic regression. SSFs are an extension of RSFs (Manly et al. 2002), and take the structure

$$
\hat{w}(\mathrm{x})=\exp \left(\beta_{1} x_{1 i j}+\ldots+\beta_{n} x_{n i j}+\gamma_{0 j}\right)
$$

where, $\beta_{1}$ to $\beta n$ are coefficients of variables $x_{1}$ to $x_{n}$, respectively, and $\gamma_{0 j}$ is the random per-subject intercept (Gillies et al. 2006). The random per-subject intercept effectively controls for variation due to unbalanced individual sampling (Gillies et al. 2006, Hebblewhite and Merrill 2008).

To test the hypothesis that forage-risk trade-off varies with familiarity and time of the day, models were fitted to a different set of predictor variables thought to influence step selection of BTD (Table 4.2). The complexity of models were gradually increased to incorporate forage availability, predation risk, and familiarity across the time of the day followed by habitat types to have a mechanistic understanding of decision making patterns of female BTD. All models were fitted to data for migratory (for summer and winter) and non-migratory BTD separately. 
Table 4.2: Candidate models used to determine step selection by 64 female black-tailed deer in the Mendocino National Forest, California, between 2004 and 2013.

\begin{tabular}{|c|c|c|}
\hline Model & Variables & $K^{\mathrm{a}}$ \\
\hline $\begin{array}{l}\text { NDVI and Risk } \\
\text { Trade-off }\end{array}$ & NDVI $\times$ risk + time of the day & 8 \\
\hline $\begin{array}{l}\text { Trade-off with } \\
\text { respect to familiarity }\end{array}$ & $\begin{array}{l}\text { NDVI } \times \text { risk }+ \text { NDVI } \times \text { familiarity }+ \text { risk } \times \\
\text { familiarity }+ \text { time of the day:familiarity }\end{array}$ & 22 \\
\hline $\begin{array}{l}\text { Trade-off with } \\
\text { respect to vegetation } \\
\text { type and familiarity }\end{array}$ & $\begin{array}{l}\text { NDVI } \times \text { risk }+ \text { NDVI } \times \text { vegetation type } \times \\
\text { familiarity }+ \text { risk } \times \text { vegetation type } \times \text { familiarity }+ \\
\text { time of the day:familiarity }\end{array}$ & 67 \\
\hline
\end{tabular}

${ }^{a} K=$ estimated number of parameters.

I tested for multicollinearity among predictor variables and variables with correlation coefficients $\geq 0.6$ were not used together in any model (Graham 2003). Mixed effect conditional logistic regression models were then fitted using the library mclogit (Elff 2017) in program R (R Development Core Team 2014).

Because animals were relocated every 1-7 hours, successive steps were not independent from one another. Such temporal autocorrelation does not influence $\beta$ values, but can produce biased estimates of variance (Nielsen et al. 2002), and can lead to model selection errors. However, inclusion of time of the day (temporal variable) as predictor in the models eliminated any temporal autocorrelation from the model residuals (Boyce et al. 2010).

I evaluated model fit by using k-fold cross-validation procedures. For k-fold cross validations, the data were randomly partitioned by individual within seasonal models to construct a training set ( $80 \%$ of data) and a test set ( $20 \%$ of data). Modelaveraged estimates from the training models were then used to calculate predicted RSF 
values for the random locations. Subsequently, I ranked the random locations based on predicted values and binned them into 10 equal groups (Boyce et al. 2002). The process was repeated for each of the 5 subsets of withheld data. The fit of the model was then quantified using the averaged Spearman rank correlation coefficient based on the frequency of used points in each of 10 equal bins of predicted values (Boyce et al. 2002).

\subsection{Results}

I obtained a total of 168,599 GPS locations from 64 female BTD during the study period. The average fix success was $83.81 \pm 1.4 \%$ (mean \pm SE). After discarding aberrant locations and locations associated with collaring, I identified 147,326 steps taken by 52 migratory and 20,435 steps taken by 12 non-migratory BTD. For migratory deer, the average number of steps per individual was 2,833 (range: 138$8,014, \mathrm{n}=52)$ with mean step lengths of $176.41 \pm 1.49 \mathrm{~m}, 152.27 \pm 1.10 \mathrm{~m}$, and 398.72 $\pm 15.34 \mathrm{~m}$ during summer, winter and migration, respectively. The mean turn angles for migratory deer was $0.64 \pm 0.43^{\circ}$ in summer, $-0.21 \pm 0.51^{\circ}$ in winter and $1.20 \pm 1.79^{\circ}$ during migrations. For non-migratory deer, the average number of steps per individual was 1,703 (range: $469-2,741, \mathrm{n}=12$ ) with a mean step length of $277.11 \pm 2.3 \mathrm{~m}$ and a turn angle of $1.64 \pm 0.79^{\circ}$.

\subsubsection{Step selection patterns of migratory BTD}

Forage availability and predation risk had significant effects on BTD movements, and varied with spatial familiarity and time of the day. Familiarity for migratory BTD was one of the most important predictors of step selection both during summer and winter, and use of familiar areas were significantly correlated with time of the day $\left(\chi_{d f=8}^{2}=\right.$ 
1002.73, $p=0.001$ for summer, and $\chi_{d f=8}^{2}=1476.52, p=0.001$ for winter; Figure 4.4a-b). The k-fold cross-validation indicated that the models were robust, with $r_{s}>$ 0.72 for all models.

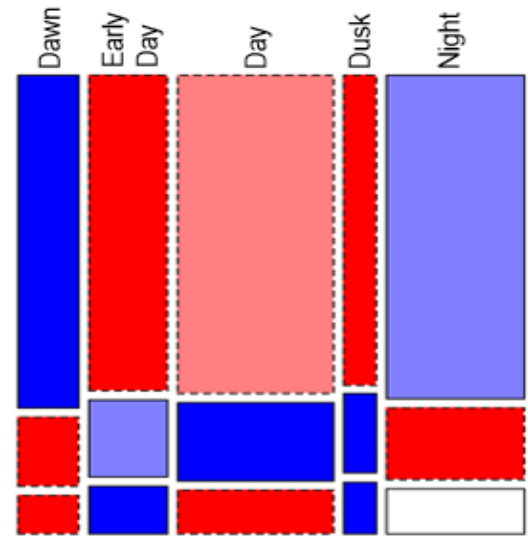

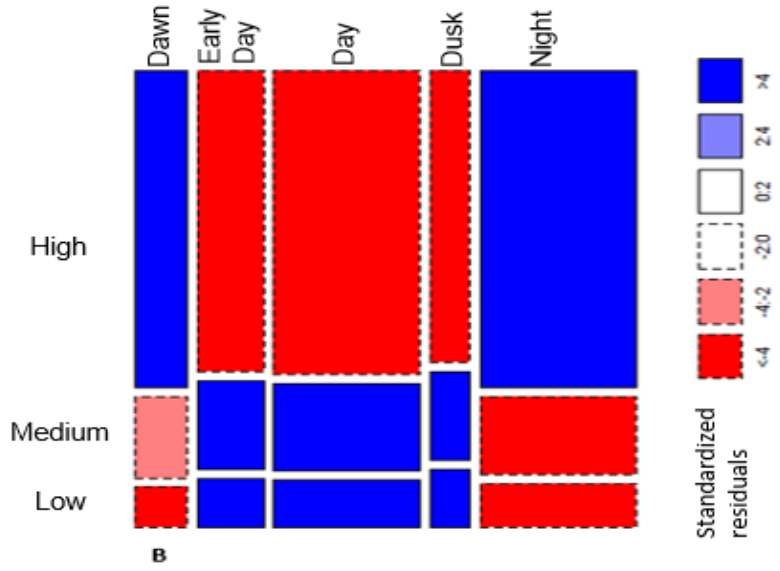

Figure 4.4: Association between time of the day and use of areas with spatial familiarity (A: Summer and B: Winter) for migratory black-tailed deer in the Mendocino National Forest, California, between 2004 and 2013.

\subsubsection{Summer}

In summer, the movement analyses of migratory BTD revealed that BTD consistently

avoided steps into areas with very high NDVI (Tables 4.3, 4.4 and 4.5).

Table 4.3: Effect estimates (mean log odds and 95\% confidence interval) of NDVI and risk trade-off model for migratory and non-migratory female black-tailed deer in the Mendocino National Forest, California, between 2004 and 2013. Selection for migratory deer further delineated for 2 distinct seasons (summer and winter) based on observed elevational migrations.

\begin{tabular}{|c|c|c|c|c|c|c|c|c|c|}
\hline \multirow[b]{2}{*}{ Covariates } & \multicolumn{3}{|c|}{ Summer } & \multicolumn{3}{|c|}{ Winter } & \multicolumn{3}{|c|}{ Non-migratory } \\
\hline & $\begin{array}{l}\text { Log } \\
\text { odds }\end{array}$ & LCI & UCI & $\begin{array}{l}\text { Log } \\
\text { odds }\end{array}$ & LCI & UCI & $\begin{array}{l}\text { Log } \\
\text { odds }\end{array}$ & LCI & UCI \\
\hline NDVI & 0.62 & 0.52 & 0.75 & 0.02 & 0.01 & 0.05 & 0.37 & 0.23 & 0.58 \\
\hline
\end{tabular}




\begin{tabular}{|l|rrr|rrr|rrr|} 
Risk & 0.54 & 0.45 & 0.65 & 0.35 & 0.26 & 0.46 & 0.55 & 0.34 & 0.88 \\
Dawn & 1.01 & 0.99 & 1.03 & 1.00 & 0.97 & 1.03 & 1.01 & 0.96 & 1.06 \\
Day & 1.00 & 0.98 & 1.02 & 1.00 & 0.98 & 1.02 & 1.00 & 0.97 & 1.04 \\
Dusk & 1.00 & 0.97 & 1.03 & 1.00 & 0.97 & 1.03 & 1.01 & 0.95 & 1.07 \\
Early Day & 1.00 & 0.98 & 1.03 & 1.00 & 0.97 & 1.03 & 1.00 & 0.96 & 1.05 \\
NDVI × Risk & 3.28 & 2.41 & 4.45 & 357.09 & 68.63 & 1858.16 & 3.54 & 1.52 & 8.24 \\
\hline
\end{tabular}

BTD also avoided steps into areas associated with high risk of getting killed by pumas (Tables $4.3,4.4$, and 4.5 ). The two-way interaction between risk and NDVI was significant in all the models (Tables 4.3, 4.4, and 4.5) showing strong evidence of trade-off between predation risk and forage availability or productivity during summer (Figure 4.5a).

The model with familiarity, risk and NDVI as fixed effects and their two-way interactions indicated that selection for areas with higher risk and productivity varied in summer with varying familiarity (Figure $4.5 \mathrm{~b}-\mathrm{d}$ ). BTD displayed non-significant avoidance or selection towards highly familiar areas while compared to moderately familiar areas (Tables 4.4 and 4.5). However, a two-way interaction between familiarity and NDVI revealed that individuals were 1.7 times more likely to step into areas with higher NDVI values when in high familiarity zones as compared to that in medium familiarity zones (Table 4.4). Further, the two-way interaction between risk and familiarity showed that individuals were 1.25 times more likely to step into areas with higher predation risk with increasing familiarity (Table 4.4). 
Table 4.4: Effect estimates (mean log odds and 95\% confidence interval) of NDVI and risk trade-off model as a function of familiarity for migratory and non-migratory female black-tailed deer in the Mendocino National Forest, California, between 2004 and 2013. Selection for migratory deer further delineated for 2 distinct seasons (summer and winter) based on observed elevational migrations.

\begin{tabular}{|c|c|c|c|c|c|c|c|c|c|}
\hline \multirow{2}{*}{ Covariates } & \multicolumn{3}{|c|}{ Summer } & \multicolumn{3}{|c|}{ Winter } & \multicolumn{3}{|c|}{ Non-Migratory } \\
\hline & $\begin{array}{l}\text { Log } \\
\text { odds }\end{array}$ & LCI & UCI & $\begin{array}{c}\text { Log } \\
\text { odd } \\
\text { S }\end{array}$ & LCI & UCI & $\begin{array}{l}\text { Log } \\
\text { odds }\end{array}$ & LCI & UCI \\
\hline NDVI & 0.66 & 0.52 & 0.83 & 0.05 & 0.01 & 0.14 & 0.45 & 0.27 & 0.76 \\
\hline Risk & 0.49 & 0.40 & 0.60 & 0.20 & 0.15 & 0.28 & 0.77 & 0.45 & 1.31 \\
\hline NDVI $\times$ Risk & 2.46 & 1.80 & 3.36 & $\begin{array}{c}66.6 \\
9\end{array}$ & $\begin{array}{c}12.5 \\
9\end{array}$ & $\begin{array}{l}353 . \\
25\end{array}$ & 1.09 & 0.46 & 2.60 \\
\hline High Familiarity & 1.07 & 0.94 & 1.21 & 0.95 & 0.81 & 1.12 & 1.07 & 0.87 & 1.32 \\
\hline Low Familiarity & 1.08 & 0.85 & 1.37 & 0.50 & 0.36 & 0.68 & 0.91 & 0.63 & 1.30 \\
\hline $\begin{array}{l}\text { NDVI } \times \text { High } \\
\text { Familiarity }\end{array}$ & 1.72 & 1.46 & 2.02 & 2.63 & 1.28 & 5.38 & 1.91 & 1.43 & 2.55 \\
\hline $\begin{array}{l}\text { NDVI } \times \text { Low } \\
\text { Familiarity }\end{array}$ & 0.31 & 0.22 & 0.42 & 0.20 & 0.05 & 0.83 & 0.07 & 0.04 & 0.11 \\
\hline
\end{tabular}




\begin{tabular}{|c|c|c|c|c|c|c|c|c|c|}
\hline $\begin{array}{l}\text { Risk } \times \text { High } \\
\text { Familiarity }\end{array}$ & 1.25 & 1.11 & 1.40 & 2.12 & 1.86 & 2.42 & 1.24 & 0.92 & 1.66 \\
\hline $\begin{array}{l}\text { Risk } \times \text { Low } \\
\text { Familiarity }\end{array}$ & 0.62 & 0.50 & 0.77 & 0.95 & 0.71 & 1.27 & 2.47 & 1.52 & 4.01 \\
\hline $\begin{array}{l}\text { High Familiarity } \times \\
\text { Dawn }\end{array}$ & 0.98 & 0.95 & 1.01 & 0.98 & 0.95 & 1.01 & 1.03 & 0.97 & 1.09 \\
\hline $\begin{array}{l}\text { Medium Familiarity } \\
\times \text { Dawn }\end{array}$ & 1.10 & 1.03 & 1.18 & 1.08 & 1.01 & 1.16 & 1.08 & 0.97 & 1.21 \\
\hline $\begin{array}{l}\text { Low Familiarity } \times \\
\text { Dawn }\end{array}$ & 1.45 & 1.28 & 1.64 & 1.31 & 1.12 & 1.53 & 0.80 & 0.65 & 0.99 \\
\hline $\begin{array}{l}\text { High Familiarity } \times \\
\text { Day }\end{array}$ & 1.02 & 1.00 & 1.04 & 1.00 & 0.98 & 1.03 & 1.05 & 1.01 & 1.10 \\
\hline $\begin{array}{l}\text { Medium Familiarity } \\
\times \text { Day }\end{array}$ & 0.99 & 0.94 & 1.04 & 1.09 & 1.03 & 1.15 & 0.88 & 0.80 & 0.96 \\
\hline $\begin{array}{l}\text { Low Familiarity } \times \\
\text { Day }\end{array}$ & 0.98 & 0.89 & 1.09 & 1.24 & 1.11 & 1.38 & 0.94 & 0.82 & 1.08 \\
\hline $\begin{array}{l}\text { High Familiarity } \times \\
\text { Dusk }\end{array}$ & 1.03 & 0.99 & 1.06 & 1.01 & 0.98 & 1.05 & 1.06 & 0.99 & 1.13 \\
\hline $\begin{array}{l}\text { Medium Familiarity } \\
\times \text { Dusk }\end{array}$ & 0.93 & 0.86 & 1.02 & 1.06 & 0.98 & 1.15 & 0.89 & 0.78 & 1.02 \\
\hline $\begin{array}{l}\text { Low Familiarity } \times \\
\text { Dusk }\end{array}$ & 0.95 & 0.81 & 1.12 & 1.06 & 0.90 & 1.24 & 0.77 & 0.60 & 0.98 \\
\hline
\end{tabular}




\begin{tabular}{|l|ccc|ccc|ccc|} 
High Familiarity $\times$ & & & \\
Early Day & 1.01 & 0.98 & 1.03 & 0.99 & 0.96 & 1.01 & 1.06 & 1.01 & 1.12 \\
Medium Familiarity & 1.08 & 1.02 & 1.15 & 1.12 & 1.05 & 1.20 & 0.92 & 0.83 & 1.03 \\
$\times$ Early Day & & & & & & & & & \\
& & & & & & & & & \\
Low Familiarity $\times$ & 1.24 & 1.11 & 1.39 & 1.50 & 1.32 & 1.71 & 0.79 & 0.65 & 0.96 \\
Early Day & & & & & & & & & \\
\hline
\end{tabular}

The most complex model accounting for familiarity, risk, NDVI and vegetation type and their interactions revealed complex patterns of trade-offs. The two-way interaction between the vegetation type and NDVI revealed that BTD were 2.02 times more likely to step into areas with higher NDVI for open canopied vegetation types like grass (Table 4.5) as compared to conifers.

Table 4.5: Effect estimates (mean log odds and 95\% confidence interval) of NDVI and risk trade-off model as a function of familiarity and vegetation type for migratory and non-migratory female black-tailed deer in the Mendocino National Forest, California, between 2004 and 2013. Selection for migratory deer further delineated for 2 distinct seasons (summer and winter) based on observed elevational migrations.

\begin{tabular}{|c|c|c|c|c|c|c|c|c|c|}
\hline \multirow{2}{*}{ Covariates } & \multicolumn{3}{|c|}{ Summer } & \multicolumn{3}{|c|}{ Winter } & \multicolumn{3}{|c|}{ Non-Migratory } \\
\hline & $\begin{array}{c}\text { Log } \\
\text { odds }\end{array}$ & LCI & UCI & $\begin{array}{l}\text { Log } \\
\text { odds }\end{array}$ & LCI & UCI & Log odds & LCI & UCI \\
\hline NDVI & 0.47 & 0.33 & 0.65 & 1.08 & 0.23 & 5.15 & 0.31 & 0.17 & 0.60 \\
\hline Risk & 0.38 & 0.28 & 0.51 & 0.17 & 0.12 & 0.26 & 0.36 & 0.17 & 0.73 \\
\hline $\begin{array}{l}\text { NDVI } \times \\
\text { Risk }\end{array}$ & 2.96 & 2.04 & 4.29 & 63.05 & 10.15 & 391.63 & 2.42 & 0.93 & 6.29 \\
\hline
\end{tabular}




\begin{tabular}{|c|c|c|c|c|c|c|c|c|c|}
\hline $\begin{array}{l}\text { High } \\
\text { Familiarity }\end{array}$ & 0.84 & 0.67 & 1.07 & 1.44 & 1.07 & 1.94 & 0.91 & 0.64 & 1.27 \\
\hline $\begin{array}{l}\text { Low } \\
\text { Familiarity }\end{array}$ & 2.41 & 1.61 & 3.60 & 0.36 & 0.21 & 0.63 & 0.60 & 0.30 & 1.20 \\
\hline $\begin{array}{l}\text { NDVI } \times \\
\text { High } \\
\text { Familiarity }\end{array}$ & 1.98 & 1.51 & 2.58 & 0.15 & 0.04 & 0.58 & 1.89 & 1.16 & 3.08 \\
\hline $\begin{array}{l}\text { NDVI } \times \text { Low } \\
\text { Familiarity }\end{array}$ & 0.18 & 0.11 & 0.29 & 0.99 & 0.08 & 11.88 & 0.37 & 0.14 & 1.00 \\
\hline $\begin{array}{l}\text { Risk } \times \text { High } \\
\text { Familiarity }\end{array}$ & 1.52 & 1.24 & 1.86 & 2.84 & 2.21 & 3.65 & 1.64 & 0.97 & 2.74 \\
\hline $\begin{array}{l}\text { Risk } \times \text { Low } \\
\text { Familiarity }\end{array}$ & 0.30 & 0.22 & 0.43 & 1.15 & 0.70 & 1.89 & 0.50 & 0.18 & 1.39 \\
\hline $\begin{array}{l}\text { High } \\
\text { Familiarity } \times \\
\text { Dawn }\end{array}$ & 0.98 & 0.96 & 1.01 & 0.98 & 0.95 & 1.01 & 1.03 & 0.98 & 1.10 \\
\hline $\begin{array}{l}\text { Medium } \\
\text { Familiarity } \times \\
\text { Dawn }\end{array}$ & 1.10 & 1.03 & 1.17 & 1.08 & 1.01 & 1.16 & 1.09 & 0.98 & 1.22 \\
\hline $\begin{array}{l}\text { Low } \\
\text { Familiarity } \times \\
\text { Dawn }\end{array}$ & 1.41 & 1.25 & 1.60 & 1.32 & 1.13 & 1.54 & 0.81 & 0.66 & 1.00 \\
\hline $\begin{array}{l}\text { High } \\
\text { Familiarity } \times \\
\text { Day }\end{array}$ & 1.02 & 1.00 & 1.04 & 1.01 & 0.99 & 1.03 & 1.06 & 1.01 & 1.10 \\
\hline $\begin{array}{l}\text { Medium } \\
\text { Familiarity } \times \\
\text { Day }\end{array}$ & 1.00 & 0.95 & 1.05 & 1.10 & 1.04 & 1.16 & 0.88 & 0.81 & 0.96 \\
\hline $\begin{array}{l}\text { Low } \\
\text { Familiarity x } \\
\text { Day }\end{array}$ & 0.97 & 0.88 & 1.08 & 1.24 & 1.11 & 1.38 & 0.95 & 0.82 & 1.09 \\
\hline
\end{tabular}




\begin{tabular}{|c|c|c|c|c|c|c|c|c|c|}
\hline $\begin{array}{l}\text { High } \\
\text { Familiarity } \times \\
\text { Dusk }\end{array}$ & 1.03 & 1.00 & 1.07 & 1.02 & 0.99 & 1.06 & 1.06 & 1.00 & 1.13 \\
\hline $\begin{array}{l}\text { Medium } \\
\text { Familiarity } \times \\
\text { Dusk }\end{array}$ & 0.94 & 0.86 & 1.02 & 1.07 & 0.99 & 1.15 & 0.89 & 0.78 & 1.02 \\
\hline $\begin{array}{l}\text { Low } \\
\text { Familiarity } \times \\
\text { Dusk }\end{array}$ & 0.96 & 0.82 & 1.13 & 1.07 & 0.91 & 1.25 & 0.78 & 0.61 & 1.00 \\
\hline $\begin{array}{l}\text { High } \\
\text { Familiarity } \times \\
\text { Early Day }\end{array}$ & 1.02 & 0.99 & 1.04 & 0.98 & 0.96 & 1.01 & 1.07 & 1.01 & 1.12 \\
\hline $\begin{array}{l}\text { Medium } \\
\text { Familiarity } \times \\
\text { Early Day }\end{array}$ & 1.09 & 1.02 & 1.15 & 1.13 & 1.06 & 1.20 & 0.93 & 0.83 & 1.04 \\
\hline $\begin{array}{l}\text { Low } \\
\text { Familiarity } \times \\
\text { Early Day }\end{array}$ & 1.23 & 1.10 & 1.37 & 1.50 & 1.32 & 1.70 & 0.82 & 0.68 & 1.00 \\
\hline Grassland & 0.54 & 0.40 & 0.73 & 1.19 & 0.83 & 1.70 & 0.72 & 0.46 & 1.11 \\
\hline Hardwood & 1.82 & 1.11 & 2.97 & 7.42 & 3.34 & 16.47 & 0.63 & 0.21 & 1.83 \\
\hline Other & 0.65 & 0.39 & 1.09 & 1.08 & 0.47 & 2.48 & 0.98 & 0.43 & 2.25 \\
\hline Riparian & 2.11 & 0.31 & 14.46 & 4.67 & 0.37 & 58.47 & 0.92 & 0.00 & 176.71 \\
\hline Srub & 0.61 & 0.43 & 0.86 & 5.01 & 3.28 & 7.65 & 0.67 & 0.35 & 1.26 \\
\hline $\begin{array}{l}\text { NDVI } \times \\
\text { Grassland }\end{array}$ & 2.02 & 1.37 & 2.97 & 0.25 & 0.04 & 1.36 & 1.19 & 0.62 & 2.27 \\
\hline
\end{tabular}




\begin{tabular}{|c|c|c|c|c|c|c|c|c|c|}
\hline $\begin{array}{l}\text { NDVI } \times \\
\text { Hardwood }\end{array}$ & 0.91 & 0.45 & 1.81 & 0.05 & 0.00 & 0.60 & 1.07 & 0.28 & 4.04 \\
\hline $\begin{array}{l}\text { NDVI } x \\
\text { Other }\end{array}$ & 1.28 & 0.63 & 2.61 & 0.03 & 0.00 & 1.31 & 0.91 & 0.27 & 3.09 \\
\hline $\begin{array}{l}\text { NDVI } \times \\
\text { Riparian }\end{array}$ & 0.13 & 0.01 & 1.73 & 0.00 & 0.00 & 0.00 & 2.16 & 0.00 & 2618.40 \\
\hline $\begin{array}{l}\text { NDVI } \times \\
\text { Shrub }\end{array}$ & 1.62 & 0.97 & 2.70 & 0.00 & 0.00 & 0.00 & 2.31 & 0.89 & 6.03 \\
\hline $\begin{array}{l}\text { High } \\
\text { Familiarity } \times \\
\text { Grassland }\end{array}$ & 1.95 & 1.41 & 2.70 & 0.88 & 0.60 & 1.31 & 1.30 & 0.80 & 2.11 \\
\hline $\begin{array}{l}\text { High } \\
\text { Familiarity } \times \\
\text { Hardwood }\end{array}$ & 0.55 & 0.32 & 0.94 & 0.13 & 0.06 & 0.31 & 3.23 & 0.92 & 11.32 \\
\hline $\begin{array}{l}\text { High } \\
\text { Familiarity } \times \\
\text { Other }\end{array}$ & 0.95 & 0.54 & 1.68 & 1.07 & 0.43 & 2.70 & 0.88 & 0.36 & 2.17 \\
\hline $\begin{array}{l}\text { High } \\
\text { Familiarity } \times \\
\text { Riparian }\end{array}$ & 0.78 & 0.09 & 7.12 & 0.03 & 0.00 & 1.09 & 0.69 & 0.00 & 209.94 \\
\hline $\begin{array}{l}\text { High } \\
\text { Familiarity } \times \\
\text { Shrub }\end{array}$ & 1.28 & 0.88 & 1.87 & 0.32 & 0.20 & 0.51 & 1.27 & 0.63 & 2.55 \\
\hline $\begin{array}{l}\text { Low } \\
\text { Familiarity } \times \\
\text { Grassland }\end{array}$ & 0.14 & 0.08 & 0.27 & 1.71 & 0.75 & 3.89 & 1.55 & 0.64 & 3.77 \\
\hline $\begin{array}{l}\text { Low } \\
\text { Familiarity } \times \\
\text { Hardwood }\end{array}$ & 0.53 & 0.19 & 1.42 & 0.52 & 0.09 & 2.96 & 3.66 & 0.50 & 27.09 \\
\hline $\begin{array}{l}\text { Low } \\
\text { Familiarity } \times \\
\text { Other }\end{array}$ & 0.17 & 0.06 & 0.47 & 1.18 & 0.24 & 5.94 & 0.26 & 0.04 & 1.89 \\
\hline
\end{tabular}




\begin{tabular}{|c|c|c|c|c|c|c|c|c|c|}
\hline $\begin{array}{l}\text { Low } \\
\text { Familiarity } \times \\
\text { Riparian }\end{array}$ & 0.59 & 0.02 & 17.98 & 0.00 & 0.00 & 2.03 & 5.32 & 0.00 & $5.49 \mathrm{E}+04$ \\
\hline $\begin{array}{l}\text { Low } \\
\text { Familiarity } \times \\
\text { Shrub }\end{array}$ & 0.69 & 0.34 & 1.39 & 1.80 & 0.79 & 4.12 & 2.12 & 0.66 & 6.75 \\
\hline $\begin{array}{l}\text { Risk } \times \\
\text { Grassland }\end{array}$ & 1.65 & 1.23 & 2.20 & 1.68 & 1.23 & 2.28 & 2.00 & 1.06 & 3.76 \\
\hline $\begin{array}{l}\text { Risk } \times \\
\text { Hardwood }\end{array}$ & 0.28 & 0.11 & 0.69 & 0.10 & 0.04 & 0.24 & 2.48 & 0.84 & 7.30 \\
\hline Risk $\times$ Other & 1.46 & 0.85 & 2.50 & 2.65 & 1.36 & 5.19 & 0.66 & 0.21 & 2.12 \\
\hline $\begin{array}{l}\text { Risk } \times \\
\text { Riparian }\end{array}$ & 1.72 & 0.28 & 10.44 & 10.20 & 0.95 & 109.46 & 0.03 & 0.00 & 7.47 \\
\hline Risk $\times$ Shrub & 1.66 & 1.20 & 2.29 & 0.84 & 0.58 & 1.20 & 1.20 & 0.48 & 2.96 \\
\hline $\begin{array}{l}\text { High } \\
\text { Familiarity } \times \\
\text { NDVI } \times \\
\text { Grassland }\end{array}$ & 0.64 & 0.42 & 0.97 & 5.94 & 0.93 & 37.99 & 1.07 & 0.53 & 2.18 \\
\hline $\begin{array}{l}\text { High } \\
\text { Familiarity } \times \\
\text { NDVI } \times \\
\text { Hardwood }\end{array}$ & 1.19 & 0.56 & 2.50 & 43.25 & 2.86 & 654.30 & 0.47 & 0.10 & 2.23 \\
\hline $\begin{array}{l}\text { High } \\
\text { Familiarity } \times \\
\text { NDVI } \times \\
\text { Other }\end{array}$ & 1.89 & 0.89 & 4.05 & 12.12 & 0.17 & 876.24 & 1.32 & 0.35 & 4.92 \\
\hline $\begin{array}{l}\text { High } \\
\text { Familiarity } \times \\
\text { NDVI } \times \\
\text { Riparian }\end{array}$ & 3.24 & 0.15 & 72.21 & $2.19 \mathrm{E}+07$ & 71.22 & $6.71 \mathrm{E}+12$ & 0.28 & 0.00 & 554.66 \\
\hline $\begin{array}{l}\text { High } \\
\text { Familiarity } \times \\
\text { NDVI } \times \\
\text { Shrub }\end{array}$ & 0.85 & 0.49 & 1.47 & 638.42 & 75.24 & $5.42 \mathrm{E}+03$ & 0.68 & 0.24 & 1.95 \\
\hline
\end{tabular}




\begin{tabular}{|c|c|c|c|c|c|c|c|c|c|}
\hline $\begin{array}{l}\text { Low } \\
\text { Familiarity } \times \\
\text { NDVI } \times \\
\text { Grassland }\end{array}$ & 3.22 & 1.38 & 7.51 & 0.12 & 0.00 & 7.05 & 0.12 & 0.03 & 0.45 \\
\hline $\begin{array}{l}\text { Low } \\
\text { Familiarity } \times \\
\text { NDVI } \times \\
\text { Hardwood }\end{array}$ & 2.10 & 0.48 & 9.20 & 0.13 & 0.00 & 30.20 & 1.36 & 0.10 & 18.01 \\
\hline $\begin{array}{l}\text { Low } \\
\text { Familiarity } \times \\
\text { NDVI } \times \\
\text { Other }\end{array}$ & 6.46 & 1.56 & 26.76 & 26.10 & 0.02 & $3.96 \mathrm{E}+04$ & 1.98 & 0.11 & 34.84 \\
\hline $\begin{array}{l}\text { Low } \\
\text { Familiarity } \times \\
\text { NDVI } \times \\
\text { Riparian }\end{array}$ & 1.52 & 0.01 & 163.12 & $3.08 \mathrm{E}+10$ & 6.58 & $1.44 \mathrm{E}+20$ & 0.00 & 0.00 & 138.56 \\
\hline $\begin{array}{l}\text { Low } \\
\text { Familiarity } \times \\
\text { NDVI } \times \\
\text { Shrub }\end{array}$ & 1.35 & 0.44 & 4.15 & 0.00 & 0.00 & 0.05 & 0.05 & 0.01 & 0.29 \\
\hline $\begin{array}{l}\text { High } \\
\text { Familiarity } \times \\
\text { Risk } \times \\
\text { Grassland }\end{array}$ & 0.54 & 0.40 & 0.74 & 0.59 & 0.42 & 0.82 & 0.57 & 0.28 & 1.14 \\
\hline $\begin{array}{l}\text { High } \\
\text { Familiarity } \times \\
\text { Risk } \times \\
\text { Hardwood }\end{array}$ & 4.46 & 1.60 & 12.45 & 8.45 & 3.22 & 22.19 & 0.18 & 0.05 & 0.61 \\
\hline $\begin{array}{l}\text { High } \\
\text { Familiarity } \times \\
\text { Risk } \times \text { Other }\end{array}$ & 0.65 & 0.36 & 1.16 & 0.27 & 0.13 & 0.56 & 1.59 & 0.44 & 5.69 \\
\hline $\begin{array}{l}\text { High } \\
\text { Familiarity } \times \\
\text { Risk } \times \\
\text { Riparian }\end{array}$ & 0.27 & 0.03 & 2.47 & 0.52 & 0.01 & 18.58 & 89.21 & 0.25 & $3.23 \mathrm{E}+04$ \\
\hline $\begin{array}{l}\text { High } \\
\text { Familiarity } \times \\
\text { Risk } \times \text { Shrub }\end{array}$ & 0.80 & 0.56 & 1.13 & 0.79 & 0.53 & 1.18 & 0.93 & 0.35 & 2.52 \\
\hline $\begin{array}{l}\text { Low } \\
\text { Familiarity } \times \\
\text { Risk } \times \\
\text { Grassland }\end{array}$ & 8.85 & 4.75 & 16.46 & 0.54 & 0.25 & 1.16 & 7.95 & 2.19 & 28.91 \\
\hline $\begin{array}{l}\text { Low } \\
\text { Familiarity } \times \\
\text { Risk } \times \\
\text { Hardwood }\end{array}$ & 0.61 & 0.08 & 4.96 & 4.47 & 0.63 & 31.65 & 0.15 & 0.02 & 1.09 \\
\hline
\end{tabular}




\begin{tabular}{|c|c|c|c|c|c|c|c|c|c|}
\hline $\begin{array}{l}\text { Low } \\
\text { Familiarity } \times \\
\text { Risk } \times \text { Other }\end{array}$ & 3.19 & 1.15 & 8.86 & 0.22 & 0.05 & 0.94 & 6.92 & 0.55 & 86.70 \\
\hline $\begin{array}{l}\text { Low } \\
\text { Familiarity } \times \\
\text { Risk } \times \\
\text { Riparian }\end{array}$ & 4.28 & 0.10 & 176.46 & 3.29 & 0.00 & 4785.57 & 617.70 & 0.03 & $1.46 \mathrm{E}+07$ \\
\hline $\begin{array}{l}\text { Low } \\
\text { Familiarity } \times \\
\text { Risk } \times \text { Shrub }\end{array}$ & 0.78 & 0.41 & 1.48 & 2.13 & 0.96 & 4.71 & 11.67 & 2.51 & 54.27 \\
\hline
\end{tabular}

A two-way interaction between risk and vegetation type also revealed that BTD are more likely to step into riskier areas when they are in open habitat like grassland and shrubs (Table 4.5). The three-way interaction between NDVI, vegetation type and familiarity revealed differential pattern of selection towards NDVI and vegetation types that varied with familiarity. For example, BTD showed preference towards high grasslands with high NDVI value in low familiar areas when compared to grasslands in medium familiar areas (Table 4.5). Additionally, the three-way interaction between vegetation type, risk, and familiarity also showed varying patterns of preference towards risk that changed with vegetation type and familiarity (Table 4.5). For example, BTD in low familiarity areas showed preference towards grassland even if they had higher predation risk, but in high familiar areas they only stepped into grasslands that were associated with low predation risk. Plotting all the variables generated complex patterns of trade-offs which largely varied with familiarity and vegetation type (Figure 4.6a-f). 

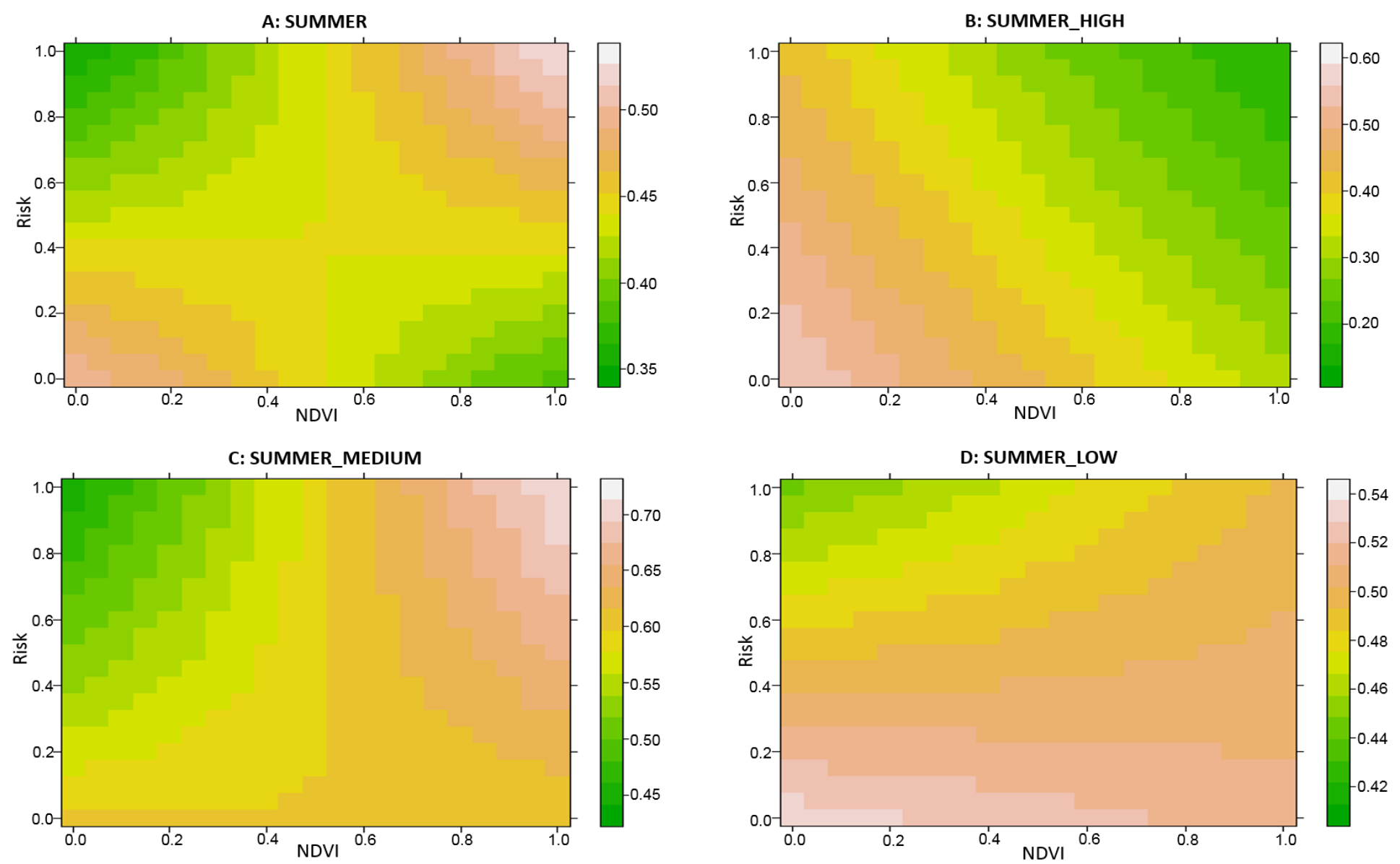

Figure 4.5: Level plots illustrating probability of selection as an interaction of NDVI and risk (A). B-D Illustrates the effect of including spatial familiarity (High, medium and low) on the NDVI-risk trade-off during summer for female migratory black-tailed deer in the Mendocino National Forest between 2004 and 2013. *Note different scales on the probability axes of the plots. 

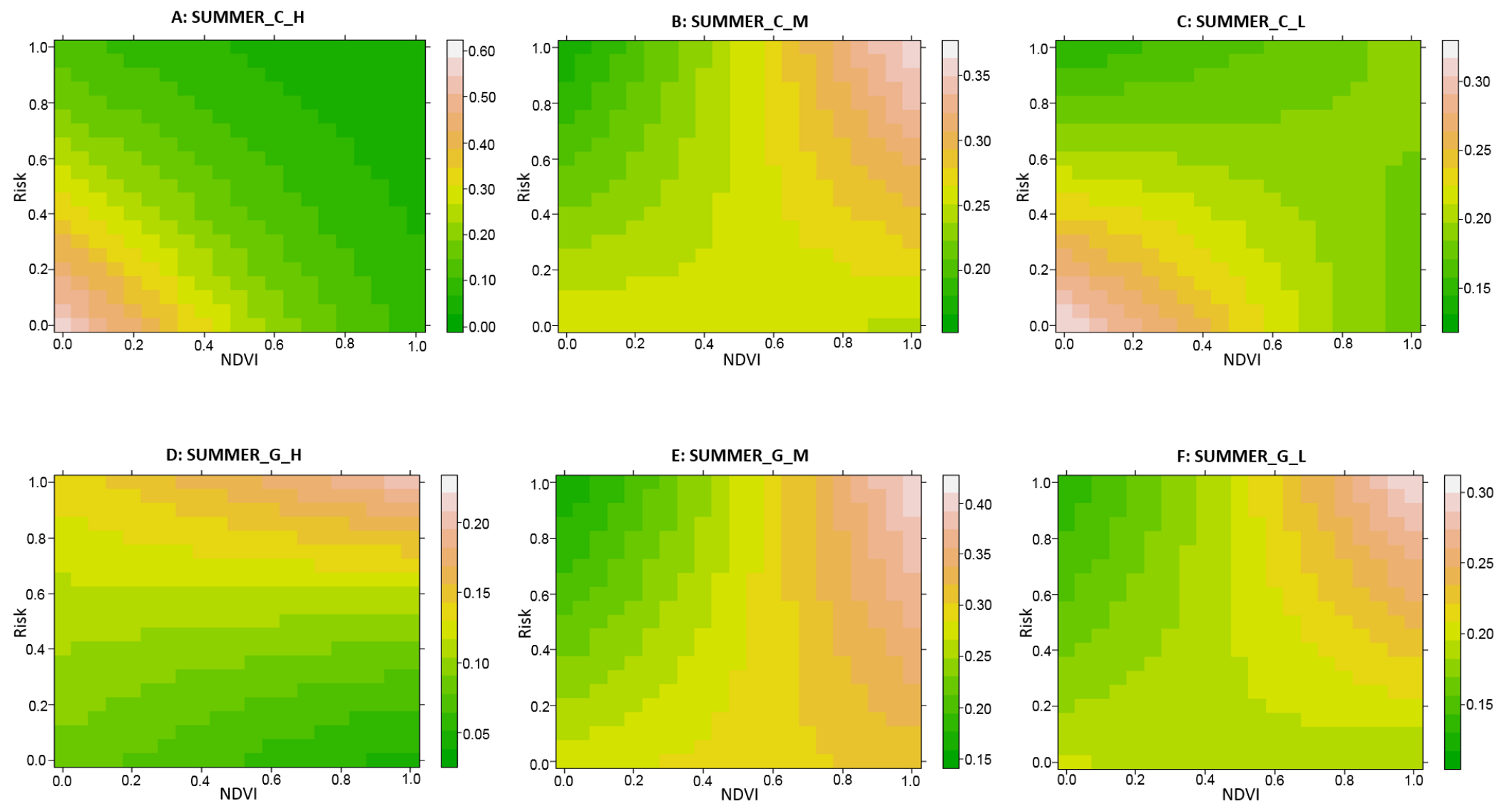

Figure 4.6: Level plots illustrating probability of selection as an interaction of NDVI and risk during summer for female migratory black-tailed deer in the Mendocino National Forest between 2004 and 2013. A-C Illustrates the effect of including spatial familiarity (High, medium and low) on the NDVI-risk trade-off in conifer forest and D-F Illustrates the effect of including spatial familiarity (High, medium and low) on the NDVI-risk trade-off in grassland. *Note different scales on the probability axes of the plots. 


\subsubsection{Winter}

Although the mean step lengths of individuals were shorter in winter than summer, the selection of resources at the step ends closely approximated results for summer. Like summer, the step endings in winter also showed that BTD avoided steps into areas associated with high risk of predation and high NDVI values and a trade-off between predation risk and forage availability was evident from the winter models (Tables 4.3, 4.4, and 4.5, Figure 4.7a).

In winter also, inclusion of familiarity in the trade-off model revealed familiarity as an important variable. The model showed that BTD were more likely to step into areas with high and medium familiarity over low familiarity (Table 4.4). The two-way interaction between familiarity and NDVI indicated preference of BTD towards higher NDVI in familiar areas when vegetation type was unaccounted for in the model (Table 4.4, Figure 4.7b-d). Similar to summer, the interaction between risk and familiarity revealed an increase in probability of using riskier areas with increase in spatial familiarity (Table 4.4, Figure 4.7b-d).

The most complex trade-off model including vegetation and familiarity revealed that the selection towards risk and NDVI varied when they interacted with familiarity and vegetation types (Table 4.5). In winter, the interaction between NDVI and vegetation type demonstrated that BTD consistently stepped into areas with lower NDVI across all vegetation types as compared to conifers (Table 4.5). But the interaction between risk and vegetation type, like summer, showed a higher probability of stepping into riskier areas when they were in open habitat like grassland. The threeway interactions between NDVI, vegetation type, and familiarity, and risk, vegetation type, and familiarity further revealed the differential pattern of balancing risk and 

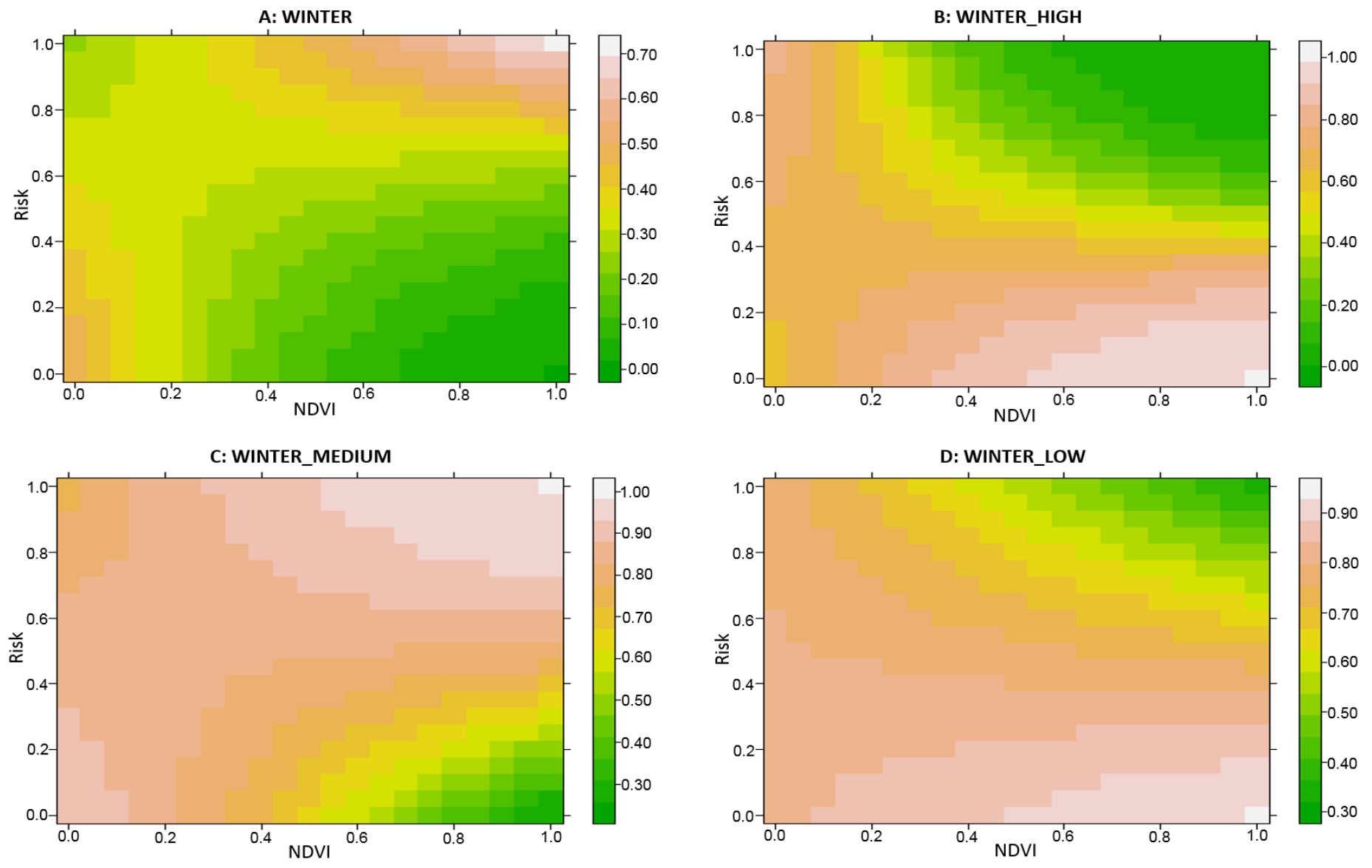

Figure 4.7: Level plots illustrating probability of selection as an interaction of NDVI and risk (A). B-D Illustrates the effect of including spatial familiarity (High, medium and low) on the NDVI-risk trade-off during winter for female migratory black-tailed deer in the Mendocino National Forest between 2004 and 2013. *Note different scales on the probability axes of the plots. 

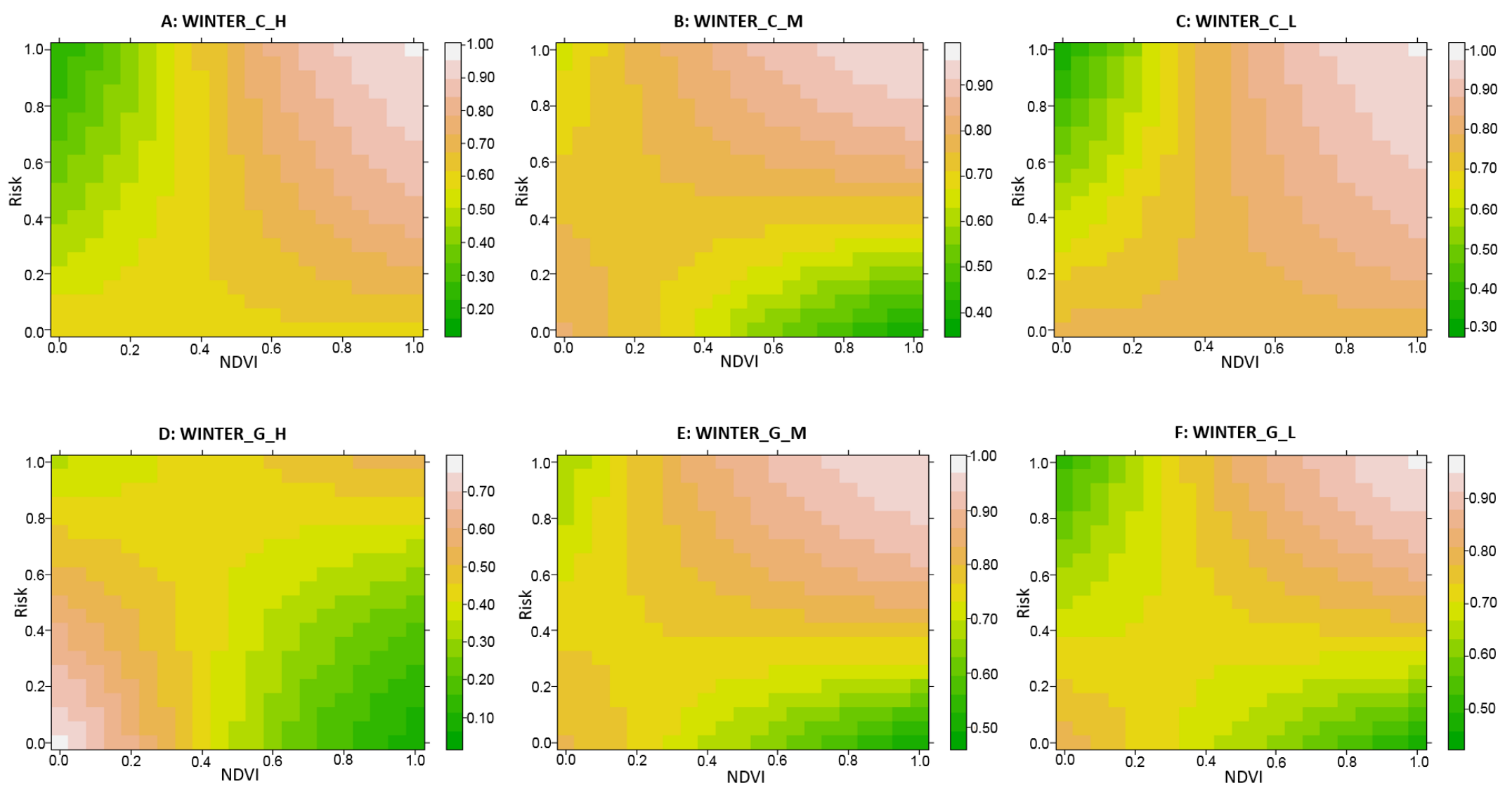

Figure 4.8: Level plots illustrating probability of selection as an interaction of NDVI and risk during winter for female migratory black-tailed deer in the Mendocino National Forest between 2004 and 2013. A-C Illustrates the effect of including spatial familiarity (High, medium and low) on the NDVI-risk trade-off in conifer forest and D-F Illustrates the effect of including spatial familiarity (High, medium and low) on the NDVI-risk trade-off in grassland. *Note different scales on the probability axes of the plots. 
forage acquisition in wintering habitat with varying spatial familiarity and resulted in complex trade-off patterns (Figure 4.8a-f).

\subsubsection{Step selection patterns of non-migratory BTD}

The movement patterns of non-migratory female BTD differed significantly from the migratory BTD. The association between familiarity and time of the day, though significant for non-migratory BTD $\left(\chi_{d f=8}^{2}=101.17, p=0.001\right)$, was less pronounced across the day as compared to migratory BTD (Figure 4.9).

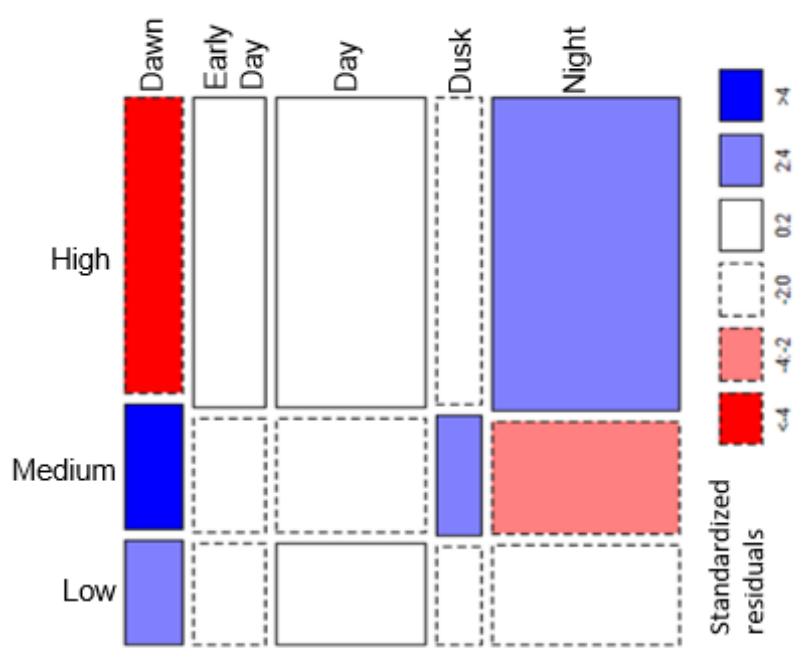

Figure 4.9 Association between time of the day and use of areas with spatial familiarity for non- migratory black-tailed deer in the Mendocino National Forest, California, between 2004 and 2013.

Non-migratory BTD, like migratory BTD, also avoided stepping into areas with high NDVI but the avoidance towards areas with high risk of predation was much weaker as compared to the results during both summer and winter for migratory deer (Tables 4.3, 4.4, and 4.5). For non-migratory BTD, significant risk-forage trade-offs were only evident in the simplest NDVI-risk trade-off model (Table 4.3; Figure 4.10a). 
The trade-off model including familiarity showed that unlike migratory BTD, familiarity was non-significant on its own (Tables 4.4 and 4.5) for non-migratory BTD but was retained in the models because it was part of significant higher interactions with NDVI and predation risk (Table 4.4) that resulted in differential risk-forage tradeoff patterns (Figure 4.10b-d). Like migratory BTD, the interaction between NDVI and familiarity revealed an increased likelihood of non-migratory BTD to step in high NDVI areas with increasing familiarity but interestingly, the interaction between risk and familiarity showed affinity of BTD to step into riskier areas with decreasing familiarity (Table 4.4). The complex trade-off model including familiarity and vegetation type revealed differential pattern of risk- forage trade-offs but shifts in patterns were weaker across familiarity and vegetation types when compared to migratory BTD (Table 4.5, Figure 4.11a-f). 

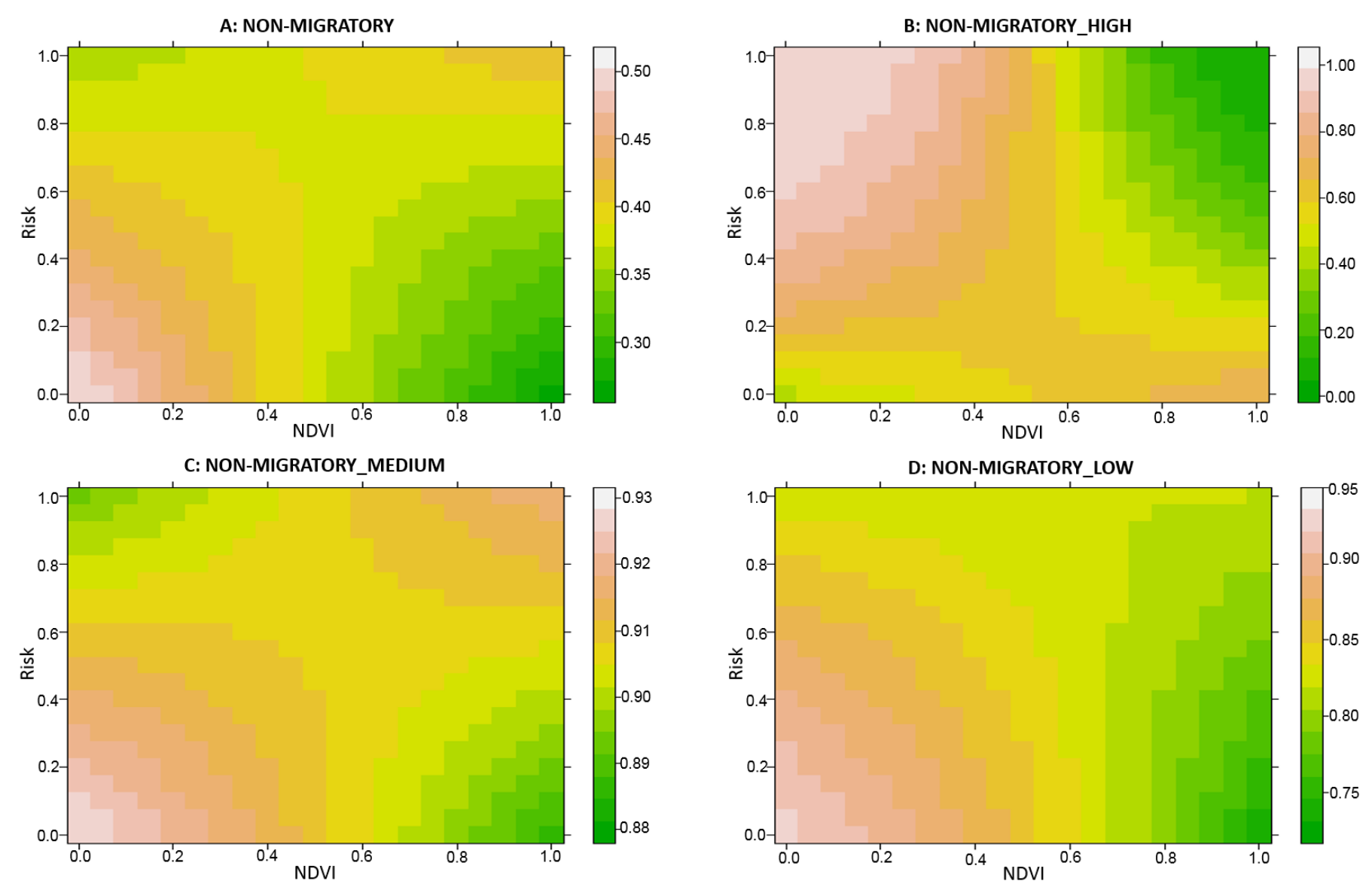

Figure 4.10: Level plots illustrating probability of selection as an interaction of NDVI and risk (A). B-D Illustrates the effect of including spatial familiarity (High, medium and low) on the NDVI-risk trade-off for female non-migratory black-tailed deer in the Mendocino National Forest between 2004 and 2013. *Note different scales on the probability axes of the plots. 

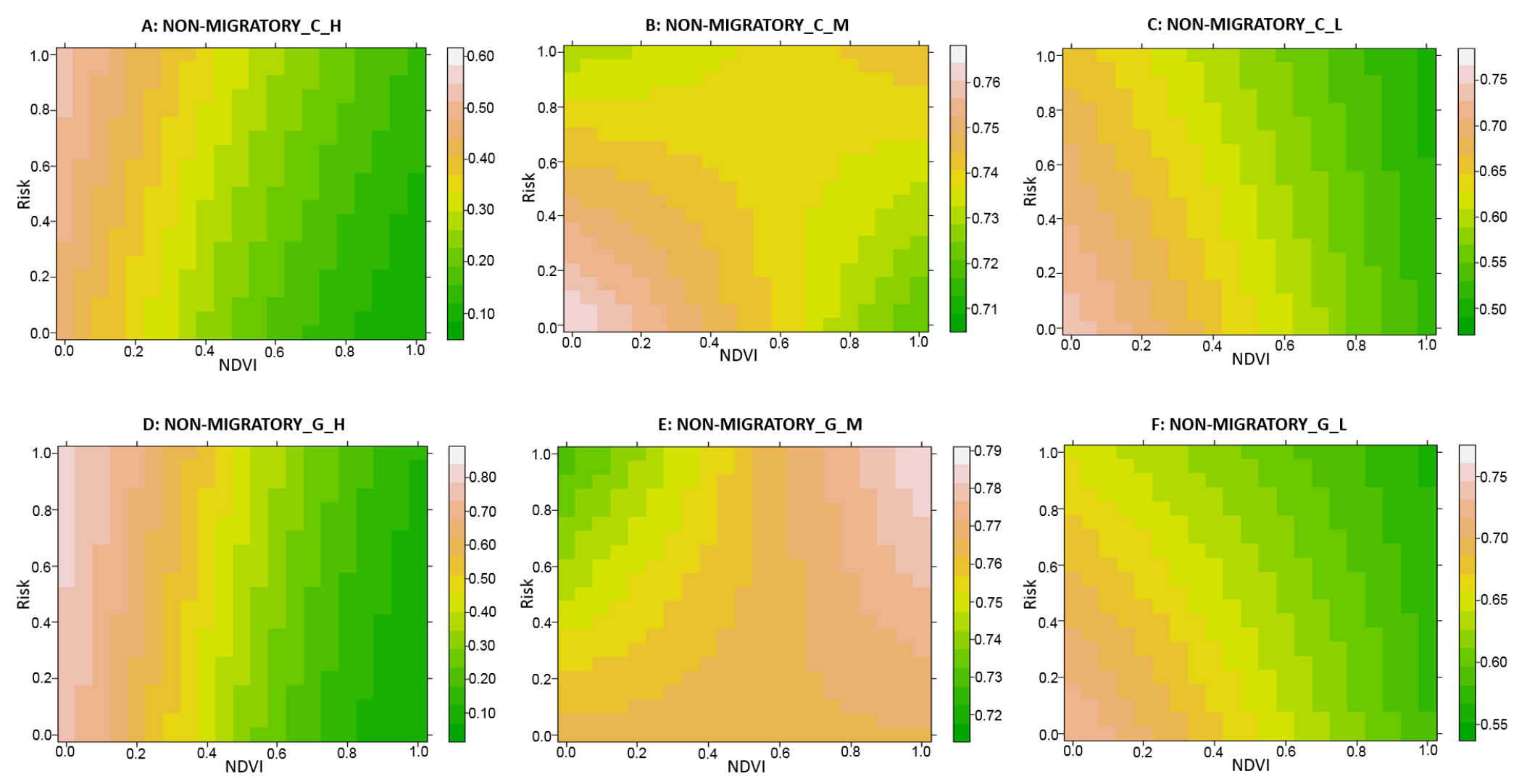

Figure 4.11: Level plots illustrating probability of selection as an interaction of NDVI and risk for female non-migratory black-tailed deer in the Mendocino National Forest between 2004 and 2013. A-C Illustrates the effect of including spatial familiarity (High, medium and low) on the NDVI-risk trade-off in conifer forest and D-F Illustrates the effect of including spatial familiarity (High, medium and low) on the NDVIrisk trade-off in grassland. *Note different scales on the probability axes of the plots. 


\subsection{Discussion}

I used step selection functions to evaluate how female BTD balance trade-offs between food acquisition and predation risk in a heterogeneous landscape with respect to spatial familiarity. Results based on GPS locations of female BTD and a refined movement model with matched availability design revealed that, in a dynamic landscape, female BTD do not move randomly in space. Rather, BTD movement is governed by forage availability, predation risk, and spatial familiarity, with selection varying over the time of the day. The interaction of vegetation type with familiarity, NDVI, and risk helped to unravel some of the underlying behavioural motivation behind selection of steps by female BTD and revealed that site familiarity plays an important role in habitat selection by an ungulate in a heterogeneous landscape. The fact that site familiarity affects habitat selection and alters trade-off pattern in ungulates is both novel and critical to understand how prey species balance foraging needs and predation risks across stages of decision making to improve fitness.

The movement analyses revealed that steps of BTD ended disproportionately more often in areas with lower NDVI values. High NDVI values indicate better availability of green herbaceous phytomass or productivity (Pettorelli et al. 2006); selection towards low NDVI value thus indicated that female BTD selected areas with low forage availability. This was contradictory to previous movement analyses on ungulates (Sawyer and Kauffman 2011, Killeen et al. 2014) where movement was directed towards areas with high NDVI values. The conflicting finding of this study is likely due to the use of raw NDVI values as the predictor variable in the analysis as opposed to Enhanced Vegetation Index (EVI; Boegh et al. 2002, Huete et al. 2006) or Soil Adjusted Vegetation Index (SAVI; Huete 1988). Raw NDVI tends to saturate in 
dense canopy areas and produces very high NDVI values (Myneni and Williams 1994, Huete et al. 1997). On the other hand, in areas with low vegetation cover or for vegetation close to the ground, raw NDVI captures the background reflectance from soil and produces a lower NDVI value for the pixel (Huete 1988, Huete et al. 1997). The raw NDVI value thus gives a relative idea about the phytomass present and also reflects the vegetation cover, especially canopy cover in a pixel (Montandon and Small 2008). As very high NDVI values in a densely forested area may not necessarily offer sufficient forage due to poor undergrowth (Falińska 1973, Myneni and Williams 1994), the study individuals generally avoided areas with very high NDVI. However, the selection towards low NDVI was inconsistent, and the step selection of BTD revealed preference towards higher NDVI in high familiarity areas and lower NDVI in low familiarity areas. The findings likely indicate that BTD avoided close canopied dense forested areas to access better forage and have greater visibility in low familiarity areas while foraging. Conversely while resting in high familiarity areas, their preference were moderate canopy cover.

Different vegetation types have different NDVI values that vary with season due to different canopy structure (Falińska 1973, Gamon et al. 1995, Carlson and Ripley 1997) and altered plant stoichiometry (changes in C : N : P ratios; Moe et al. 2005). For example the NDVI value of oak changes significantly across the year with the value peaking to 0.8 in high canopy areas during spring and summer, whereas in riparian areas it has a very low NDVI signature year round due to lower canopy cover and its proximity to water (Gamon et al. 1995). Thus, it is important to factor in the difference in NDVI values of different vegetation types while accounting for forage availability in an area. In addition, different plants produce varying amounts of energy on digestion (Mattson Jr. 1980, Cook et al. 2016), and BTD may engage in risky 
behaviour to obtain forage that yields more energy on digestion according to the optimal foraging theory (Krebs 1980, Bergman et al. 2001). The step selection of female BTD thus aptly revealed the differential selection towards NDVI that varied largely across vegetation types and showed movement towards areas with higher NDVI in foraging habitats like grassland and shrubs and lower NDVI in resting habitats like conifers and oaks (Bunnell 1990).

The movement analyses of female BTD showed that individuals tend to avoid high-risk areas, especially if familiarity with the area is low (Figure 4.5 and 4.7). The result is consistent with the hypothesis that BTD will only step in high risk areas where they have high spatial familiarity, which may allow them to both avoid and escape predators (Clarke et al. 1993). The avoidance of risk in areas with low familiarity was particularly strong for migratory BTD, especially in summer when puma kill rates in the study area were highest due to kleptoparasitism by black bear (Allen et al. 2015). Further, migratory BTD showed variation in their use of familiar areas with the time of day (Figure 4.4). The increased use of familiar areas was associated with the time of the day when BTD usually rest or ruminate. Resting is considered the most dangerous activity that BTD engage in because of reduced vigilance at that time (Lashley et al. 2014). Since BTD incur low travel costs within their small seasonal home ranges, they tend to move to more familiar areas to rest in the safer habitats as an anti-predatory behaviour, especially during night-time hours when pumas are more active (Sweanor et al. 2008).

The finding that BTD used open habitat significantly more in unfamiliar areas was evidence that habitat type also plays an important role in anti-predator response. In unfamiliar areas, where the spatial memory of refuges is low, BTD used more open 
habitat likely to increase their visibility to have a greater chance to escape pumas. The result was in agreement with previous studies which demonstrated that open habitats like grassland, while providing sufficient forage, can also offer the additional benefit of carrying a diminished risk of predation by ambush predators (Hornocker 1970, Murphy 1998, Kunkel and Pletscher 1999). The result was also congruent with the previous chapter on resource selection (Chapter 3), where BTD were more likely to occur in habitats characterized by open canopy and younger vegetation while active and foraging and use areas with denser vegetation near the edges while resting. The increased use of open grassland, which provide low quality but sufficient forage and low risk, suggests an adaptive trade-off response in BTD; appropriate for prey species cohabiting a heterogeneous landscape with only ambush predator like pumas.

The migratory female BTD in the study area were likely exposed to higher risk from puma predation in their use of seasonal ranges than the non-migratory BTD, as the pumas in the study area follow the altitudinal movement of migratory BTD (Allen et al. 2014). The locations in seasonal ranges with higher phytomass were thus mostly associated with higher risk of predation (Figure 4.2), which was highest in summer (Allen et al. 2014). The selection of steps in low familiarity areas in summer was thus surprising, but can be explained by the use of medium to low familiarity areas during longer days for greater forage intake in order to meet physiological needs (Parker et al. 2009).The step selection analysis revealed that the steps of migratory BTD were carefully chosen based on the spatial and temporal variation in risk during summer, and the general pattern of simple risk-forage trade-off could be decomposed into underlying mechanism of step selection by inclusion of familiarity. The inclusion of familiarity significantly changed the trade-off pattern and revealed how different riskforage combinations are selected across different familiarity zones. The use of low to 
medium NDVI areas in highly familiar zone probably reflected the use of open areas associated with resting during night to have visual advantage over pumas (Smith et al. 1986). As medium and low familiarity areas were associated with foraging and ruminating during the day, a shift towards areas with higher NDVI was detected with BTD venturing into high risk areas in medium familiarity zone. Furthermore, introduction of vegetation type revealed switching between habitats based on activity that allowed female BTD to benefit from lower risk of predation especially while resting. The analysis showed that in open vegetation such as grassland, which is a preferred foraging habitat during summer (Wickstorm et al. 1984, Bunnel et al. 1990), they always prefer to step in high NDVI areas irrespective of the risk. However, in canopied vegetation such as oak and conifer which are associated more with resting cycles (Bunnel 1990, Germaine et al. 2004), BTD preferred to step into low canopy areas with less ground vegetation in high and low familiarity areas. This may presumably have been to gain visual advantage over pumas, while using higher canopy cover areas when in medium familiarity zone, most likely while ruminating during the day for thermoregulation.

Similarly for winter, the simple forage-risk trade-off was evident but the probability of step ends shifted more towards the high-risk-high-NDVI areas, most likely due to lower predation rates and higher need for canopy cover during winter. Decoupling of the simple trade-off, first by introducing familiarity revealed that how in winter, BTD chose high NDVI low-risk areas in high and low familiarity zones. Conversely, in moderately familiar areas, steps more often ended in sites with high NDVI and high-risk. The observation was in agreement with findings from the previous chapter on resource selection (Chapter 3), which hints at higher use of areas with good vegetation cover to provide thermoregulation (Bunnell 1990, Mysterud and 
Ostbye 1999). In winter, since BTD spend more time resting (Bunnell 1990), the high probability of use of high-NDVI and low-risk areas in highly familiar zones was unsurprising. The inclusion of vegetation type further unravelled the behavioural motivation behind selection of step by BTD in a multi-predator landscape. The consistent choice of high-risk-high-NDVI areas for coniferous vegetation underscores the need for BTD to prioritize movement responses towards higher cover during winter. Further, the diffused signature of probability of use in medium and low familiarity zones shows that BTD also use more open coniferous forest in winter, albeit in lower proportions for foraging during the daytime.

In contrast, non-migratory BTD displayed inconsistent responses to spatial and temporal variation of risks showing little shift in pattern when risk-forage trade-off was considered. The non-migratory female BTD included in this study mostly had home ranges in mid- to low-elevation areas in younger forested areas (see Chapter 3 on resource selection) closer to the campgrounds (unpublished data). Maintaining annual home ranges in high forage areas with increased anthropogenic disturbances may have disrupted the predator-prey dynamics and created a low-risk-high-forage refugia for migrant BTD, as established by previous studies on ungulates (Berger 2007, Hebblewhite et al. 2005). The refugia hypothesis thus supports the lack of pattern in selection of familiar areas with the time of the day for non-migratory BTD, as they would not have to make fine-scale trade-offs with spatial variation in predation risk, which were significantly lower on these annual ranges. Surprisingly, the selection of steps by non-migratory BTD even in the presence of low risk was largely directed towards low to moderate phytomass (Figures 4.10 and 4.11). This was most likely because non-migratory BTD would need to spend more time actively foraging as the forage quality at lower elevations is poorer compared to the ridgetops during spring 
and summer. The higher number of foraging steps could have shifted the selection towards open to moderate vegetation cover, which is consistent with ungulate use of open areas for foraging (Bunnell 1990, Skovlin et al. 2002). Alternatively, use of open areas with low to moderate cover areas is also linked to increased vigilance in ungulates as a response to increased human presence (Jayakody et al. 2008). By using low cover areas while foraging, the individuals could also increase their vigilance without spending additional energy on movement. Thus, the consistent usage of areas with low vegetation cover in both open and closed vegetation types (even in low predation risk zones), was likely the outcome of complex trade-offs associated with BTD residing in the vicinity of increased human activity.

The results of this study should be interpreted in the light of the study's limitations. First, because of the limited ways of evaluating spatial familiarity from telemetry data, I assessed the familiarity based on kernel density estimate of the telemetry locations (Morse et al. 2009, Tumenta et al 2013). This resulted in dependent and independent variables being derived from the same telemetry data which could have introduced circularity in the model (Gould 2001) with potentially biased results for selection towards high familiarity areas. However, this bias is not reflected in the results possibly due to the difference in the scale of sampling, as the BTD in the system had very small step lengths and familiarity was assessed at landscape scale. In addition, the risk layer used in the study was developed from the BTD kills by pumas. Evaluating risk from kill sites is an established method of identifying spatial risk (Kunkel and Pletscher 2000, Blake and Gese 2016) but relative probability of encounter can also enhance the perceived sense of risk in the prey (Hebblewhite et al. 2005). The probability of predator-prey encounter is largely dependent on the temporal and spatial density of predator in the study system. As the 
pumas in the study area were only monitored for two years towards the end of the BTD monitoring, I had to develop the risk layer by extrapolating the results of kill site selection by puma. This may have led to under sampling risk for the study area due to the non-inclusion of puma encounters that did not result in successful kill. Finally, NDVI is used as a proxy for forage availability in this study. NDVI is an excellent measure of resources for ungulates (Pettorelli et al. 2006; Hamel et al. 2009) and a good predictor for movement (van Beest et al. 2011; Pettorelli et al. 2011). However, at very fine spatial scales, measures of NDVI may not adequately reflect quality/quantity of forage due to confounding effects associated with snow and/or canopy cover (Sawyer et al. 2005; Pettorelli et al. 2006; Wilcove \& Wikelski 2008). Hence, canopy cover and vegetation type were used as additional predictor variables in the model and data modelled separately for summer and winter, to offset the potential biases resulting from the use of just NDVI values as a proxy for forage availability.

Trade-off between forage and predation risk in ungulates is a complex process governed by multiple factors and is central to our understanding of behaviour and resource selection in prey species (Lind and Cresswell 2005; McNamara and Houston 1986). Recent empirical studies have shown how physical, physiological and spatial variables affect trade-off in a migratory ungulate (Boyer and Walsh 2010, Fagan et al. 2013). Despite the limitations, this is one of the first few studies that have used physical and spatial variables together in a phenomenological model to try and understand step selection by a medium-sized ungulate in a heterogeneous landscape. The use of matched step availability in my movement model offered an improvement over the random availability model by restricting availability to areas that are potentially usable by an individual on the basis of its movement decisions. By 
modelling availability in a space-time continuum, the present study has revealed the selection process occurring at a specific level, clarifying inferences about the motivation behind selection of steps. The study also provided a nuanced understanding of how female BTD handle food versus safety trade-offs across different levels of selection. Understanding the drivers of anti-predator responses and the efficiency with which BTD trade-off food versus safety is vital as anti-predator behavioural modification can have profound consequences on fitness, and ultimately, population dynamics of ungulates (Gaillard et al. 2010). Such understanding is crucial to the study of the distribution and social organization of species, and can help direct conservation and wildlife management efforts (Moorter et al. 2013). 
Chapter 5

General Discussion 


\subsection{Introduction:}

Maintaining a long-term stable population of migratory ungulates in a fragmented landscape largely depends on active management of the local populations and their habitats (Gordon et al. 2004, Appollonio et al. 2010). But the effectiveness of the conservation efforts made by managers is dependent on the scale at which they need to target plans for habitat management (Gordon et al. 2004). So, the central aim of my thesis was to identify the spatial and temporal scale that may affect habitat selection, movement, and ultimately fitness of individuals in a declining population of blacktailed deer (BTD, Odocoileus hemionus columbianus) in the Mendocino National Forest, California (Marescot et al. 2015). The three chapters comprising this research provide insight into how patterns of habitat selection and movement in BTD can be perceived with the changing scale of study and thus highlight the importance of considering spatial and temporal resolution and scale when developing management strategies. Here, I provide a summary of the findings of each research chapter and then discuss their implications on conservation and management of BTD in a managed multi-use landscape.

\subsection{Chapter Overviews}

\subsubsection{Chapter 2: Implications of fidelity and philopatry on the population structure} of BTD

Population dynamics in ungulates is largely derived from females (Gaillard et al. 2000, Forrester and Wittmer 2013). As a consequence, it is of utmost importance to understand the extent of dispersal and mixing of adult females among adjacent 
population to assess the spatial scale of study and have an accurate estimate of population growth $(\lambda)$. Medium-sized ungulates such as mule and black-tailed deer have been known to show extreme fidelity to their seasonal ranges with directly correlated fitness benefits (Forrester et al. 2015, Bose et al. 2017). Coupled with high fidelity, BTD also display sex-biased dispersal, where only the juvenile males disperse while the females are recruited into the same social group (Bunnell and Harestad 1983). As a result of this high fidelity, and philopatric behaviour, female BTD may get trapped in smaller matriarchal units as a subset of the larger population (Coulson et al. 1999). This would in effect drive the local population dynamics of female BTD at a much smaller spatial scale, rather than the assumed larger population scale consisting of many matriarchal units. Hence in Chapter 2, an integrative approach was used to explore the consequences of fidelity and philopatry on the fine-scale genetic structure in BTD population within the study area. Fidelity was assessed from long-term telemetry data and philopatry was ascertained from mitochondrial DNA (mtDNA) haplotypes extracted from tissue samples.

The results demonstrated that strong site fidelity and sex-biased philopatry can affect population structuring and dynamics at a much finer scale than previously established in BTD. The pattern of low-level gene flow, as evidenced by the occurrence of few representative mtDNA haplotypes in each ridge, reflected the high levels of philopatry and very low female movement between adjacent subpopulations (matriarchal units). This contradicted the assumption of panmixia within the study area, which would consequently expose each subpopulation to increased risk of demographic isolation with locally varying vital rates. In effect, the findings highlight the need to target matrilineal groups as the basic unit of conservation and management, particularly in ungulate populations such as BTD where fine scale population 
structuring as a consequence of fidelity and philopatry occurs. The importance of considering BTD matrilineal units in conservation planning is all the more relevant due to the ever-pressing risks of demographic contracting and stochastic environmental events which could lead to loss of unique locally adapted alleles, and potentially slower recolonization of the areas due to low female dispersal, high adult and fawn mortality, and overall declining population (Albon et al. 1992).

\subsubsection{Chapter 3: Effect of activity states on fine-scale habitat selection patterns of BTD}

Temporal scale is an important component in understanding the fine-scale habitat selection of ruminating ungulates as changes in temporal resolution can affect inferences on habitat selection patterns, thereby directly impacting management decisions (Ager et al. 2003, Godvik et al. 2009). Ruminating ungulates undergo short foraging period followed by rumination and resting (Green and Bear 1990, Ager 2003). For enhanced fitness, the short-term forage-rest-forage cycle requires them to have access to both foraging and resting habitats within their small seasonal home ranges. Chapter 3 was focused on comparing habitat characteristics selected by BTD from a pooled model (all telemetry locations pooled across activity states) with habitat characteristics associated with foraging and resting. The identification of activity specific habitat characteristics was critical for detecting lesser-used habitats associated with particular activity states.

Ungulates have evolved strategies to minimize foraging time (rumination, selecting high quality forage) in order to minimize energy expenditure and maximize increase fitness (Kie 1999, Bergman et al. 2001). Due to larger proportion of resting and ruminating locations, the pooled model mostly failed to identify critical foraging 
habitats and predominantly reflected habitats associated with resting. The frequent misidentification for important ecological covariates associated with foraging was a testimony that pooling data across activity states for a ruminating ungulate like BTD can negatively impact our understanding about habitat selection by the species. As the results of resource selection studies are applied for species and land management, it is imperative for estimates to be robust, and lesser-used important habitats to be appropriately characterized for survival and fitness of species. This study thus highlights that by modelling the impact of behaviour within resource selection estimates, somewhat mechanistic perspectives on species-habitat relationships can be obtained for the development of conservation and management initiatives with better efficiency.

\subsubsection{Chapter 4: Trade-offs between forage and predation risk as a function of landscape familiarity}

Movement is the central theme of behavioural ecology. Prey species such as BTD show altered behaviour and adaptive movement choices in response to the presence of predators, which reflect trade-offs between forage and risk to increase individual fitness (Creel et al. 2005, Frair et al. 2005, Hebblewhite and Merrill 2009). Effective conservation and management of ungulate species thus needs a mechanistic understanding of the ways in which extrinsic and intrinsic factors alter movement patterns and influence habitat selection (Johnson et al. 2002b, Bolger et al. 2008). Chapter 4 was aimed at developing a movement model to assess the effect of matched step availability in the model. The finding from Chapter 2 that site familiarity positively affects individual fitness was used to derive a familiarity matrix, which was incorporated in the movement model to test for variation in trade-off patterns with 
varying levels of familiarity. The matched case step-selection further offered an improvement over the random availability model developed in Chapter 3 by restricting availability to areas that are potentially usable by an individual on the basis of its movement decisions.

By modelling availability in a space-time continuum, this study revealed the selection process occurring at a specific level, clarifying inferences about the motivation behind selection of each step. The analyses demonstrated that familiarity affects the trade-off patterns by BTD in a heterogeneous landscape. The complex nature of trade-off also varied with the time of the day, with BTD selecting highly familiar areas for resting at night and dawn, and less familiar areas during the day. This is likely an adaptive response to avoid predation by an ambush nocturnal predator like puma (Currier 1983, Sweanor et al. 2008), their only predator in the landscape. The demonstrated preference for familiar locations during resting within home ranges emphasize that spatial familiarity is important not only for large scale processes such as selection of home range, but also for smaller scale habitat selection associated with foraging and resting. Understanding the fine scale selection that affects efficient riskforage trade-off is important to gain a better insight into adaptive behavioural responses of BTD to perceived sense of risk and can have vital consequences on fitness, and ultimately, population dynamics of this species (Gaillard et al. 2010).

\subsection{Conclusions}

Population-level patterns in demography and distribution are influenced to some degree by behavioural processes and mechanisms that drive habitat use and occupancy. For my dissertation I tried to identify the spatial and temporal scale and behavioural motivation for habitat selection by female BTD surviving in a multi-use landscape. 
Overall my study took important steps towards unravelling the behavioural motivation behind fine scale habitat selection and how that can impact current understanding of BTD demography and distribution.

Female ungulate populations have often been considered to be spatially homogeneous in a continuous landscape due to their dispersal ability. So there is a general paucity of work on small-scale spatial dynamics within populations and demographic components such as natality, survival, and mortality have often been correlated with intrinsic population data on total density or age structure (Marescot et al. 2015). However, my results from Chapter 2 suggest that female BTD are organized in exclusive matrilineal groups which rarely disperse due to positive fitness consequences associated with fidelity, eventually leading to substructuring within a population. This substructuring can cause small-scale variation in estimates of population growth $(\lambda)$ which can affect the local age structure and density.

Studies have shown that animals disperse when density becomes high to avoid intraspecific competition (Bowler and Benton 2005). In BTD, where familiarity has direct fitness benefit, an individual dispersing into a new area may be affected by reduced survival probability. To disperse into a new area, an individual first needs to acquire a new spatial map of forage availability and predation risk to effectively strike a forage-risk trade-off (Wolf et al. 2009). Additionally, as BTD form female social groups (Dasmann and Taber 1956), an individual will also need to establish its position in an existing dominance hierarchy. Previous studies on ungulates have shown that dominant females or matriarchs get access to better foraging habitats (Taillon et al. 2006). Thus, unless an individual has prior knowledge of the area that it is dispersing into, it may disperse into a poorer unfamiliar habitat than it was in prior to dispersal. 
Thus the cost of staying put in a familiar area with lower forage availability may outweigh the cost of moving into an unknown area with uncertain access to better forage. In the long run, this high fidelity behaviour would eventually lead to increasing the density of individuals in an area.

Due to the uncertainty and fitness consequences associated with dispersal, population density can vary between adjacent areas depending on group size of the matrilineage occupying the area. The population growth rate $(\lambda)$ can thus be affected by local population density which affects breeding by female yearlings (McCullough 1997). Breeding in BTD typically occurs under low population density. When populations of BTD reach moderate to high densities and nears the carrying capacity, due to constraints on forage availability, female fawns do not reach sexual maturity until one year of age, and produce offspring only in their second year (McCullough 1997). Moreover, Allen et al. (2014) have previously established that pumas in the study area exhibit a functional response to the increase of prey abundance and density. Allen (2014) observed that in areas with high BTD density, pumas increase their kill rates during the summer months that coincides with the birth pulse exhibited by BTD. This may be because in high density BTD areas, fitness of younger females accompanied by fawns may be severely impaired due to lack of forage and suitable cover that interferes with their complex trade-off strategies. Thus in high density BTD habitats, where the natality is already lowered by delayed maturation of juveniles, an increased mortality of fawns due to predation may severely affect population recruitment, resulting in reduced population growth rate. So, vital rates of the demographically isolated matrilineages will vary locally with varying density and forage availability which is observed by differential fawn survival between these two subpopulations in Mendocino (Marescot et al. 2015). 
Besides these top-down (predation) and bottom-up effects (forage availability) that affect BTD population dynamics and survival, other disturbances like habitat degradation due to anthropogenic activities may further hinder the population growth rate. National Forests such as Mendocino are also used for harvesting natural resources like timber. Timber extraction though largely regulated now, had been extensively carried out in the past decades. The past silviculture practices in the Mendocino National Forest have created vast areas of homogenous coniferous forest stands and exotic grasslands. However, these vast expanses of homogenous forest patches are unsuitable for BTD which need an optimum mix of cover and forage within a small spatial extent to increase their fitness (Chapters 3 and 4).

BTD, like white-tailed deer form matriarchal groups primarily consisting of female offspring and siblings (Mathews 1989, Porter et al. 1991, Kie and Czech 2000). The spatial orientation of individuals within these social groups is analogous to rose petals as the older (presumably dominant) females occupy a home range that is at the centre of the group, with younger individuals occupying home ranges that overlap and extend outward. Thus, with increasing group size, BTD gradually expand into nearby areas. If the periphery of group range approach homogenous or unsuitable habitat, the females on the outer zone may reduce their home range size as moving into an unsuitable habitat may severely limit the survival probability against predators (Forrester et al. 2015). This would in effect place constraints over BTD forage availability, affecting the fitness of younger individuals that are within reproductive age and may be accompanied by fawns.

Further, due to dry summers, Mendocino witnesses frequent forest fires (Safford and Van de Water 2014). Stochastic and natural events like wildfires can 
negatively affect the familiar seasonal ranges occupied by BTD matrilineages. Fire significantly increases vulnerability of BTD to heightened mortality risks by not only reducing net forage availability, but also by altering the spatial map of the occupied range (Cherry et al. 2018), or displacing individuals to an unfamiliar habitat. Regeneration of forest habitat with adequate assemblage and complexity of cover and forage species takes a long time. Under such conditions, BTD are forced to utilize adjacent forest patches. If these patches are homogenous due to anthropogenic activities, BTD are further disadvantaged by lack of forage (homogenous conifer strands) or lack of cover (exotic grasslands). Thus an entire group of BTD can face increased risk of predation over a relatively short period of time, due to lack of habitat heterogeneity (appropriate forage and cover species) to strike a trade-off between foraging and predation risk.

The results of my study highlight the importance of ecological patterns and scales in studying population dynamics of ungulates, particularly for species conservation in dynamic multi-use managed landscapes. The identification of small spatial displacement of BTD and very small seasonal home ranges of the study individuals which have positive fitness consequences associated with familiarity underscores the need to manage resources at a spatial scale comparable to the size of their home ranges. Given the complex trade-off pattern that BTD exhibits, it is of vital importance for resource managers to maintain a mosaic of habitat types, as traditional large scale homogeneous habitat enhancements can be detrimental for sustaining BTD in a multi-predator system. Besides small scale habitat management which is required to provide individual BTD with suitable habitat, the results also imply that current land management decisions need to factor in patterns beyond individual home-ranges. This is more so as BTD matrilineal groups at Mendocino National Forest are 
demographically isolated and largely driven by localized habitat conditions and density.

In conclusion, by modelling movement patterns and habitat selection at multiple spatial and temporal scales I was able to obtain an improved understanding of key intrinsic and extrinsic dimensions of resource selection that can affect habitat use and fitness of individuals. Further, as habitat selection and movement are inherently linked, the use of a mechanistic movement model to model telemetry data with familiarity matrix helped me unravel the complex behavioural motivations behind habitat use in the species. My study thus provides a unique perspective for managing a declining deer population in a human-dominated landscape and highlights the influence of individual patterns on population processes.

\subsection{Limitations}

This study was largely conceptualized after the completion of the long-term monitoring project of BTD population in Mendocino National Forest in 2013, and the subsequent accumulation of telemetry data for estimation of vital rates, and population growth (Wittmer et al. 2014). Accordingly, data collection was targeted from deer individuals sampled at the population-wide scale, without specific focus on smaller matriarchal groups. The study was thus limited by the scope of data available at hand and due to this reason, there are a few obvious shortcomings of this dissertation.

The present study has shown that the identification of spatial sub-structuring helps improve our understanding of the dynamics of a population subjected to smallscale spatial differences in demographic vital rates among matriarchal groups. These differences are maintained by trade-offs between availability of suitable habitat within the group range and social and energetic risk of dispersal to a different area. Due to 
lack of telemetry data associated with identified matrilineal groups, I was not able to tie in the performance of localized groups of BTD to indices of habitat use.

Another major limitation of this study is the inability to incorporate female BTD's reproductive status in the habitat selection models due to the lack of information on the life history stage of the collared individuals. The selection of habitat components is known to vary with life-history stages and physiological condition of females, such as during parturition in BTD (Bowyer and Kie 1998). BTD, like other ungulates, are most likely to utilize habitats differently and show different trade-off strategies during different stages of their life history to obtain resources necessary for growth, reproduction, and survival, as well as the needs of their offspring. Through the analysis of GPS movement data from adult female BTD without associated physiological data, I was only able to identify general trade-off patterns and associated behavioural motivation for selection at a coarser scale

Use of biotic and abiotic habitat variables allowed me to explicitly examine forage-risk correlations with familiarity of landscape, and to directly assess and interpret selection for resources. Multiple factors that I have accounted for in the habitat and step selection models like forage availability, cover type, stand age, and predation risk can be affected by short term temporal changes (Polansky and Wittemyer 2011). Since my study was conceived after the project was over, I was solely reliant on using remotely sensed spatial data averaged over larger temporal scale for my study area. While I believe that this approach has allowed me to test for a large number of biotic and abiotic variables, the lack of field validation of the spatial data may have failed to incorporate short term changes in habitat variables and 
inadvertently introduced some errors in this resource-oriented approach to habitat selection thus reducing the inferential power of my models.

Further, in my study system, adult BTD are only preyed upon by pumas while the fawns are additionally preyed upon by coyotes, bobcats and black bears (Forrester 2015). Even though my study primarily revolved around habitat trade-off choices by adult female BTD in a system dominated by a single primary predator, I was not able to discern direct effects of pumas on behavioural decisions by adult BTD alone, versus adult BTD with accompanying fawn. In the latter case, the female BTD is also liable for the safety of the offspring. Whereas solo adults would most likely consider only the presence of pumas towards their decision making strategies, a female BTD with offspring on the other hand would additionally have to take into account the presence of potential other predators of the fawn which may affect their trade-off decision. But due to the low number of collared females with identified fawns, I could not test whether female BTD implement trade-off strategies only to avoid puma predation or whether it perceives the landscape as a multi-predator system.

\subsection{Directions for future research}

Despite the limitations, the results of my study advance our understanding of the habitat selection and ecology of black-tailed deer in northern California. It provides compelling evidence of the consequences of site fidelity and philopatry for conservation and management of black-tailed deer. Future research could advance this knowledge by identifying the fine-scale differences in trade-off strategies and habitat use between varying social groups. Quantifying the costs and benefits of movement between matriarchal groups within a population would help reveal the actual mechanisms that lead to small-scale spatial variation in demographic rates. 
The correlative nature of the study to understand habitat selection of BTD can be significantly improved by acquiring spatial variables measured at short temporal scale as experienced by the species. This will give us a better insight into the decisionmaking process underpinning habitat selection and trade-off strategies by female BTD in a stochastic environment. Additionally, future studies on modelling age structure and physiological condition of BTD in a trade-off model can provide more comprehensive understanding about the varying habitat needs of female BTD and help aid in developing targeted management plans.

In summary to have a better perspective of the competing effects of predation risk and foraging needs on the adaptive behaviour and overall population dynamics of BTD and other ungulates in general, in-depth research is necessary to investigate linkages between vital rates, survivorship and individual fitness of matriarchal groups with habitat resources at multiple scales. Future studies need to focus on the interactive effects between predation risk and forage availability at short temporal scales, as well as the influence of other extrinsic factors that can affect animal behaviour such as climatic stochasticity and anthropogenic disturbances.

\subsection{Management recommendations}

The findings of my study are a testament towards the need for a scale-based integrative approach to achieve a mechanistic understanding of ungulate space use and fitness at multiple scales. My results provide managers with a portion of the baseline information needed to inform BTD habitat management in Mendocino National Forest, California. The major recommendation from this dissertation is to identify the size of the matriarchal groups and habitat conditions associated with their seasonal ranges. This is required as the matriarchal groups operate in relatively discrete 
subpopulation groups with vital rates that are distinct from the overall population. As evidenced by the strong fidelity, small home-range sizes, and high genetic differentiation, it would be relatively easy to identify unique matriarchal groups from telemetry and genetic data. Next, abundance and density estimates would be required for each of the identified matriarchal groups (subpopulations), as the information would aid in estimation of vital rates, fitness, survival and demographic growth specific for each subpopulation. By tying in these key parameters with extrinsic factors on habitat condition and predation pressure, a thorough understanding of the proximate causes underpinning small scale variation in BTD population dynamics can be effectively quantified.

Robust density estimation is necessary for long-term monitoring of the identified subpopulations. This would help in maintaining viable BTD populations that the habitats in the area can effectively sustain. Due to high site fidelity and positive fitness consequences associated with familiarity, female BTD tend to remain in the same natal group. Over time, this clustering would lead to high ungulate density within a small area, resulting in density-dependent feedbacks on natality, population recruitment and eventual negative population growth. By identifying matriarchal groups that are suffering decline due to over population and/or lower nutritional carrying capacity of their habitat (Ballard et al. 2001), site-specific interventions pertaining to habitat conditions can be carried out where required. Further improving the habitat quality of known blocks in winter and summer ranges and their peripheral areas may help to relieve the pressure associated with localized density, by providing females at the outer edge of the 'rose petal' social group with increased access to suitable habitat. So, it is necessary to reduce anthropogenic activities like grazing and 
timber harvesting in and around identified seasonal ranges when evaluating future land development proposals.

In addition to large scale habitat management, my study also emphasizes the fine-scale habitat requirements for BTD in Mendocino that managers need to be aware of. Given the very small seasonal home ranges of the study individuals and fitness consequences associated with high fidelity that affect deer survival, it is critical to manage habitat heterogeneity at a spatial scale comparable to the size of their home ranges. Thus, it is imperative for conservation managers to have a critical understanding of activity specific requirements of BTD so that fine-scale habitat use can be factored in while drawing up a framework for well-informed land management strategies for long-term survival of this population. 


\section{Literature Cited}

Ager, A. A., Johnson, B. K., Kern, J. W., \& Kie, J. G. (2003). Daily and seasonal movements and habitat use by female Rocky Mountain elk and mule deer. Journal of Mammalogy, 84(3), 1076-1088.

Albon, S.D., Clutton-Brock, T.H., Langvatn, R. (1992). Cohort variation in reproduction and survival: implications for population demography. In R. D. Brown (Ed.), The Biology of Deer (pp. 15-21). New York, USA: Springer-Verlag.

Allen, M. L. (2014). The ecology and behaviour of pumas (Puma concolor) in northern California, USA (Doctoral dissertation).Victoria University of Wellington, Wellington, New Zealand.

Allen, M. L., Elbroch, L. M., Casady, D. S., \& Wittmer, H. U. (2014). Seasonal variation in the feeding ecology of pumas (Puma concolor) in northern California. Canadian Journal of Zoology, 92(5), 397-403.

Allen, M. L., Elbroch, L. M., Wilmers, C. C., \& Wittmer, H. U. (2015). The comparative effects of large carnivores on the acquisition of carrion by scavengers. The American Naturalist, 185(6), 822-833.

Allen, T. F., \& Starr, T. B. (1982). Hierarchy: perspectives for ecological complexity. Chicago, USA: University of Chicago Press.

Anderson, D. P., Forester, J. D., Turner, M. G., Frair, J. L., Merrill, E. H., Fortin, D., ... \& Boyce, M. S. (2005). Factors influencing female home range sizes in elk (Cervus elaphus) in North American landscapes. Landscape Ecology, 20(3), 257271.

Apollonio, M., Andersen, R., \& Putman, R. (Eds.). (2010). European ungulates and their management in the 21st century. Cambridge: Cambridge University Press.

Apps, C. D., Mclellan, B. N., Kinley, T. A., Serrouya, R., Seip, D. R., \& Wittmer, H. U. (2013). Spatial factors related to mortality and population decline of 
endangered mountain caribou. The Journal of Wildlife Management, 77(7), 14091419.

Bailey, D. W., Gross, J. E., Laca, E. A., Rittenhouse, L. R., Coughenour, M. B., Swift, D. M., \& Sims, P. L. (1996). Mechanisms that result in large herbivore grazing distribution patterns. Journal of Range Management, 49(5), 386-400.

Ball, J. P., Nordengren, C., \& Wallin, K. (2001). Partial migration by large ungulates: characteristics of seasonal moose Alces alces ranges in northern Sweden. Wildlife Biology, 7(1), 39-47.

Ballard, W. B., Lutz, D., Keegan, T. W., Carpenter, L. H., \& deVos Jr, J. C. (2001). Deer-predator relationships: a review of recent North American studies with emphasis on mule and black-tailed deer. Wildlife Society Bulletin, 29(1), 99-115.

Bandelt, H. J., Forster, P., \& Röhl, A. (1999). Median-joining networks for inferring intraspecific phylogenies. Molecular biology and evolution, 16(1), 37-48.

Bates, D. Maechler, M. Bolker, B., \& Walker, S. (2015). Fitting linear mixed-effects models using lme4. Journal of Statistical Software, 67(1), 1-48.

Battin, J. (2004). When good animals love bad habitats: ecological traps and the conservation of animal populations. Conservation Biology, 18(6), 1482-1491.

Beletsky, L. D., \& Orians, G. H. (1991). Effects of breeding experience and familiarity on site fidelity in female red-winged blackbirds. Ecology, 72(3), 787-796.

Belovsky, G. E. (1986). Optimal foraging and community structure: implications for a guild of generalist grassland herbivores. Oecologia, 70(1), 35-52.

Berger, J. (2007). Fear, human shields and the redistribution of prey and predators in protected areas. Biology Letters, 3(6), 620-623.

Berger, J., \& Cain, S. L. (2014). Moving beyond science to protect a mammalian migration corridor. Conservation Biology, 28(5), 1142-1150.

Bergerud, A. T., Wyett, W., \& Snider, B. (1983). The role of wolf predation in limiting a moose population. The Journal of Wildlife Management, 47(4), 977-988. 
Bergman, C. M., Fryxell, J. M., Gates, C. C., \& Fortin, D. (2001). Ungulate foraging strategies: energy maximizing or time minimizing?. Journal of Animal Ecology, 70(2), 289-300.

Beyer, H.L. (2012). Geospatial Modelling Environment (Version 0.7.3.0). (software). URL: http://www.spatialecology.com/gme.

Bitume, E. V., Bonte, D., Ronce, O., Bach, F., Flaven, E., Olivieri, I., \& Nieberding, C. M. (2013). Density and genetic relatedness increase dispersal distance in a subsocial organism. Ecology Letters, 16(4), 430-437.

Bjørneraas, K., Solberg, E. J., Herfindal, I., Van Moorter, B., Rolandsen, C. M., Tremblay, J. P., ... \& Astrup, R. (2011). Moose Alces alces habitat use at multiple temporal scales in a human-altered landscape. Wildlife Biology, 17(1), 44-54.

Blumstein, D. T., \& Daniel, J. C. (2002). Isolation from mammalian predators differentially affects two congeners. Behavioral Ecology, 13(5), 657-663.

Bobek, B., Merta, D., \& Furtek, J. (2016). Winter food and cover refuges of large ungulates in lowland forests of south-western Poland. Forest Ecology and Management, 359, 247-255.

Boegh, E., Soegaard, H., Broge, N., Hasager, C. B., Jensen, N. O., Schelde, K., \& Thomsen, A. (2002). Airborne multispectral data for quantifying leaf area index, nitrogen concentration, and photosynthetic efficiency in agriculture. Remote Sensing of Environment, 81(2), 179-193.

Bolger, D. T., Newmark, W. D., Morrison, T. A., \& Doak, D. F. (2008). The need for integrative approaches to understand and conserve migratory ungulates. Ecology Letters, 11(1), 63-77.

Boone, R. B., Thirgood, S. J., \& Hopcraft, J. G. C. (2006). Serengeti wildebeest migratory patterns modeled from rainfall and new vegetation growth. Ecology, 87(8), 1987-1994.

Booth, J., Yull, P., \& Murray, L. (1982). Mendocino deer herd management plan. California, USA: Department of Fish and Game. 
Bose, S., Forrester, T. D., Brazeal, J. L., Sacks, B. N., Casady, D. S., \& Wittmer, H. U. (2017). Implications of fidelity and philopatry for the population structure of female black-tailed deer. Behavioral Ecology, 28(4), 983-990.

Bowler, D. E., \& Benton, T. G. (2005). Causes and consequences of animal dispersal strategies: relating individual behaviour to spatial dynamics. Biological Reviews, 80(2), 205-225.

Bowyer, R. T., Kie, J. G., \& Van Ballenberghe, V. (1998). Habitat selection by neonatal black-tailed deer: climate, forage, or risk of predation?. Journal of Mammalogy, 79(2), 415-425.

Bowyer, R. T., \& Kie, J. G. (2006). Effects of scale on interpreting life-history characteristics of ungulates and carnivores. Diversity and Distributions, 12(3), 244-257.

Bowyer, R. T., \& Kie, J. G. (2009). Thermal landscapes and resource selection by black-tailed deer: implications for large herbivores. California Fish and Game, 95(3), 128-139.

Boyce, M. S., Vernier, P. R., Nielsen, S. E., \& Schmiegelow, F. K. (2002). Evaluating resource selection functions. Ecological Modelling, 157(2), 281-300.

Boyce, M. S., Mao, J. S., Merrill, E. H., Fortin, D., Turner, M. G., Fryxell, J., \& Turchin, P. (2003). Scale and heterogeneity in habitat selection by elk in Yellowstone National Park. Ecoscience, 10(4), 421-431.

Boyce, M. S., Pitt, J., Northrup, J. M., Morehouse, A. T., Knopff, K. H., Cristescu, B., \& Stenhouse, G. B. (2010). Temporal autocorrelation functions for movement rates from global positioning system radiotelemetry data. Philosophical Transactions of the Royal Society B: Biological Sciences, 365(1550), 2213-2219.

Boyer, D., \& Walsh, P. D. (2010). Modelling the mobility of living organisms in heterogeneous landscapes: does memory improve foraging success?. Philosophical Transactions of the Royal Society of London A: Mathematical, Physical and Engineering Sciences, 368(1933), 5645-5659. 
Brinkman, T. J., Deperno, C. S., Jenks, J. A., Haroldson, B. S., \& Osborn, R. G. (2005). Movement of female white-tailed deer: effects of climate and intensive row-crop agriculture. Journal of Wildlife Management, 69(3), 1099-1111.

Bunnell, F. L., \& Harestad, A. S. (1983). Dispersal and dispersion of black-tailed deer: models and observations. Journal of Mammalogy, 64(2), 201-209.

Bunnell, F. L., \& Gillingham, M. P. (1985). Foraging behavior: dynamics of dining out. In R. J. Hudson and R. G. White (Eds.), Bioenergetics of wild herbivores (pp. 53-79). Boca Raton, Florida, USA: CRC Press.

Bunnell, F. L. (1990). Ecology of black-tailed deer. In J. B. Nyberg and D. W. Janz, (Eds.), Deer and elk habitat in Coastal Forests of southern BC Special Report Series (pp. 31-63). Victoria, Canada: Research Branch B. C. Ministry of Forests.

Burnham, K. P., \& Anderson, D. R. (2003). Model selection and multimodel inference: a practical information-theoretic approach ( $2^{\text {nd }}$ ed.). New York, USA: SpringerVerlag.

Calenge, C. (2006). The package "adehabitat" for the R software: a tool for the analysis of space and habitat use by animals. Ecological Modelling, 197(3), 516-519.

Camp, M. J., Rachlow, J. L., Woods, B. A., Johnson, T. R., \& Shipley, L. A. (2013). Examining functional components of cover: the relationship between concealment and visibility in shrub-steppe habitat. Ecosphere, 4(2), 1-14.

Carlson, T. N., \& Ripley, D. A. (1997). On the relation between NDVI, fractional vegetation cover, and leaf area index. Remote sensing of Environment, 62(3), 241252.

Casady, D. S., \& Allen, M. L. (2013). Handling adjustments to reduce chemical capture-related mortality in black-tailed deer. California Fish and Game, 99(2), 104-109.

Chang, K. T., Verbyla, D. L., \& Yeo, J. J. (1995). Spatial analysis of habitat selection by Sitka black-tailed deer in southeast Alaska, USA. Environmental Management, 19(4), 579-589. 
Cherry, M. J., Chandler, R. B., Garrison, E. P., Crawford, D. A., Kelly, B. D., Shindle, D. B., ... \& Conner, L. M. (2018). Wildfire affects space use and movement of white-tailed deer in a tropical pyric landscape. Forest Ecology and Management, 409, 161-169.

Chesser, R. K. (1991). Influence of gene flow and breeding tactics on gene diversity within populations. Genetics, 129(2), 573-583.

Ciuti, S., Northrup, J. M., Muhly, T. B., Simi, S., Musiani, M., Pitt, J. A., \& Boyce, M. S. (2012). Effects of humans on behaviour of wildlife exceed those of natural predators in a landscape of fear. PloS one, 7(11), e50611.

Clarke, M. F., da Silva, K. B., Lair, H., Pocklington, R., Kramer, D. L., \& McLaughlin, R. L. (1993). Site familiarity affects escape behaviour of the eastern chipmunk, Tamias striatus. Oikos, 66(3), 533-537.

Cleves, M.A., Gould, W.W., \& Gutierrez, R.G. (2004). An introduction to survival analyses using stata. College Station, TX, USA: Stata Press.

Clutton-Brock, T. H., \& Coulson, T. (2002). Comparative ungulate dynamics: the devil is in the detail. Philosophical Transactions of the Royal Society of London B: Biological Sciences, 357(1425), 1285-1298.

Coltman, D. W., Pilkington, J. G., \& Pemberton, J. M. (2003). Fine-scale genetic structure in a free-living ungulate population. Molecular Ecology, 12(3), 733-742.

Conner, L. M., \& Leopold, B. D. (2001). A Euclidean distance metric to index dispersion from radiotelemetry data. Wildlife Society Bulletin, 29(3), 783-786.

Connolly, G. E. (1981). Assessing populations. Mule and black-tailed deer of North America. University of Nebraska Press, Lincoln, USA, 287-345.

Cook, J. G., Cook, R. C., Davis, R. W., \& Irwin, L. L. (2016). Nutritional ecology of elk during summer and autumn in the Pacific Northwest. Wildlife Monographs, 195(1), 1-81.

Coulon, A., Morellet, N., Goulard, M., Cargnelutti, B., Angibault, J. M., \& Hewison, A. M. (2008). Inferring the effects of landscape structure on roe deer (Capreolus 
capreolus) movements using a step selection function. Landscape Ecology, 23(5), 603-614.

Coulson, T., Albon, S., Pilkington, J., \& Clutton-Brock, T. (1999). Small-scale spatial dynamics in a fluctuating ungulate population. Journal of Animal Ecology, 68(4), 658-671.

Cox, D. R. (1972). Regression models and life-tables. Journal of the Royal Statistical Society. Series B (Methodological), 34(2), 187-220.

Crawley, M.J. (1993). Glim for ecologists. Oxford, UK: Blackwell Science.

Creel, S., \& Winnie, J. A. (2005). Responses of elk herd size to fine-scale spatial and temporal variation in the risk of predation by wolves. Animal Behaviour, 69(5), 1181-1189.

Creel, S., Winnie, J., Maxwell, B., Hamlin, K., \& Creel, M. (2005). Elk alter habitat selection as an antipredator response to wolves. Ecology, 86(12), 3387-3397.

Cresswell, W. (2008). Non-lethal effects of predation in birds. Ibis, 150(1), 3-17.

Currier, M. J. P. (1983). Felis concolor. Mammalian species, (200), 1-7.

Dardaillon, M. (1986). Seasonal variations in habitat selection and spatial distribution of wild boar (Sus scrofa) in the Camargue, Southern France. Behavioural Processes, 13(3), 251-268.

Dasmann, R. F., \& Taber, R. D. (1956). Behavior of Columbian black-tailed deer with reference to population ecology. Journal of Mammalogy, 37(2), 143-164.

Debeffe, L., Morellet, N., Cargnelutti, B., Lourtet, B., Bon, R., Gaillard, J. M., \& Mark Hewison, A. J. (2012). Condition-dependent natal dispersal in a large herbivore: Heavier animals show a greater propensity to disperse and travel further. Journal of Animal Ecology, 81(6), 1327-1327.

DeCesare, N. J., Hebblewhite, M., Bradley, M., Hervieux, D., Neufeld, L., \& Musiani, M. (2014). Linking habitat selection and predation risk to spatial variation in survival. Journal of Animal Ecology, 83(2), 343-352. 
DeVos, J. C., Conover, M. R., \& Headrick, N. E. (Eds.). (2003). Mule deer conservation: issues and management strategies. Utah State University, USA: Jack H. Berryman Institute Press.

D'Eon, R. G., \& Serrouya, R. (2005). Mule deer seasonal movements and multiscale resource selection using global positioning system radiotelemetry. Journal of Mammalogy, 86(4), 736-744.

Doerr, J. G., Degayner, E. J., \& Ith, G. (2005). Winter habitat selection by Sitka blacktailed deer. Journal of Wildlife Management, 69(1), 322-331.

Duckworth, R. A. (2008). Adaptive dispersal strategies and the dynamics of a range expansion. The American Naturalist, 172(S1), S4-S17.

Dzialak, M. R., Harju, S. M., Osborn, R. G., Wondzell, J. J., Hayden-Wing, L. D., Winstead, J. B., \& Webb, S. L. (2011). Prioritizing conservation of ungulate calving resources in multiple-use landscapes. PLoS One, 6(1), e14597.

Edwards, G. R., Newman, J. A., Parsons, A. J., \& Krebs, J. R. (1994). Effects of the scale and spatial distribution of the food resource and animal state on diet selection: an example with sheep. Journal of Animal Ecology, 63(4), 816-826.

Elbroch, L. M., \& Wittmer, H. U. (2013). The effects of puma prey selection and specialization on less abundant prey in Patagonia. Journal of Mammalogy, 94(2), 259-268.

Elbroch, L. M., Lendrum, P. E., Allen, M. L., \& Wittmer, H. U. (2014). Nowhere to hide: pumas, black bears, and competition refuges. Behavioral Ecology, 26(1), 247-254.

Elff, M. (2014). mclogit: Mixed Conditional Logit. R package version 0.3-1. http://CRAN.R- project.org/package=mclogit.

Elton, C. (1950). Ecology of animals. London: Methuen.

Ensing, E. P., Ciuti, 3S., de Wijs, F. A., Lentferink, D. H., ten Hoedt, A., Boyce, M. S., \& Hut, R. A. (2014). GPS based daily activity patterns in European red deer 
and North American elk (Cervus elaphus): indication for a weak circadian clock in ungulates. PLoS One, 9(9), e106997.

Ewald, M., Dupke, C., Heurich, M., Müller, J., \& Reineking, B. (2014). LiDAR remote sensing of forest structure and GPS telemetry data provide insights on winter habitat selection of European roe deer. Forests, 5(6), 1374-1390.

Excoffier, L., \& Lischer, H. E. (2010). Arlequin suite ver 3.5: a new series of programs to perform population genetics analyses under Linux and Windows. Molecular Ecology Resources, 10(3), 564-567.

Fagan, W. F., Lewis, M. A., Auger-Méthé, M., Avgar, T., Benhamou, S., Breed, G., ... \& Forester, J. (2013). Spatial memory and animal movement. Ecology Letters, 16(10), 1316-1329.

Fahrig, L. (2007). Non-optimal animal movement in human-altered landscapes. Functional Ecology, 21(6), 1003-1015.

Falinska, K. (1973). Phenology of the species of the genus Vaccinium L. in the forest communities of the Bialowieza National Park. Fragm Florist et Geobot, 19(3), 327338.

Fisher, N. I., \& Lee, A. J. (1983). A correlation coefficient for circular data. Biometrika, 70(2), 327-332.

Forester, J. D., Ives, A. R., Turner, M. G., Anderson, D. P., Fortin, D., Beyer, H. L., ... \& Boyce, M. S. (2007). State-space models link elk movement patterns to landscape characteristics in Yellowstone National Park. Ecological Monographs, 77(2), 285-299.

Formanowicz Jr, D. R., \& Bobka, M. S. (1989). Predation risk and microhabitat preference: an experimental study of the behavioral responses of prey and predator. American Midland Naturalist, 121(2), 379-386.

Forrester, T. D., \& Wittmer, H. U. (2013). A review of the population dynamics of mule deer and black-tailed deer Odocoileus hemionus in North America. Mammal Review, 43(4), 292-308. 
Forrester, T. D., Casady, D. S., \& Wittmer, H. U. (2015). Home sweet home: fitness consequences of site familiarity in female black-tailed deer. Behavioral Ecology and Sociobiology, 69(4), 603-612.

Fortin, D., Fryxell, J. M., \& Pilote, R. (2002). The temporal scale of foraging decisions in bison. Ecology, 83(4), 970-982.

Fortin, D., Beyer, H. L., Boyce, M. S., Smith, D. W., Duchesne, T., \& Mao, J. S. (2005). Wolves influence elk movements: behavior shapes a trophic cascade in Yellowstone National Park. Ecology, 86(5), 1320-1330.

Frair, J. L., Merrill, E. H., Visscher, D. R., Fortin, D., Beyer, H. L., \& Morales, J. M. (2005). Scales of movement by elk (Cervus elaphus) in response to heterogeneity in forage resources and predation risk. Landscape Ecology, 20(3), 273-287.

Frost, W. E., Bartolome, J. W., \& Connor, J. M. (1997). Understory-canopy relationships in oak woodlands and savannas. In N. H. Pillsbury, J. Verner, W. D. Tieje, (technical coordinators), Proceedings of a symposium on oak woodlands: ecology, management, and urban interface issues (pp. 183-190), 19-22 March 1996. San Luis Obispo, California, USA. General Technical Report PSW-GTR160.

Fryxell, J. M., \& Sinclair, A. R. E. (1988). Seasonal migration by white-eared kob in relation to resources. African Journal of Ecology, 26(1), 17-31.

Fryxell, J. M. (1991). Forage quality and aggregation by large herbivores. The American Naturalist, 138(2), 478-498.

Fryxell, J. M. (1995). Aggregation and migration by grazing ungulates in relation to resources and predators. In A. R. E. Sinclair and P. Arcese (Eds.), Serengeti II: dynamics, management, and conservation of an ecosystem (pp. 257-273). Chicago, USA: University of Chicago Press.

Fryxell, J. M., Wilmshurst, J. F., \& Sinclair, A. R. (2004). Predictive models of movement by Serengeti grazers. Ecology, 85(9), 2429-2435. 
Fryxell, J. M., Hazell, M., Börger, L., Dalziel, B. D., Haydon, D. T., Morales, J. M., ... \& Rosatte, R. C. (2008). Multiple movement modes by large herbivores at multiple spatiotemporal scales. Proceedings of the National Academy of Sciences, 105(49), 19114-19119.

Gaillard, J. M., Festa-Bianchet, M., Yoccoz, N. G., Loison, A., \& Toigo, C. (2000). Temporal variation in fitness components and population dynamics of large herbivores. Annual Review of Ecology and Systematics, 31(1), 367-393.

Gaillard, J. M., Hebblewhite, M., Loison, A., Fuller, M., Powell, R., Basille, M., \& Van Moorter, B. (2010). Habitat-performance relationships: finding the right metric at a given spatial scale. Philosophical Transactions of the Royal Society of London B: Biological Sciences, 365(1550), 2255-2265.

Gamon, J. A., Field, C. B., Goulden, M. L., Griffin, K. L., Hartley, A. E., Joel, G., ... \& Valentini, R. (1995). Relationships between NDVI, canopy structure, and photosynthesis in three Californian vegetation types. Ecological Applications, 5(1), 28-41.

Garrott, R. A., White, G. C., Bartmann, R. M., Carpenter, L. H., \& Alldredge, A. W. (1987). Movements of female mule deer in northwest Colorado. The Journal of Wildlife Management, 51(3), 634-643.

Garshelis, D. L. (2000). Delusions in habitat evaluation: measuring use, selection, and importance. In L. Boitani and T. K. Fuller (Eds.), Research techniques in animal ecology: controversies and consequences (pp. 111-164). New York, USA: Columbia University Press,

Gautestad, A. O., Loe, L. E., \& Mysterud, A. (2013). Inferring spatial memory and spatiotemporal scaling from GPS data: comparing red deer Cervus elaphus movements with simulation models. Journal of Animal Ecology, 82(3), 572-586.

Gaylord, A. J. (2013). Ungulate activity classification: calibrating activity monitor GPS collars for Rocky Mountain elk, mule deer, and cattle (Doctoral dissertation).Oregon State University, Corvallis, Oregon, USA. 
Geist, V. (1981). Behavior: adaptive strategies in mule deer. In O. C. Wallmo (Ed.), Mule and black-tailed deer of North America (pp.157-223). Lincoln, USA: University of Nebraska Press.

Geist, V. (1998). Deer of the world: their evolution, behaviour, and ecology. Mechanicsburg, Pennsylvania, USA: Stackpole books.

Germaine, S. S., Germaine, H. L., \& Boe, S. R. (2004). Characteristics of mule deer day-bed and forage sites in current-condition and restoration-treated ponderosa pine forest. Wildlife Society Bulletin, 32(2), 554-564.

Getz, W. M., Fortmann-Roe, S., Cross, P. C., Lyons, A. J., Ryan, S. J., \& Wilmers, C. C. (2007). LoCoH: nonparameteric kernel methods for constructing home ranges and utilization distributions. PloS one, 2(2), e207.

Gillies, C. S., Hebblewhite, M., Nielsen, S. E., Krawchuk, M. A., Aldridge, C. L., Frair, J. L., ... \& Jerde, C. L. (2006). Application of random effects to the study of resource selection by animals. Journal of Animal Ecology, 75(4), 887-898.

Gillingham, M. P. (2004). Ecology of black-tailed deer in north coastal environments. In J. Gaston, T. E. Golumbia, J. L. Martin and S. T. Sharpe (Eds.), Lessons from the Islands: Proceedings from the Research Group on Introduced Species 2002 Conference (pp. 39-47). Queen Charlotte City, British Columbia: Canadian Wildlife Service, Environment Canada, Ottawa.

Gillingham, M. P., Parker, K. L., \& Hanley, T. A. (1997). Forage intake by blacktailed deer in a natural environment: bout dynamics. Canadian Journal of Zoology, 75(7), 1118-1128.

Godvik, I. M. R., Loe, L. E., Vik, J. O., Veiberg, V., Langvatn, R., \& Mysterud, A. (2009). Temporal scales, trade-offs, and functional responses in red deer habitat selection. Ecology, 90(3), 699-710.

Gordon, I. J., Hester, A. J., \& Festa-Bianchet, M. (2004). The management of wild large herbivores to meet economic, conservation and environmental objectives. Journal of Applied Ecology, 41(6), 1021-1031. 
Gould, J.E., (2001). Concise handbook of experimental methods for the behavioral and biological sciences. Boca Raton, Florida, USA: CRC Press.

Graham, M. H. (2003). Confronting multicollinearity in ecological multiple regression. Ecology, 84(11), 2809-2815.

Green, R. A., \& Bear, G. D. (1990). Seasonal cycles and daily activity patterns of Rocky Mountain elk. The Journal of Wildlife Management, (54)2, 272-279.

Greenwood, P. J. (1980). Mating systems, philopatry and dispersal in birds and mammals. Animal Behaviour, 28(4), 1140-1162.

Gross, J. E., Zank, C., Hobbs, N. T., \& Spalinger, D. E. (1995). Movement rules for herbivores in spatially heterogeneous environments: responses to small scale pattern. Landscape Ecology, 10(4), 209-217.

Guttal, V., \& Couzin, I. D. (2010). Social interactions, information use, and the evolution of collective migration. Proceedings of the National Academy of Sciences, 107(37), 16172-16177.

Hamel, S., Garel, M., Festa-Bianchet, M., Gaillard, J. M., \& Côté, S. D. (2009). Spring normalized difference vegetation index (NDVI) predicts annual variation in timing of peak faecal crude protein in mountain ungulates. Journal of Applied Ecology, 46(3), 582-589.

Hanley, T. A. (1982). The nutritional basis for food selection by ungulates. Journal of Range Management, 35(2) 146-151.

Hanley, T. A. (1983). Black-tailed deer, elk, and forest edge in a western Cascades watershed. The Journal of Wildlife Management, 47(1), 237-242.

Hansen, A. J., Neilson, R. P., Dale, V. H., Flather, C. H., Iverson, L. R., Currie, D. J., ... \& Bartlein, P. J. (2001). Global Change in Forests: Responses of Species, Communities, and Biomes: Interactions between climate change and land use are projected to cause large shifts in biodiversity. AIBS Bulletin, 51(9), 765-779. 
Harris, G., Thirgood, S., Hopcraft, J. G. C., Cromsigt, J. P., \& Berger, J. (2009). Global decline in aggregated migrations of large terrestrial mammals. Endangered Species Research, 7(1), 55-76.

Hebblewhite, M., Merrill, E. H., \& McDonald, T. L. (2005). Spatial decomposition of predation risk using resource selection functions: an example in a wolf-elk predator-prey system. Oikos, 111(1), 101-111.

Hebblewhite, M., \& Merrill, E. (2008). Modelling wildlife-human relationships for social species with mixed-effects resource selection models. Journal of Applied Ecology, 45(3), 834-844.

Hebblewhite, M., Merrill, E., \& McDermid, G. (2008). A multi-scale test of the forage maturation hypothesis in a partially migratory ungulate population. Ecological Monographs, 78(2), 141-166.

Hebblewhite, M., \& Merrill, E. H. (2009). Trade-offs between predation risk and forage differ between migrant strategies in a migratory ungulate. Ecology, 90(12), 3445-3454.

Hebblewhite, M., \& Haydon, D. T. (2010). Distinguishing technology from biology: a critical review of the use of GPS telemetry data in ecology. Philosophical Transactions of the Royal Society of London B: Biological Sciences, 365(1550), 2303-2312.

Heffelfinger, J., \& Messmer. T. A. (2003). Introduction. In J. C. deVos, M. R. Conover and N. E. Headrick (Eds.), Mule deer conservation: Issues and management strategies (pp. 1-11). Utah State University, Logan, Utah, USA:.Berryman Institute Press.

Hildén, O. (1965). Habitat selection in birds: a review. Annales Zoologici Fennici, 2(1), 53-75.

Hobbs, N. T. (1996). Modification of ecosystems by ungulates. The Journal of Wildlife Management, 695-713. 
Horn, B. K. P. (1981). Hill shading and the reflectance map. Proceedings of the IEEE, 69(1), 14-47.

Hornocker, M. G. (1970). An analysis of mountain lion predation upon mule deer and elk in the Idaho Primitive Area. Wildlife Monographs, (21), 3-39.

Huete, A. R. (1988). A soil-adjusted vegetation index (SAVI). Remote Sensing of Environment, 25(3), 295-309.

Huete, A. R., Liu, H. Q., Batchily, K., \& Van Leeuwen, W. J. D. A. (1997). A comparison of vegetation indices over a global set of TM images for EOSMODIS. Remote Sensing of Environment, 59(3), 440-451.

Huete, A. R., Didan, K., Shimabukuro, Y. E., Ratana, P., Saleska, S. R., Hutyra, L. R., ... \& Myneni, R. (2006). Amazon rainforests green-up with sunlight in dry season. Geophysical Research Letters, 33(6).

Jayakody, S., Sibbald, A. M., Gordon, I. J., \& Lambin, X. (2008). Red deer Cervus elephus vigilance behaviour differs with habitat and type of human disturbance. Wildlife Biology, 14(1), 81-91.

Johnson, C. J., Parker, K. L., Heard, D. C., \& Gillingham, M. P. (2002a). Movement parameters of ungulates and scale-specific responses to the environment. Journal of Animal Ecology, 71(2), 225-235.

Johnson, C. J., Parker, K. L., Heard, D. C., \& Gillingham, M. P. (2002b). A multiscale behavioral approach to understanding the movements of woodland caribou. Ecological Applications, 12(6), 1840-1860.

Johnson, D. H. (1980). The comparison of usage and availability measurements for evaluating resource preference. Ecology, 61(1), 65-71.

Kamler, J. F., Jędrzejewska, B., \& Jędrzejewski, W. (2007). Activity patterns of red deer in Białowieża National Park, Poland. Journal of Mammalogy, 88(2), 508514.

Kelt, D. A., \& Van Vuren, D. H. (2001). The ecology and macroecology of mammalian home range area. The American Naturalist, 157(6), 637-645. 
Kendall, B. E., Bjørnstad, O. N., Bascompte, J., Keitt, T. H., \& Fagan, W. F. (2000). Dispersal, environmental correlation, and spatial synchrony in population dynamics. The American Naturalist, 155(5), 628-636.

Kie, J. G. (1999). Optimal foraging and risk of predation: effects on behavior and social structure in ungulates. Journal of Mammalogy, 80(4), 1114-1129.

Kie, J. G., \& Bowyer, R. T. (1999). Sexual segregation in white-tailed deer: densitydependent changes in use of space, habitat selection, and dietary niche. Journal of Mammalogy 80(3):1004-1020.

Kie, J. G., \& Czech, B. 2000. Mule and black-tailed deer. In S. Demarais and P.R. Krausman, (Eds.), Ecology and management of large mammals in North America (pp 629-657). Upper Saddle River, New Jersey, USA: Prentice Hall,

Kie, J. G., Bowyer, R. T., Nicholson, M. C., Boroski, B. B., \& Loft, E. R. (2002). Landscape heterogeneity at differing scales: effects on spatial distribution of mule deer. Ecology, 83(2), 530-544.

Killeen, J., Thurfjell, H., Ciuti, S., Paton, D., Musiani, M., \& Boyce, M. S. (2014). Habitat selection during ungulate dispersal and exploratory movement at broad and fine scale with implications for conservation management. Movement Ecology, 2(1), 15.

Knapp, A. K., Blair, J. M., Briggs, J. M., Collins, S. L., Hartnett, D. C., Johnson, L. C., \& Towne, E. G. (1999). The keystone role of bison in North American tallgrass prairie: Bison increase habitat heterogeneity and alter a broad array of plant, community, and ecosystem processes. BioScience, 49(1), 39-50.

Knopff, K. H., Knopff, A. A., Kortello, A., \& Boyce, M. S. (2010). Cougar kill rate and prey composition in a multiprey system. Journal of Wildlife Management, 74(7), 1435-1447.

Kokko, H., \& Sutherland, W. J. (2001). Ecological traps in changing environments: ecological and evolutionary consequences of a behaviourally mediated Allee effect. Evolutionary Ecology Research, 3(5), 603-610. 
Krebs, C. J. (1985). A general theory: the ecological web. Science, 228(4701), 873874.

Krebs, J. R. (1980). Optimal foraging, predation risk and territory defence. Ardea, 68, 83-90.

Kremsater, L. L., \& Bunnell, F. L. (1992). Testing responses to forest edges: the example of black-tailed deer. Canadian Journal of Zoology, 70(12), 2426-2435.

Kunkel, K., \& Pletscher, D. H. (1999). Species-specific population dynamics of cervids in a multipredator ecosystem. The Journal of Wildlife Management, 63(4), 1082-1093.

Kunkel, K.E. and Pletscher, D.H., (2000). Habitat factors affecting vulnerability of moose to predation by wolves in southeastern British Columbia. Canadian Journal of Zoology, 78(1), pp.150-157.

Laliberte, A. S., \& Ripple, W. J. (2004). Range contractions of North American carnivores and ungulates. AIBS Bulletin, 54(2), 123-138.

Larson, T. J., Rongstad, O. J., \& Terbilcox, F. W. (1978). Movement and habitat use of white-tailed deer in southcentral Wisconsin. The Journal of Wildlife Management, 42(1), 113-117.

Lashley, M. A., Chitwood, M. C., Biggerstaff, M. T., Morina, D. L., Moorman, C. E., \& DePerno, C. S. (2014). White-tailed deer vigilance: the influence of social and environmental factors. PLoS One, 9(3), e90652.

Latch, E. K., Heffelfinger, J. R., Fike, J. A., \& Rhodes, J. (2009). Species-wide phylogeography of North American mule deer (Odocoileus hemionus): cryptic glacial refugia and postglacial recolonization. Molecular Ecology, 18(8), 17301745.

Latch, E. K., Reding, D. M., Heffelfinger, J. R., Alcalá-Galván, C. H., \& Rhodes, O. E. (2014). Range-wide analysis of genetic structure in a widespread, highly mobile species (Odocoileus hemionus) reveals the importance of historical biogeography. Molecular Ecology, 23(13), 3171-3190. 
Laundré, J. W., Hernández, L., \& Altendorf, K. B. (2001). Wolves, elk, and bison: reestablishing the" landscape of fear" in Yellowstone National Park, USA. Canadian Journal of Zoology, 79(8), 1401-1409.

Laundré, J. W., Hernández, L., \& Ripple, W. J. (2010). The landscape of fear: ecological implications of being afraid. Open Ecology Journal, 3, 1-7.

Leblond, M., Frair, J., Fortin, D., Dussault, C., Ouellet, J. P., \& Courtois, R. (2011). Assessing the influence of resource covariates at multiple spatial scales: an application to forest-dwelling caribou faced with intensive human activity. Landscape Ecology, 26(10), 1433-1446.

Leopold, A. (1933). The conservation ethic. Journal of Forestry, 31(6), 634-643.

Leopold, A., Sowls, L. K., \& Spencer, D. L. (1947). A survey of over-populated deer ranges in the United States. The Journal of Wildlife Management, 11(2), 162-177.

Lesage, L., Crête, M., Huot, J., Dumont, A., \& Ouellet, J. P. (2000). Seasonal home range size and philopatry in two northern white-tailed deer populations. Canadian Journal of Zoology, 78(11), 1930-1940.

Levin, S. A. (1992). The problem of pattern and scale in ecology: the Robert H. MacArthur award lecture. Ecology, 73(6), 1943-1967.

Librado, P., \& Rozas, J. (2009). DnaSP v5: a software for comprehensive analysis of DNA polymorphism data. Bioinformatics, 25(11), 1451-1452.

Lima, S. L. (2002). Putting predators back into behavioral predator-prey interactions. Trends in Ecology \& Evolution, 17(2), 70-75.

Lima, S. L., \& Dill, L. M. (1990). Behavioral decisions made under the risk of predation: a review and prospectus. Canadian Journal of Zoology, 68(4), 619-640.

Lind, J., \& Cresswell, W. (2005). Determining the fitness consequences of antipredation behavior. Behavioral Ecology, 16(5), 945-956. 
Lindenmayer, D., Hobbs, R. J., Montague-Drake, R., Alexandra, J., Bennett, A., Burgman, M., ... \& Driscoll, D. (2008). A checklist for ecological management of landscapes for conservation. Ecology Letters, 11(1), 78-91.

Long, R. A., Kie, J. G., Bowyer, R. T., \& Hurley, M. A. (2009a). Resource selection and movements by female mule deer Odocoileus hemionus: effects of reproductive stage. Wildlife Biology, 15(3), 288-298.

Long, R. A., Muir, J. D., Rachlow, J. L., \& Kie, J. G. (2009b). A comparison of two modeling approaches for evaluating wildlife-habitat relationships. Journal of Wildlife Management, 73(2), 294-302.

Longhurst, W. M., Garton, E. O., Heady, H. F., \& Connolly, G. E. (1976). The California deer decline and possibilities for restoration. Transactions of the Western Section of the Wildlife Society, 12, 1-41.

Lorimer, C. G., Chapman, J. W., \& Lambert, W. D. (1994). Tall understorey vegetation as a factor in the poor development of oak seedlings beneath mature stands. Journal of Ecology, 82(2), 227-237.

Lounsberry, Z. T., Forrester, T. D., Olegario, M. T., Brazeal, J. L., Wittmer, H. U., \& Sacks, B. N. (2015). Estimating sex-specific abundance in fawning areas of a highdensity Columbian black-tailed deer population using fecal DNA. The Journal of Wildlife Management, 79(1), 39-49.

Mangel, M., \& Clark, C. W. (1986). Towards a unified foraging theory. Ecology, 67(5), 1127-1138.

Manly, B. F. J., McDonald, L. L., Thomas, D. L., McDonald, T. L., \& Erickson, W. P. (2002). Resource selection by animals: statistical analysis and design for field studies. Nordrecht, The Netherlands: Kluwer.

Marescot, L., Forrester, T. D., Casady, D. S., \& Wittmer, H. U. (2015). Using multistate capture-mark-recapture models to quantify effects of predation on agespecific survival and population growth in black-tailed deer. Population Ecology, 57(1), 185-197. 
Matthysen, E. (2005). Density-dependent dispersal in birds and mammals. Ecography, 28(3), 403-416.

Mattson Jr, W. J. (1980). Herbivory in relation to plant nitrogen content. Annual Review of Ecology and Systematics, 11(1), 119-161.

Mauffette, Y., \& Oechel, W. C. (1989). Seasonal variation in leaf chemistry of the coast live oak Quercus agrifolia and implications for the California oak moth Phryganidia californica. Oecologia, 79(4), 439-445.

Mayer, K. E., \& Laudenslayer, W. F. (1988). A guide to wildlife habitats of California. Sacramento, California, USA: California Department of Forestry and Fire Protection,

Mayor, S. J., Schaefer, J. A., Schneider, D. C., \& Mahoney, S. P. (2009a). The spatial structure of habitat selection: A caribou's-eye-view. Acta oecologica, 35(2), 253260.

Mayor, S. J., Schneider, D. C., Schaefer, J. A., \& Mahoney, S. P. (2009b) Habitat selection at multiple scales. Ecoscience, 16(2), 238-247.

McCain, E. B. (2008). Daily activity patterns of mountain lions (Puma concolor) in relation to the activity of their prey species in southern Arizona (Doctoral dissertation). Humboldt State University, USA.

McCullough, D. R. (1997). Breeding by female fawns in black-tailed deer. Wildlife Society Bulletin (1973-2006), 25(2), 296-297.

McNamara, J. M., \& Houston, A. I. (1986). The common currency for behavioral decisions. The American Naturalist, 127(3), 358-378.

McNaughton, S. J. (1979). Grazing as an optimization process: grass-ungulate relationships in the Serengeti. The American Naturalist, 113(5), 691-703.

McNaughton, S. J., Banyikwa, F. F., \& McNaughton, M. M. (1997). Promotion of the cycling of diet-enhancing nutrients by African grazers. Science, 278(5344), 17981800 . 
Mennechez, G., Petit, S., Schtickzelle, N., \& Baguette, M. (2004). Modelling mortality and dispersal: consequences of parameter generalisation on metapopulation dynamics. Oikos, 106(2), 243-252.

Merkle, J. A., Fortin, D., \& Morales, J. M. (2014). A memory-based foraging tactic reveals an adaptive mechanism for restricted space use. Ecology Letters, 17(8), 924-931.

Merkle, J. A., Cherry, S. G., \& Fortin, D. (2015). Bison distribution under conflicting foraging strategies: site fidelity vs. energy maximization. Ecology, 96(7), 17931801.

Mielke Jr, P. W., Berry, K. J., \& Johnson, E. S. (1976). Multi-response permutation procedures for a priori classifications. Communications in Statistics-Theory and Methods, 5(14), 1409-1424.

Miller, B. F., DeYoung, R. W., Campbell, T. A., Laseter, B. R., Ford, W. M., \& Miller, K. V. (2010). Fine-scale genetic and social structuring in a central Appalachian white-tailed deer herd. Journal of Mammalogy, 91(3), 681-689.

Milner-Gulland, E. J., Kholodova, M. V., Bekenov, A., Bukreeva, O. M., Grachev, I. A., Amgalan, L., \& Lushchekina, A. A. (2001). Dramatic declines in saiga antelope populations. Oryx, 35(4), 340-345.

Mitchell, W. A., \& Lima, S. L. (2002). Predator-prey shell games: large-scale movement and its implications for decision-making by prey. Oikos, 99(2), 249-259.

Moe, S. J., Stelzer, R. S., Forman, M. R., Harpole, W. S., Daufresne, T., \& Yoshida, T. (2005). Recent advances in ecological stoichiometry: insights for population and community ecology. Oikos, 109(1), 29-39.

Moll, R. J., Redilla, K. M., Mudumba, T., Muneza, A. B., Gray, S. M., Abade, L., ... \& Montgomery, R. A. (2017). The many faces of fear: A synthesis of the methodological variation in characterizing predation risk. Journal of Animal Ecology, 86(4), 749-765. 
Montandon, L. M., \& Small, E. E. (2008). The impact of soil reflectance on the quantification of the green vegetation fraction from NDVI. Remote Sensing of Environment, 112(4), 1835-1845.

Monteith, K. L., Bleich, V. C., Stephenson, T. R., Pierce, B. M., Conner, M. M., Klaver, R. W., \& Bowyer, R. T. (2011). Timing of seasonal migration in mule deer: effects of climate, plant phenology, and life-history characteristics. Ecosphere, 2(4), 1-34.

Monteith, K. L., Bleich, V. C., Stephenson, T. R., Pierce, B. M., Conner, M. M., Kie, J. G., \& Bowyer, R. T. (2014). Life-history characteristics of mule deer: Effects of nutrition in a variable environment. Wildlife Monographs, 186(1), 1-62.

Moorter, B., Bunnefeld, N., Panzacchi, M., Rolandsen, C. M., Solberg, E. J., \& Sæther, B. E. (2013). Understanding scales of movement: animals ride waves and ripples of environmental change. Journal of Animal Ecology, 82(4), 770-780.

Morales, J. M., Moorcroft, P. R., Matthiopoulos, J., Frair, J. L., Kie, J. G., Powell, R. A., ... \& Haydon, D. T. (2010). Building the bridge between animal movement and population dynamics. Philosophical Transactions of the Royal Society of London B: Biological Sciences, 365(1550), 2289-2301.

Morgan, E. R., Lundervold, M., Medley, G. F., Shaikenov, B. S., Torgerson, P. R., \& Milner-Gulland, E. J. (2006). Assessing risks of disease transmission between wildlife and livestock: the Saiga antelope as a case study. Biological Conservation, 131(2), 244-254.

Morris, D. W. (2003). How can we apply theories of habitat selection to wildlife conservation and management?. Wildlife Research, 30(4), 303-319.

Morrison, T. A., \& Bolger, D. T. (2012). Wet season range fidelity in a tropical migratory ungulate. Journal of Animal Ecology, 81(3), 543-552.

Morse, B. W., Nibbelink, N. P., Osborn, D. A., \& Miller, K. V. (2009). Home range and habitat selection of an insular fallow deer (Dama dama L.) population on Little St. Simons Island, Georgia, USA. European Journal of Wildlife Research, 55(4), $325-332$. 
Mueller, T., Olson, K. A., Dressler, G., Leimgruber, P., Fuller, T. K., Nicolson, C., ... \& Calabrese, J. M. (2011). How landscape dynamics link individual-to population-level movement patterns: a multispecies comparison of ungulate relocation data. Global Ecology and Biogeography, 20(5), 683-694.

Munro, R. M., Nielsen, S. E., Price, M. H., Stenhouse, G. B., \& Boyce, M. S. (2006). Seasonal and diel patterns of grizzly bear diet and activity in west-central Alberta. Journal of Mammalogy, 87(6), 1112-1121.

Murphy, K. M. (1998). The ecology of the cougar (Puma concolor) in the northern Yellowstone ecosystem: interactions with prey, bears, and humans (Doctoral dissertation). University of Idaho, USA.

Myneni, R. B., \& Williams, D. L. (1994). On the relationship between FAPAR and NDVI. Remote Sensing of Environment, 49(3), 200-211.

Mysterud, A., \& Østbye, E. (1999). Cover as a habitat element for temperate ungulates: effects on habitat selection and demography. Wildlife Society Bulletin, 27(2), 385394.

Nathan, R., Getz, W. M., Revilla, E., Holyoak, M., Kadmon, R., Saltz, D., \& Smouse, P. E. (2008). A movement ecology paradigm for unifying organismal movement research. Proceedings of the National Academy of Sciences, 105(49), 1905219059.

Newman, J. A., Parsons, A. J., Thornley, J. H., Penning, P. D., \& Krebs, J. R. (1995). Optimal diet selection by a generalist grazing herbivore. Functional ecology, 9(2), 255-268.

Nielsen, S. E., Boyce, M. S., Stenhouse, G. B., \& Munro, R. H. (2002). Modeling grizzly bear habitats in the Yellowhead ecosystem of Alberta: taking autocorrelation seriously. Ursus, 13, 45-56.

Nussey, D. H., Coltman, D. W., Coulson, T., Kruuk, L. E. B., Donald, A., Morris, S. J., ... \& Pemberton, J. (2005). Rapidly declining fine-scale spatial genetic structure in female red deer. Molecular Ecology, 14(11), 3395-3405. 
Olofsson, J., \& Oksanen, L. (2002). Role of litter decomposition for the increased primary production in areas heavily grazed by reindeer: a litterbag experiment. Oikos, 96(3), 507-515.

Orians, G. H., \& Wittenberger, J. F. (1991). Spatial and temporal scales in habitat selection. The American Naturalist, 137, S29-S49.

Owen-Smith, N., Fryxell, J. M., \& Merrill, E. H. (2010). Foraging theory upscaled: the behavioural ecology of herbivore movement. Philosophical Transactions of the Royal Society of London B: Biological Sciences, 365(1550), 2267-2278.

Pang, G., Wang, X., \& Yang, M. (2017). Using the NDVI to identify variations in, and responses of, vegetation to climate change on the Tibetan Plateau from 1982 to 2012. Quaternary International, 444, 87-96.

Parker, K. L., Barboza, P. S., \& Gillingham, M. P. (2009). Nutrition integrates environmental responses of ungulates. Functional Ecology, 23(1), 57-69.

Parker, K. L., Robbins, C. T., \& Hanley, T. A. (1984). Energy expenditures for locomotion by mule deer and elk. The Journal of Wildlife Management, 48(2), 474488.

Peterson, D. L., \& Parker, V. T. (1998). Ecological scale: theory and applications. Columbia, USA: Columbia University Press.

Pettorelli, N., Vik, J. O., Mysterud, A., Gaillard, J. M., Tucker, C. J., \& Stenseth, N. C. (2005). Using the satellite-derived NDVI to assess ecological responses to environmental change. Trends in Ecology \& Evolution, 20(9), 503-510.

Pettorelli, N., Gaillard, J. M., Mysterud, A., Duncan, P., Delorme, D., Van Laere, G., ... \& Klein, F. (2006). Using a proxy of plant productivity (NDVI) to find key periods for animal performance: the case of roe deer. Oikos, 112(3), 565-572.

Pettorelli, N., Pelletier, F., Hardenberg, A. V., Festa-Bianchet, M., \& Côté, S. D. (2007). Early onset of vegetation growth vs. rapid green-up: Impacts on juvenile mountain ungulates. Ecology, 88(2), 381-390. 
Pettorelli, N., Coulson, T., Durant, S. M., \& Gaillard, J. M. (2011). Predation, individual variability and vertebrate population dynamics. Oecologia, 167(2), 305.

Pickett, S. T., \& Cadenasso, M. L. (1995). Landscape ecology: spatial heterogeneity in ecological systems. Science, 269(5222), 331.

Pierce, B. M., Bowyer, R. T., \& Bleich, V. C. (2004). Habitat selection by mule deer: forage benefits or risk of predation?. Journal of Wildlife Management, 68(3), 533541.

Pinheiro, J., Bates, D., DebRoy, S., Sarkar, D. \& R Core Team. (2014). nlme: Linear and Nonlinear Mixed Effects Models. R package version 3.1-118, URL: http://CRAN.R-project.org/package=nlme.

Piper, W. H. (2011). Making habitat selection more "familiar": a review. Behavioral Ecology and Sociobiology, 65(7), 1329-1351.

Polansky, L., \& Wittemyer, G. (2011). A framework for understanding the architecture of collective movements using pairwise analyses of animal movement data. Journal of the Royal Society Interface, 8(56), 322-333.

Porter, W. F., Mathews, N. E., Underwood, H. B., Sage, R. W., \& Behrend, D. F. (1991). Social organization in deer: implications for localized management. Environmental Management, 15(6), 809-814.

Prugh, L. R., \& Golden, C. D. (2014). Does moonlight increase predation risk? Metaanalysis reveals divergent responses of nocturnal mammals to lunar cycles. Journal of Animal Ecology, 83(2), 504-514.

Purdue, J. R., Smith, M. H., \& Patton, J. C. (2000). Female philopatry and extreme spatial genetic heterogeneity in white-tailed deer. Journal of Mammalogy, 81(1), 179-185.

Pusey, A. E. (1987). Sex-biased dispersal and inbreeding avoidance in birds and mammals. Trends in ecology \& evolution, 2(10), 295-299. 
R Development Core Team (2014). R: A language and environment for statistical computing. $\mathrm{R}$ foundation for statistical computing, Vienna, Austria. http://www.R-project.org/.

Renaud, V., Innes, J. L., Dobbertin, M., \& Rebetez, M. (2011). Comparison between open-site and below-canopy climatic conditions in Switzerland for different types of forests over 10 years (1998- 2007). Theoretical and Applied Climatology, 105(1-2), 119-127.

Rettie, W. J., \& Messier, F. (2000). Hierarchical habitat selection by woodland caribou: its relationship to limiting factors. Ecography, 23(4), 466-478.

Riley, S. J., \& Dood, A. R. (1984). Summer movements, home range, habitat use, and behavior of mule deer fawns. The Journal of Wildlife Management, 48(4), 13021310.

Robertson, B. A., \& Hutto, R. L. (2006). A framework for understanding ecological traps and an evaluation of existing evidence. Ecology, 87(5), 1075-1085.

Robertson, G. J., \& Cooke, F. (1999). Winter philopatry in migratory waterfowl. The Auk, 116(1) 20-34.

Robinson, R. A., Crick, H. Q., Learmonth, J. A., Maclean, I., Thomas, C. D., Bairlein, F., ... \& Harwood, J. (2009). Travelling through a warming world: climate change and migratory species. Endangered Species Research, 7(2), 87-99.

Roever, C. L., Beyer, H. L., Chase, M. J., \& Aarde, R. J. (2014). The pitfalls of ignoring behaviour when quantifying habitat selection. Diversity and Distributions, 20(3), 322-333.

Rosenzweig, M. L. (1991). Habitat selection and population interactions: the search for mechanism. The American Naturalist, 137, S5-S28.

Runge, C. A., Martin, T. G., Possingham, H. P., Willis, S. G., \& Fuller, R. A. (2014). Conserving mobile species. Frontiers in Ecology and the Environment, 12(7), 395-402. 
Safford, H. D., \& Van de Water, K. M. (2014). Using fire return interval departure (FRID) analysis to map spatial and temporal changes in fire frequency on national forest lands in California. Albany, California, USA: U.S. Department of Agriculture, Forest Service, Pacific Southwest Research Station

Salminen, J. P., Roslin, T., Karonen, M., Sinkkonen, J., Pihlaja, K., \& Pulkkinen, P. (2004). Seasonal variation in the content of hydrolyzable tannins, flavonoid glycosides, and proanthocyanidins in oak leaves. Journal of Chemical Ecology, 30(9), 1693-1711.

Sappington, J. M., Longshore, K. M., \& Thompson, D. B. (2007). Quantifying landscape ruggedness for animal habitat analysis: a case study using bighorn sheep in the Mojave Desert. Journal of Wildlife Management, 71(5), 1419-1426.

Sawyer, H., Lindzey, F., \& McWhirter, D. (2005). Mule deer and pronghorn migration in western Wyoming. Wildlife Society Bulletin, 33(4), 1266-1273.

Sawyer, H., Nielson, R. M., Lindzey, F., \& McDonald, L. L. (2006). Winter habitat selection of mule deer before and during development of a natural gas field. Journal of Wildlife Management, 70(2), 396-403.

Sawyer, H., Nielson, R. M., Lindzey, F. G., Keith, L., Powell, J. H., \& Abraham, A. A. (2007). Habitat selection of Rocky Mountain elk in a nonforested environment. Journal of Wildlife Management, 71(3), 868-874.

Sawyer, H., \& Kauffman, M. J. (2011). Stopover ecology of a migratory ungulate. Journal of Animal Ecology, 80(5), 1078-1087.

Sawyer, H., Lebeau, C., \& Hart, T. (2012). Mitigating roadway impacts to migratory mule deer - a case study with underpasses and continuous fencing. Wildlife Society Bulletin, 36(3), 492-498.

Schaefer, J. A., Bergman, C. M., \& Luttich, S. N. (2000). Site fidelity of female caribou at multiple spatial scales. Landscape Ecology, 15(8), 731-739.

Schoener, T. W. (1971). Theory of feeding strategies. Annual Review of Ecology and Systematics, 2(1), 369-404. 
Schoenfeld, D. (1982). Partial residuals for the proportional hazards regression model. Biometrika, 69(1), 239-241.

Schreiner, E. G., Krueger, K. A., Houston, D. B., \& Happe, P. J. (1996). Understory patch dynamics and ungulate herbivory in old-growth forests of Olympic National Park, Washington. Canadian Journal of Forest Research, 26(2), 255-265.

Seaman, D. E., \& Powell, R. A. (1996). An evaluation of the accuracy of kernel density estimators for home range analysis. Ecology, 77(7), 2075-2085.

Senft, R. L., Coughenour, M. B., Bailey, D. W., Rittenhouse, L. R., Sala, O. E., \& Swift, D. M. (1987). Large herbivore foraging and ecological hierarchies. BioScience, 37(11), 789-799.

Sih, A., \& McCarthy, T. M. (2002). Prey responses to pulses of risk and safety: testing the risk allocation hypothesis. Animal Behaviour, 63(3), 437-443.

Sih, A. (2005). Predator-prey space use as an emergent outcome of a behavioral response race. In P. Barbosa, and I. Castellanos (Eds.), Ecology of predator-prey interactions (pp. 240-255). Oxford, UK: Oxford University Press.

Singer, F. J., \& Schoenecker, K. A. (2003). Do ungulates accelerate or decelerate nitrogen cycling?. Forest Ecology and Management, 181(1), 189-204.

Skovlin, J. M., Zager, P., \& Johnson, B. K. (2002). Elk habitat selection and evaluation. North American elk: ecology and management. Smithsonian Institution Press, Washington, DC, USA, 531-556.

Smith, H. D., Oveson, M. C., \& Pritchett, C. L. (1986). Characteristics of mule deer beds. The Great Basin Naturalist, 542-546.

Stankowich, T. (2008). Ungulate flight responses to human disturbance: a review and meta-analysis. Biological Conservation, 141(9), 2159-2173.

Stewart, K. M., Bowyer, R. T., Kie, J. G., Cimon, N. J., \& Johnson, B. K. (2002). Temporospatial distributions of elk, mule deer, and cattle: resource partitioning and competitive displacement. Journal of Mammalogy, 83(1), 229-244. 
Storz, J. F. (1999). Genetic consequences of mammalian social structure. Journal of Mammalogy, 80(2), 553-569.

Sweanor, L. L., Logan, K. A., Bauer, J. W., Millsap, B., \& Boyce, W. M. (2008). Puma and human spatial and temporal use of a popular California State Park. Journal of Wildlife Management, 72(5), 1076-1084.

Switzer, P. V. (1993). Site fidelity in predictable and unpredictable habitats. Evolutionary Ecology, 7(6), 533-555.

Taber, R. D. (1953). Studies of black-tailed deer reproduction on three chaparral cover types. California Fish and Game, 39(2), 177-186.

Taber, R. D., \& Dasmann, R. F. (1957). The dynamics of three natural populations of the deer Odocoileus hemionus columbianus. Ecology, 38(2), 233-246.

Taillon, J., Sauvé, D. G., \& Côté, S. D. (2006). The effects of decreasing winter diet quality on foraging behavior and life-history traits of white-tailed deer fawns. Journal of Wildlife Management, 70(5), 1445-1454.

Taylor, L. R., \& Taylor, R. A. (1977). Aggregation, migration and population mechanics. Nature, 265(5593), 415-421.

Therneau, T. M., \& Grambsch, P. M. (2000). The Cox model. In Modeling survival data: extending the Cox model (pp. 39-77). New York, USA: Springer.

Thomson, R., T Forsman, J., Sardà-Palomera, F., \& Mönkkönen, M. (2006). Fear factor: prey habitat selection and its consequences in a predation risk landscape. Ecography, 29(4), 507-514.

Travis, J. M., \& Dytham, C. (1999). Habitat persistence, habitat availability and the evolution of dispersal. Proceedings of the Royal Society of London B: Biological Sciences, 266(1420), 723-728.

Tumenta, P. N., Visser, H. D., van Rijssel, J., Müller, L., de Iongh, H. H., Funston, P. J., \& Udo de Haes, H. A. (2013). Lion predation on livestock and native wildlife in Waza National Park, northern Cameroon. Mammalia, 77(3), 247-251. 
Turchin, P. (2003). Complex population dynamics: a theoretical/empirical synthesis (Vol. 35). Princeton, New Jersey, USA: Princeton University Press.

Turner, M. G. (1989). Landscape ecology: the effect of pattern on process. Annual Review of Ecology and Systematics, 20(1), 171-197.

Valeix, M., Loveridge, A. J., Chamaillé-Jammes, S., Davidson, Z., Murindagomo, F., Fritz, H., \& Macdonald, D. W. (2009). Behavioral adjustments of African herbivores to predation risk by lions: spatiotemporal variations influence habitat use. Ecology, 90(1), 23-30.

Van Beest, F. M., Mysterud, A., Loe, L. E., \& Milner, J. M. (2010). Forage quantity, quality and depletion as scale-dependent mechanisms driving habitat selection of a large browsing herbivore. Journal of Animal Ecology, 79(4), 910-922.

Van Beest, F. M., Rivrud, I. M., Loe, L. E., Milner, J. M., \& Mysterud, A. (2011). What determines variation in home range size across spatiotemporal scales in a large browsing herbivore?. Journal of Animal Ecology, 80(4), 771-785.

Van Beest, F. M., Vander Wal, E., Stronen, A. V., Paquet, P. C., \& Brook, R. K. (2013). Temporal variation in site fidelity: scale-dependent effects of forage abundance and predation risk in a non-migratory large herbivore. Oecologia, 173(2), 409-420.

Van Moorter, B., Gaillard, J. M., McLoughlin, P. D., Delorme, D., Klein, F., \& Boyce, M. S. (2009). Maternal and individual effects in selection of bed sites and their consequences for fawn survival at different spatial scales. Oecologia, 159(3), 669678.

Van Moorter, B., Visscher, D., Benhamou, S., Börger, L., Boyce, M. S., \& Gaillard, J. M. (2009). Memory keeps you at home: a mechanistic model for home range emergence. Oikos, 118(5), 641-652.

Van Soest, P. J. (1994). Nutritional ecology of the ruminant. New York, USA: Cornell University Press. 
Vucetich, J. A., Smith, D. W., \& Stahler, D. R. (2005). Influence of harvest, climate and wolf predation on Yellowstone elk, 1961-2004. Oikos, 111(2), 259-270.

Wallace, L. L., Turner, M. G., Romme, W. H., O'Neill, R. V., \& Wu, Y. (1995). Scale of heterogeneity of forage production and winter foraging by elk and bison. Landscape Ecology, 10(2), 75-83.

Wallmo, O. C. (1981). Mule and black-tailed deer in North America. Nebraska, USA: University of Nebraska Press.

Weaver, J. L., Paquet, P. C., \& Ruggiero, L. F. (1996). Resilience and conservation of large carnivores in the Rocky Mountains. Conservation Biology, 10(4), 964-976.

Wickstrom, M. L., Robbins, C. T., Hanley, T. A., Spalinger, D. E., \& Parish, S. M. (1984). Food intake and foraging energetics of elk and mule deer. The Journal of Wildlife Management, 48(4), 1285-1301.

Willems, E. P., \& Hill, R. A. (2009). Predator-specific landscapes of fear and resource distribution: effects on spatial range use. Ecology, 90(2), 546-555.

Wilmers, C. C., Nickel, B., Bryce, C. M., Smith, J. A., Wheat, R. E., \& Yovovich, V. (2015). The golden age of bio-logging: how animal-borne sensors are advancing the frontiers of ecology. Ecology, 96(7), 1741-1753.

Wilson, K. J. (1992). Spatial scales of muskox resource selection in late winter (Doctoral dissertation). University of Alaska Fairbanks, USA.

Winterstein, S. R., Pollock, K. H., \& Bunck, C. M. (2001). Analysis of survival data from radiotelemetry studies. In J. J. Millspaugh, J. M. Marzluff, (Eds.), Radio tracking and animal populations (pp. 351-380). San Diego, California, USA: Academic Press.

Wittmer, H. U., Forrester, T. D., Allen, M. L., Marescot, L., \& Casady, D. S. (2014). Black-tailed deer population assessment in the Mendocino National Forest, California. Sacramento: California Department of Fish and Wildlife. 
Wittmer, H. U., McLellan, B. N., \& Hovey, F. W. (2006). Factors influencing variation in site fidelity of woodland caribou (Rangifer tarandus caribou) in southeastern British Columbia. Canadian Journal of Zoology, 84(4), 537-545.

Wittmer, H. U., McLellan, B. N., Serrouya, R., \& Apps, C. D. (2007). Changes in landscape composition influence the decline of a threatened woodland caribou population. Journal of Animal Ecology, 76(3), 568-579.

Wolf, M., Frair, J., Merrill, E., \& Turchin, P. (2009). The attraction of the known: the importance of spatial familiarity in habitat selection in wapiti Cervus elaphus. Ecography, 32(3), 401-410.

Worton, B. J. (1989). Kernel methods for estimating the utilization distribution in home-range studies. Ecology, 70(1), 164-168.

Xie, Y., Ahmed, K. F., Allen, J. M., Wilson, A. M., \& Silander, J. A. (2015). Greenup of deciduous forest communities of northeastern North America in response to climate variation and climate change. Landscape Ecology, 30(1), 109-123.

Zimmerman, G. M., Goetz, H., \& Mielke, P. W. (1985). Use of an improved statistical method for group comparisons to study effects of prairie fire. Ecology, 66(2), 606611. 
Appendices 


\section{Appendix 1}

Table A1.1: Capture, activity, movement and mortality information of 64 female black-tailed deer captured and monitored between 2004 -

2013 in the Mendocino National Forest, California, USA.

\begin{tabular}{|c|c|c|c|c|c|c|c|c|c|c|}
\hline ID & $\begin{array}{c}\text { Age } \\
\text { (in } \\
\text { years) }\end{array}$ & $\begin{array}{l}\text { Area } \\
\text { (Ridge } \\
\text { name) }\end{array}$ & $\begin{array}{c}\text { From } \\
\text { (Date } \\
\text { collared) }\end{array}$ & $\begin{array}{c}\text { To } \\
\text { (Date died/ } \\
\text { collar drop) }\end{array}$ & $\begin{array}{c}\text { Fix } \\
\text { Interval } \\
\quad \text { in } \\
\text { hours })\end{array}$ & $\begin{array}{l}\text { Activity Data } \\
\text { (collar with } \\
\text { accelerometer) }\end{array}$ & $\begin{array}{l}\text { Summer } \\
\text { (No. of } \\
\text { seasons } \\
\text { spent in } \\
\text { summer } \\
\text { habitat) }\end{array}$ & $\begin{array}{l}\text { Winter } \\
\text { (No. of } \\
\text { seasons } \\
\text { spent in } \\
\text { summer } \\
\text { habitat) }\end{array}$ & \begin{tabular}{|c|} 
Non- \\
Migratory \\
(No \\
migration \\
between \\
summer- \\
winter \\
habitat) \\
\end{tabular} & $\begin{array}{l}\text { Status } \\
\text { (Dead/ alive } \\
\text { at the end } \\
\text { of } \\
\text { monitoring) }\end{array}$ \\
\hline 1485 & 9 & $\mathrm{FH} 7$ & $12 / 07 / 2012$ & $10 / 07 / 2013$ & 1 & $\mathrm{~N}$ & 2 & 1 & 0 & Alive \\
\hline 5730 & 2 & M1 & $29 / 09 / 2004$ & $18 / 11 / 2005$ & 7 & $\mathrm{~N}$ & 2 & 1 & 0 & Unknown \\
\hline 5731 & 13 & M1 & $30 / 09 / 2004$ & $27 / 01 / 2006$ & 7 & $\mathrm{~N}$ & 2 & 1 & 0 & Dead \\
\hline 5733 & 4 & M1 & $2 / 11 / 2004$ & $7 / 05 / 2006$ & 7 & $\mathrm{~N}$ & 2 & 1 & 0 & Uncertain \\
\hline 5734 & 3 & M1 & $23 / 11 / 2004$ & $11 / 03 / 2005$ & 7 & $\mathrm{~N}$ & 1 & 1 & 0 & Dead \\
\hline 5735 & 2 & M1 & $25 / 02 / 2005$ & $17 / 05 / 2005$ & 7 & $\mathrm{~N}$ & 0 & 1 & 0 & Dead \\
\hline 5738 & 4 & M1 & $22 / 04 / 2005$ & $28 / 12 / 2005$ & 7 & $\mathrm{~N}$ & 1 & 0 & 0 & Dead \\
\hline
\end{tabular}




\begin{tabular}{|c|c|c|c|c|c|c|c|c|c|c|}
\hline 5741 & 5 & M1 & $17 / 06 / 2005$ & $17 / 09 / 2007$ & 7 & $\mathrm{~N}$ & 3 & 2 & 0 & Unknown \\
\hline 5744 & 1 & M1 & $23 / 08 / 2005$ & $19 / 09 / 2007$ & 7 & $\mathrm{~N}$ & 3 & 2 & 0 & Unknown \\
\hline 5745 & 2 & M1 & $24 / 08 / 2005$ & $18 / 02 / 2006$ & 7 & $\mathrm{~N}$ & 0 & 0 & 1 & Dead \\
\hline 5747 & 5 & M1 & $31 / 08 / 2005$ & $7 / 03 / 2006$ & 7 & $\mathrm{~N}$ & 1 & 1 & 0 & Dead \\
\hline 7037 & 3 & M1 & $25 / 06 / 2011$ & $27 / 02 / 2012$ & 5 & $\mathrm{Y}$ & 0 & 0 & 1 & Dead \\
\hline 7079 & 10 & FH7 & $9 / 07 / 2011$ & $5 / 07 / 2012$ & 5 & $\mathrm{Y}$ & 0 & 0 & 1 & Alive \\
\hline 7216 & 6 & FH7 & $12 / 06 / 2012$ & $1 / 09 / 2013$ & 1 & $\mathrm{~N}$ & 2 & 1 & 0 & Alive \\
\hline 7227 & 3 & FH7 & $13 / 06 / 2012$ & $1 / 09 / 2013$ & 1 & $\mathrm{~N}$ & 2 & 1 & 0 & Alive \\
\hline 7274 & 1 & M1 & $7 / 09 / 2012$ & $11 / 01 / 2013$ & 1 & $\mathrm{Y}$ & 1 & 1 & 0 & Alive \\
\hline 7276 & 4 & M1 & $5 / 06 / 2012$ & $28 / 08 / 2013$ & 1 & $\mathrm{Y}$ & 2 & 1 & 0 & Alive \\
\hline 7285 & 5 & FH7 & $10 / 09 / 2012$ & $13 / 08 / 2013$ & 5 & $\mathrm{Y}$ & 2 & 1 & 0 & Alive \\
\hline 7298 & 5 & FH7 & $12 / 07 / 2012$ & $1 / 09 / 2013$ & 1 & $\mathrm{~N}$ & 2 & 1 & 0 & Alive \\
\hline 7303 & 7 & FH7 & $6 / 06 / 2012$ & $2 / 09 / 2013$ & 1 & $\mathrm{Y}$ & 2 & 1 & 0 & Alive \\
\hline 7308 & 3 & M1 & $6 / 07 / 2011$ & $20 / 08 / 2011$ & 5 & $\mathrm{Y}$ & 1 & 0 & 0 & Dead \\
\hline 7314 & 5 & FH7 & $13 / 07 / 2012$ & $19 / 10 / 2012$ & 5 & $\mathrm{~N}$ & 1 & 0 & 0 & Dead \\
\hline
\end{tabular}




\begin{tabular}{|c|c|c|c|c|c|c|c|c|c|c|}
\hline 7318 & 7 & FH7 & $13 / 07 / 2012$ & $13 / 09 / 2013$ & 1 & $\mathrm{Y}$ & 2 & 1 & 0 & Alive \\
\hline 7331 & 3 & FH7 & 8/06/2012 & $1 / 09 / 2013$ & 1 & $\mathrm{~N}$ & 2 & 1 & 0 & Alive \\
\hline 7447 & 5 & FH7 & $10 / 09 / 2012$ & $13 / 09 / 2013$ & 1 & $\mathrm{Y}$ & 2 & 1 & 0 & Alive \\
\hline 7449 & 3 & M1 & $18 / 06 / 2012$ & $1 / 09 / 2013$ & 1 & $\mathrm{~N}$ & 2 & 1 & 0 & Alive \\
\hline 7581 & 2 & M1 & $29 / 03 / 2007$ & $10 / 09 / 2007$ & 7 & $\mathrm{~N}$ & 1 & 0 & 0 & Alive \\
\hline 7582 & 3 & M1 & $28 / 03 / 2007$ & $17 / 09 / 2007$ & 7 & $\mathrm{~N}$ & 1 & 0 & 0 & Unknown \\
\hline 7583 & 3 & FH7 & $28 / 07 / 2010$ & $6 / 06 / 2012$ & 5 & $\mathrm{Y}$ & 3 & 2 & 0 & Dead \\
\hline 7585 & 5 & M1 & $16 / 07 / 2010$ & $19 / 06 / 2012$ & 5 & $\mathrm{Y}$ & 3 & 2 & 0 & Alive \\
\hline 7588 & 5 & FH7 & $24 / 06 / 2010$ & $10 / 06 / 2012$ & 5 & $\mathrm{~N}$ & 2 & 1 & 0 & Alive \\
\hline 7597 & 11 & FH7 & $23 / 06 / 2010$ & $4 / 06 / 2011$ & 5 & $\mathrm{Y}$ & 1 & 1 & 0 & Dead \\
\hline 7616 & 1 & M1 & $9 / 09 / 2012$ & $20 / 12 / 2012$ & 1 & $\mathrm{Y}$ & 1 & 1 & 0 & Dead \\
\hline 7884 & 5 & M1 & $26 / 06 / 2011$ & $24 / 06 / 2012$ & 5 & $\mathrm{Y}$ & 2 & 1 & 0 & Alive \\
\hline 7885 & 2 & FH7 & $26 / 08 / 2010$ & $8 / 12 / 2010$ & 5 & $\mathrm{Y}$ & 1 & 1 & 0 & Dead \\
\hline 7893 & 4 & M1 & $22 / 06 / 2011$ & $21 / 08 / 2012$ & 5 & $\mathrm{Y}$ & 0 & 0 & 1 & Alive \\
\hline 8796 & 6 & M1 & $8 / 06 / 2009$ & 4/10/2009 & 5 & $\mathrm{~N}$ & 1 & 1 & 0 & Dead \\
\hline
\end{tabular}




\begin{tabular}{|c|c|c|c|c|c|c|c|c|c|c|}
\hline 8798 & 6 & FH7 & $10 / 06 / 2009$ & $1 / 05 / 2011$ & 5 & $\mathrm{~N}$ & 0 & 0 & 1 & Alive \\
\hline 8800 & 4 & FH7 & $11 / 06 / 2009$ & $1 / 05 / 2011$ & 5 & $\mathrm{~N}$ & 0 & 0 & 1 & Alive \\
\hline 8801 & 3 & M1 & $10 / 06 / 2009$ & $5 / 05 / 2011$ & 5 & $\mathrm{~N}$ & 0 & 0 & 1 & Alive \\
\hline 8802 & 3 & M1 & $8 / 08 / 2009$ & $7 / 06 / 2010$ & 5 & $\mathrm{Y}$ & 2 & 1 & 0 & Dead \\
\hline 8803 & 2 & FH7 & $11 / 06 / 2009$ & $1 / 05 / 2011$ & 5 & $\mathrm{~N}$ & 2 & 2 & 0 & Alive \\
\hline 8804 & 10 & FH7 & $11 / 06 / 2009$ & $26 / 05 / 2010$ & 5 & $\mathrm{~N}$ & 2 & 1 & 0 & Dead \\
\hline 8805 & 3 & M1 & $9 / 06 / 2009$ & $20 / 01 / 2010$ & 5 & $\mathrm{~N}$ & 0 & 0 & 1 & Dead \\
\hline 8808 & 2 & FH7 & $10 / 06 / 2009$ & 8/08/2009 & 5 & $\mathrm{~N}$ & 1 & 0 & 0 & Dead \\
\hline 8810 & 3 & M1 & $9 / 06 / 2009$ & $1 / 05 / 2011$ & 5 & $\mathrm{~N}$ & 2 & 2 & 0 & Alive \\
\hline 8812 & 4 & FH7 & $13 / 07 / 2012$ & $13 / 09 / 2013$ & 1 & $\mathrm{Y}$ & 2 & 1 & 0 & Alive \\
\hline 8813 & 6 & M1 & $25 / 06 / 2011$ & $20 / 06 / 2012$ & 5 & $\mathrm{Y}$ & 2 & 1 & 0 & Alive \\
\hline 8815 & 5 & FH7 & $20 / 06 / 2010$ & $12 / 12 / 2010$ & 5 & $\mathrm{~N}$ & 1 & 0 & 0 & Dead \\
\hline 8816 & 6 & M1 & $21 / 06 / 2011$ & $18 / 06 / 2012$ & 5 & $\mathrm{Y}$ & 0 & 0 & 1 & Alive \\
\hline 8817 & 1 & FH7 & $14 / 08 / 2009$ & $12 / 08 / 2011$ & 5 & $\mathrm{Y}$ & 3 & 2 & 0 & Alive \\
\hline 8818 & 5 & FH7 & $16 / 06 / 2012$ & $3 / 09 / 2013$ & 1 & $\mathrm{~N}$ & 2 & 1 & 0 & Alive \\
\hline
\end{tabular}




\begin{tabular}{|c|c|c|c|c|c|c|c|c|c|c|}
\hline 8819 & 6 & FH7 & $24 / 08 / 2010$ & $20 / 06 / 2012$ & 5 & $\mathrm{~N}$ & 0 & 0 & 1 & Alive \\
\hline 8820 & 3 & FH7 & $21 / 06 / 2010$ & $7 / 07 / 2011$ & 5 & $\mathrm{Y}$ & 0 & 0 & 1 & Dead \\
\hline 8822 & 3 & M1 & $25 / 06 / 2011$ & $25 / 08 / 2012$ & 5 & $\mathrm{Y}$ & 2 & 1 & 0 & Alive \\
\hline 8823 & 3 & FH7 & $24 / 06 / 2010$ & $16 / 09 / 2011$ & 5 & $\mathrm{~N}$ & 0 & 0 & 1 & Dead \\
\hline 8826 & 10 & FH7 & $25 / 06 / 2010$ & $15 / 04 / 2012$ & 5 & $\mathrm{~N}$ & 2 & 2 & 0 & Dead \\
\hline 8828 & 10 & M1 & $21 / 06 / 2011$ & $11 / 10 / 2011$ & 5 & $\mathrm{Y}$ & 1 & 0 & 0 & Dead \\
\hline 8829 & 9 & M1 & $7 / 06 / 2012$ & $29 / 08 / 2013$ & 1 & $\mathrm{Y}$ & 2 & 1 & 0 & Alive \\
\hline 8834 & 11 & M1 & $21 / 12 / 2009$ & $15 / 12 / 2010$ & 5 & $\mathrm{Y}$ & 2 & 1 & 0 & Dead \\
\hline 8835 & 3 & M1 & $13 / 08 / 2009$ & $29 / 03 / 2010$ & 5 & $\mathrm{Y}$ & 1 & 1 & 0 & Dead \\
\hline 5740_05 & 4 & M1 & $9 / 06 / 2005$ & $29 / 11 / 2007$ & 7 & $\mathrm{~N}$ & 3 & 2 & 0 & Alive \\
\hline 5740_09 & 8 & M1 & $9 / 06 / 2009$ & $29 / 11 / 2009$ & 7 & $\mathrm{~N}$ & 1 & 1 & 0 & Dead \\
\hline A 255 & 1 & M1 & $31 / 08 / 2005$ & $16 / 09 / 2007$ & 7 & $\mathrm{~N}$ & 3 & 2 & 0 & Dead \\
\hline A 279 & 3 & M1 & $10 / 05 / 2006$ & $1 / 03 / 2007$ & 7 & $\mathrm{~N}$ & 1 & 1 & 0 & Dead \\
\hline
\end{tabular}




\section{Appendix 2}

\section{Modelling predation risk by Puma (Puma concolor) based on kill site selection in Mendocino National Forest, California, USA}

\section{Animal captures}

Between June 2010 and November 2012, 7 pumas (5 females, 2 males) were captured using trained hounds and box traps in Mendocino National Forest, California, USA. Based on gum-line recession (Laundre et al. 2000), one female was classified as subadult (i.e., <3 years); all other pumas were considered adults. Capture methods are described in detail in Allen et al. (2015) and approved by the Institutional Animal Care and Use Committee at the University of California, Davis (Protocols 15341 and 16886), and by the Wildlife Investigations Laboratory of the California Department of Fish and Wildlife.

\section{Collar programming and field methods}

All captured pumas were fitted with combined ARGOS satellite GPS/radio telemetry collars (Lotek 7000SAW, New Market, Ontario, Canada). Collars were programmed to acquire GPS locations every 2 hours and downloaded location data via satellite every 3 days. Location data were displayed in ArcGIS 3.2 (ESRI, Redlands, CA) to identify clusters of GPS points and thus potential kill and prey consumption sites. Following Elbroch and Wittmer (2013), GPS clusters were then defined as $\geq 5$ locations (or a minimum of 8 hours between first and last locations) within $150 \mathrm{~m}$ of each other that contained at least one crepuscular or nocturnal location. Using handheld GPS units (Garnim 60csx) 598 of the 609 identified clusters were 
investigated to search for possible prey remains. Clusters were investigated by experienced, CyberTracker-certified individuals (Elbroch et al. 2011).

Prey species found at clusters (i.e., kill sites) were identified through skeletal features and external characteristics (hair, pelage, or feathers) and carcass state and locations of bite marks were used to assess whether the prey had been killed or whether pumas had been scavenging. Further, black-tailed deer (BTD) carcasses were classified into fawns $(<1$ year old) and a combined juvenile/adult category that included all other individuals. Overall, from the remains at 352 of the clusters that were investigated, 288 were confirmed as BTD kills (Allen et al. 2015).

\section{Kill sites and random sites}

I employed a use-availability resource selection function (RSF) design (Manly et al. 2002) to evaluate possible kill site characteristics associated with BTD kill by pumas based on 288 identified kill of BTD. I extracted habitat covariates associated with kill sites for the first telemetry location of each cluster.

To generate available habitats, I first estimated individual $100 \%$ minimum convex polygon (MCP) home ranges for all 7 collared pumas and then generated 1000 random sites for every puma within their respective MCP in ArcMap 10.2 (ESRI, Redlands, CA). The same random sites were used for both summer/fall (JuneNovember) and winter/spring (December-May) models. The large number of random sites allowed sampling of less common habitat types within the study area (Northrup et al. 2013). Potential bias from "contamination" or "false-negatives" (i.e., pixels classified as available that may have been used) due to the large number of random sites was counteracted by sampling at the landscape scale which contained a large numbers of available pixels relative to the sample of used pixels. To further reduce 
false-negatives, I created a buffer with 75 m radius (following Allen 2014) from the centre of each identified kill cluster and sampled availability outside these buffers.

\section{Habitat covariates}

For the predation risk analyses, I included covariates known to be associated with kill sites of pumas (e.g., Elbroch and Wittmer 2012, Blake and Gese 2016). Covariates included topography (elevation, slope, aspect, and ruggedness), vegetation (7 vegetation types), cover (canopy at base height), and edge density.

Topography: I obtained elevation from the 30-m resolution ASTER (Advanced Spaceborne Thermal Emission and Reflection radiometer) global digital elevation model (GDEM: www.gdem.aster.ersdac.or.jp; Accessed 12 December 2013). I derived slope (\%) and aspect (sine and cosine transformed) from the ASTER GDEM layer using the Spatial Analyst surface tools in ArcGIS 10.2. I calculated vector ruggedness measure (VRM) from the ASTER GDEM in ArcGIS 10.2 following Sappington et al. (2007).

Vegetation and edge density: I acquired vegetation layers including vegetation type $(\mathrm{n}=7)$ and vertical cover (canopy at base height; cbh) from Landscape Fire and Resource Management Planning databases (LandFire; www.landfire.gov; Accessed 19 January 2017). Based on previous studies (e.g., Dickson et al. 2005, Elbroch and Wittmer 2012), I broadly re-classified the original vegetation types into 7 distinct habitat categories: conifer, hardwood, grassland, riparian, shrub, open (barren and sparse vegetation), and other (developed upland forests, agricultural land and water). I used conifer as the reference class for comparison among vegetation types, as it was the most abundant form of vegetation in the study area. 
To estimate edge density, I obtained a road layer for my study area from USDA Forest Service maps (https://www.fs.usda.gov/detail/r5/landmanagement; Accessed 25 January, 2017) and overlaid it on Google Earth maps. Additional or incomplete tracks and roads within the study area were then digitised and the modified layer was used for the final analysis. I generated a river/stream layer by hydrological modelling of the ASTER DEM layer in ArcGIS 10.2 using the hydrology toolset. I then calculated the density of edges or linear features, defined as the interface between open and closed-canopy vegetation and between river/stream/road per pixel using the Spatial Analyst density tools in ArcGIS 10.2. The resulting combined "edge density" information was then used as a predictor variable in the analyses.

\section{Resource selection functions}

Based on existing knowledge of puma ecology, I built a set of 15 candidate models for summer/fall and winter/spring separately with likely combinations of explanatory variables (Table A2.1):

Table A2.1: Candidate models used to determine predation risk layer from 288 identified black-tailed deer kills by 7 radio-collared pumas in the Mendocino National Forest, California, between 2010 and 2012.

\begin{tabular}{|l|l|l|}
\hline No. & Candidate models & $\begin{array}{l}\text { Model } \\
\text { Category }\end{array}$ \\
\hline 1 & Null & Null \\
2 & Elevation, slope, aspect, ruggedness & Physical \\
3 & Edge, vegetation, canopy at base height & Vegetation \\
4 & Edge, vegetation, aspect, slope & $\begin{array}{l}\text { Ungulate } \\
\text { Presence (UP) } \\
\text { Ungulate } \\
\text { Presence (UP) }\end{array}$
\end{tabular}




\begin{tabular}{|c|c|c|}
\hline 6 & Edge, elevation, aspect & $\begin{array}{l}\text { Ungulate } \\
\text { Presence (UP) }\end{array}$ \\
\hline 7 & Ruggedness, canopy at base height, edge & $\begin{array}{l}\text { Hiding Cover } \\
\text { (HC) }\end{array}$ \\
\hline 8 & Slope, edge, canopy at base height & $\begin{array}{l}\text { Hiding Cover } \\
\text { (HC) }\end{array}$ \\
\hline 9 & Vegetation, ruggedness, edge, elevation, slope & $\mathrm{UP} / \mathrm{HC}$ \\
\hline 10 & Slope, elevation, vegetation, canopy at base height & $\mathrm{UP} / \mathrm{HC}$ \\
\hline 11 & Edge, elevation, aspect, ruggedness & $\mathrm{UP} / \mathrm{HC}$ \\
\hline 12 & Edge, ruggedness, vegetation, canopy at base height, aspect & $\mathrm{UP} / \mathrm{HC}$ \\
\hline 13 & Vegetation, slope, canopy at base height, ruggedness & $\mathrm{UP} / \mathrm{HC}$ \\
\hline 14 & Ruggedness, edge, aspect, vegetation, slope & $\mathrm{UP} / \mathrm{HC}$ \\
\hline 15 & Full & Full \\
\hline
\end{tabular}

To examine if site characteristics differed between BTD kills and random locations, I estimated RSFs using logistic regression of the form:

$$
g(\mathrm{x})=\ln \left[\frac{\pi(X)}{1-\pi(x)}\right]=\beta_{0}+\beta_{1} x_{1 i j}+\ldots+\beta_{n} x_{n i j}+\gamma_{0 j}
$$

where $\beta_{n}$ is the estimated coefficient for covariate $x_{n}$, and $\gamma_{0 j}$ is the random per-subject intercept (Gillies et al. 2006), which effectively controls for variation due to unbalanced individual sampling (Gillies et al. 2006, Hebblewhite and Merrill 2008).

Before running the RSFs, I tested for multicollinearity among the predictor variables used in each model. Variables with correlation coefficients $\geq 0.6$ were not used together in any model (Graham 2003). All continuous variables were standardized to allow direct comparisons of parameter estimates. Generalized linear mixed models (GLMMs) were fitted using the library 'Ime4' (Bates 2015) in program 
R (R Development Core Team 2014). I used an information-theoretic approach based on Akaike's Information Criterion with a correction for small sample sizes (AICc, Burnham and Anderson 2002) to identify the best performing models. When competing models had $\triangle \mathrm{AIC} c<2$, I retained the most parsimonious model to avoid inclusion of uninformative parameters (Arnold 2010).

I assessed model fit of our top models with $k$-fold cross-validation (Boyce et al. 2002). I randomly partitioned the data by individual within seasonal models to construct a training set ( $80 \%$ of data) and test set (20\% of data). Model-averaged estimates from the training models were then used to calculate predicted RSF values for the random locations. Subsequently, I ranked the random locations based on predicted values and binned them into 10 equal groups (Boyce et al. 2002). The fit was then quantified using the Spearman rank correlation coefficient based on the frequency of used points in each of 10 equal bins of predicted values (Boyce et al. 2002).

\section{Results}

During June 2010- November 2012, 19,988 GPS relocations from collared pumas $(\overline{\mathrm{x}}=2,855 \pm 603 \mathrm{SE}$, range $971-5,342)$ were obtained. During the same period 598 GPS location clusters were visited in the field typically within one week $(\overline{\mathrm{x}}=6.78$ $\pm 8.18 \mathrm{SD}$ ) after the puma left the area. Evidence of puma killing of black-tailed deer was found at 288 clusters (mean per puma 41, range 9-65).

\section{Summer}

The top summer predation risk model included physical and topographical variables like elevation, slope, aspect, and ruggedness (Table A2.2) and provided good fit to the data $\left(r_{\mathrm{s}}=0.84\right)$. 
Table A2.2: Ranked models for black-tailed deer kill site selection by puma during summer in the Mendocino National Forest, California, 2010-2012.

\begin{tabular}{|l|rrrrrr|}
\hline Variables & \multicolumn{1}{|c}{$K^{\mathrm{a}}$} & $\mathrm{AICc}^{\mathrm{b}}$ & \multicolumn{1}{c}{$\Delta \mathrm{AICc}$} & $w_{i}^{\mathrm{c}}$ & \multicolumn{1}{c}{$\mathrm{LL}^{\mathrm{d}}$} \\
\hline 2. & Elevation, slope, aspect, ruggedness & 7 & 1803.02 & 0 & 0.52 & -894.5 \\
13. & Vegetation, slope, cbh, ruggedness & 11 & 1805.59 & 2.57 & 0.14 & -891.78 \\
9. & Vegetation, ruggedness, edge, elevation, slope & 12 & 1805.85 & 2.83 & 0.13 & -890.9 \\
14. & Ruggedness, edge, aspect, vegetation,slope & 13 & 1806.94 & 3.92 & 0.07 & -890.44 \\
7. & Ruggedness, cbh, edge & 5 & 1808.53 & 5.51 & 0.03 & -899.26 \\
8. & Slope, edge, cbh & 5 & 1808.53 & 5.51 & 0.03 & -899.26 \\
15. & Full & 15 & 1808.8 & 5.78 & 0.03 & -889.37 \\
11. & Edge, elevation, aspect, ruggedness & 7 & 1809.19 & 6.17 & 0.02 & -897.59 \\
1. & Null & 2 & 1810.95 & 7.93 & 0.01 & -903.47 \\
4. & Edge, vegetation, aspect,slope & 12 & 1812.85 & 9.83 & 0 & -894.4 \\
6. & Edge, elevation, aspect & 6 & 1813.35 & 10.34 & 0 & -900.67 \\
10. & Slope, elevation, vegetation, cbh & 11 & 1813.96 & 10.94 & 0 & -895.96 \\
12. & Edge, ruggedness, vegetation, cbh, aspect & 13 & 1815.57 & 12.55 & 0 & -894.76 \\
3. & Edge, vegetation, cbh & 10 & 1815.79 & 12.77 & 0 & -897.88 \\
5. & Edge, vegetation, elevation, aspect & 12 & 1817.86 & 14.84 & 0 & -896.91 \\
\hline
\end{tabular}

${ }^{a} K=$ estimated number of parameters.

${ }^{\mathrm{b}} \mathrm{AIC} c=$ Akaike's Information Criterion with a correction for small sample sizes.

${ }^{\mathrm{c}} w_{i}=\mathrm{AIC}$ weight

$\mathrm{LL}^{\mathrm{d}}=\mathrm{Log}$ likelihood

The coefficients of the top summer risk model indicated that the BTD kill sites in summer was strongly associated with slope and terrain ruggedness (Table A2.3).

Table A2.3: Coefficient estimates $(\beta)$ from the top summer model for black-tailed deer kill site selection by puma in the Mendocino National Forest, California, between 2010-2012.

\begin{tabular}{|l|ccc|}
\hline Covariates & Estimate & SE & $p$ value \\
\hline Elevation & 0.018 & 0.07 & 0.08 \\
Slope & -0.228 & 0.07 & 0.00
\end{tabular}




\begin{tabular}{|l|ccc|} 
Eastern Aspect & 0.039 & 0.07 & 0.58 \\
Northern Aspect & -0.099 & 0.07 & 0.17 \\
Ruggedness & 0.210 & 0.06 & 0.00 \\
\hline
\end{tabular}

The analyses revealed that BTD were more often killed in rugged $(\beta=0.210)$ terrain with gentler slope $(\beta=-0.228)$. Though slightly insignificant, the BTD kills in summer were also associated with higher elevations $(\beta=0.018)$. As there was only one candidate model for summer predation risk with $\triangle \mathrm{AIC} c$ scores of $<2$ (Table 2.2), it was considered as the clear top model and the coefficient estimate from this model was used to generate summer predation risk layer for the study area.

\section{Winter}

Two models for selection of sites for killing deer were supported for winter. These two models had intermediate number of parameters, with the top model having an AICc weight $>0.6$. The top winter predation risk model included variables like elevation, aspect and edge density (Table A2.4) and had excellent predictive power $\left(\mathrm{r}_{\mathrm{s}}=0.95\right)$.

Table A2.4: Ranked models for black-tailed deer kill site selection by puma during winter in the Mendocino National Forest, USA, 2010-2012.

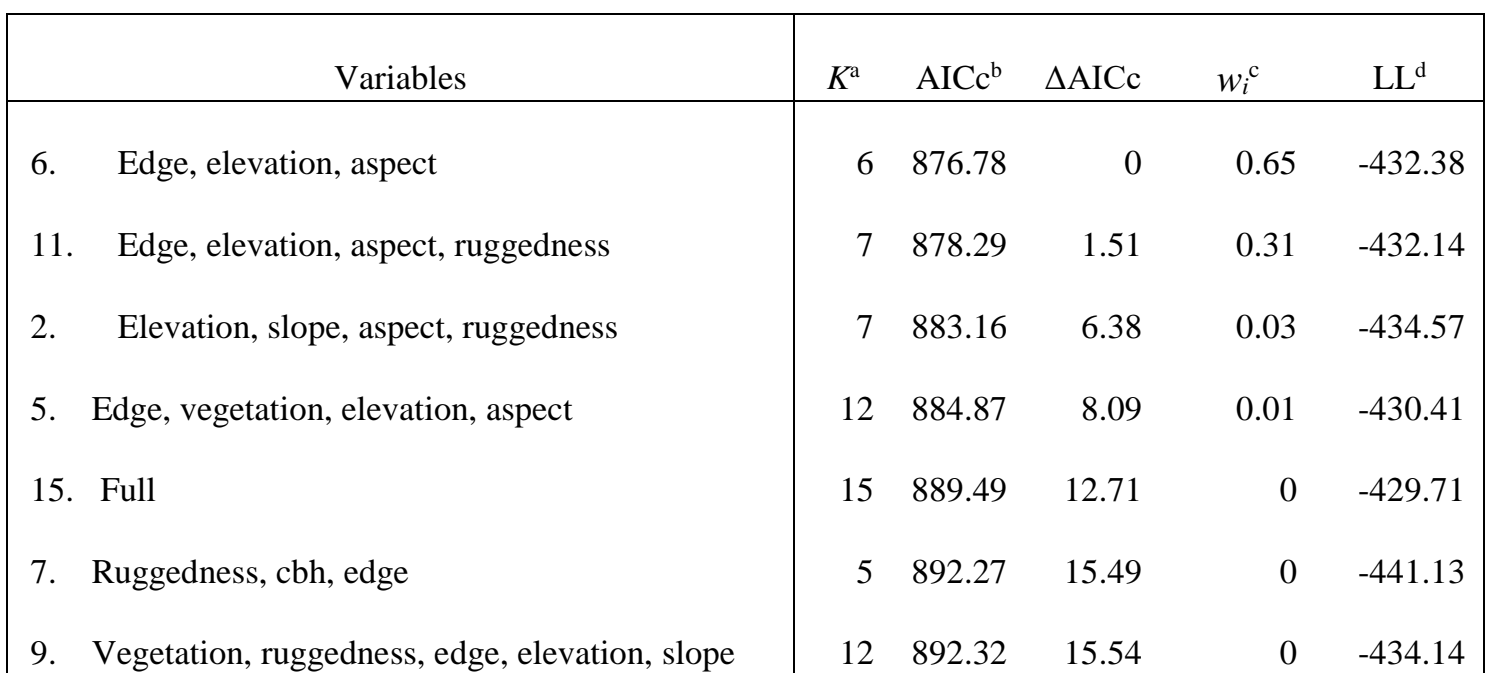


8. Slope, edge, cbh

10. Slope, elevation, vegetation, cbh

4. Edge, vegetation, aspect,slope

12. Edge, ruggedness, vegetation, cbh, aspect

14. Ruggedness, edge, aspect, vegetation,slope

3. Edge, vegetation, cbh

1. Null

13. Vegetation, slope, cbh, ruggedness

${ }^{a} K=$ estimated number of parameters.

${ }^{\mathrm{b}} \mathrm{AIC} c=$ Akaike's Information Criterion with a correction for small sample sizes. ${ }^{\mathrm{c}} w_{i}=\mathrm{AIC}$ weight

$\mathrm{LL}^{\mathrm{d}}=$ Log likelihood

The coefficients of the top winter risk model indicated that the BTD kill sites in winter was strongly associated with lower elevation $(\beta=-0.444)$ and western aspect $(\beta=0.288)$. The analyses also revealed that BTD were more often killed areas with higher edge density $(\beta=0.253)$ (Table A2.5).

Table A2.5: Coefficient estimates $(\beta)$ from the top winter model for black-tailed deer kill site selection by puma in the Mendocino National Forest, California, between 2010-2012.

\begin{tabular}{|l|ccc|}
\hline Covariates & Estimate & SE & $p$ value \\
\hline Edge Density & 0.253 & 0.11 & 0.02 \\
Eastern Aspect & 0.288 & 0.11 & 0.01 \\
Northern Aspect & -0.191 & 0.11 & 0.09 \\
Elevation & -0.444 & 0.12 & 0.00 \\
\hline
\end{tabular}

As the top model was a subset of the competing model and had $\triangle \mathrm{AICc}<2$ (Table 2.4), following Arnold (2010), I only used the coefficient estimates from the most parsimonious model to generate winter predation risk layer for the study area. 


\section{References:}

Allen, M. L. (2014). The ecology and behaviour of pumas (Puma concolor) in northern California, USA (Doctoral dissertation).Victoria University of Wellington, Wellington, New Zealand.

Allen, M. L., Elbroch, L. M., Casady, D. S., \& Wittmer, H. U. (2015). Feeding and spatial ecology of mountain lions in the Mendocino National Forest, California. California Fish and Game, 101(1), 51-65.

Arnold, T. W. (2010). Uninformative parameters and model selection using Akaike's Information Criterion. Journal of Wildlife Management, 74(6), 1175-1178.

Bates, D. Maechler, M. Bolker, B., \& Walker, S. (2015). Fitting linear mixed-effects models using lme4. Journal of Statistical Software, 67(1), 1-48.

Blake, L. W., \& Gese, E. M. (2016). Resource selection by cougars: Influence of behavioral state and season. The Journal of Wildlife Management, 80(7), 12051217.

Boyce, M. S., Vernier, P. R., Nielsen, S. E., \& Schmiegelow, F. K. (2002). Evaluating resource selection functions. Ecological Modelling, 157(2), 281-300.

Burnham, K. P., \& Anderson, D. R. (2003). Model selection and multimodel inference: a practical information-theoretic approach ( $2^{\text {nd }}$ ed.). New York, USA: SpringerVerlag.

Dickson, B. G., Jenness, J. S., \& Beier, P. (2005). Influence of vegetation, topography, and roads on cougar movement in southern California. Journal of Wildlife Management, 69(1), 264-276.

Elbroch, M., Mwampamba, T. H., Santos, M. J., Zylberberg, M., Liebenberg, L., Minye, J., ... \& Reddy, E. (2011). The value, limitations, and challenges of employing local experts in conservation research. Conservation Biology, 25(6), 1195-1202. 
Elbroch, L. M., \& Wittmer, H. U. (2012). Puma spatial ecology in open habitats with aggregate prey. Mammalian Biology-Zeitschrift für Säugetierkunde, 77(5), 377384.

Elbroch, L. M., \& Wittmer, H. U. (2013). The effects of puma prey selection and specialization on less abundant prey in Patagonia. Journal of Mammalogy, 94(2), 259-268.

Gillies, C. S., Hebblewhite, M., Nielsen, S. E., Krawchuk, M. A., Aldridge, C. L., Frair, J. L., ... \& Jerde, C. L. (2006). Application of random effects to the study of resource selection by animals. Journal of Animal Ecology, 75(4), 887-898.

Graham, M. H. (2003). Confronting multicollinearity in ecological multiple regression. Ecology, 84(11), 2809-2815.

Hebblewhite, M., \& Merrill, E. (2008). Modelling wildlife-human relationships for social species with mixed-effects resource selection models. Journal of Applied Ecology, 45(3), 834-844.

Laundré, J. W., \& Hernández, L. (2002). Growth curve models and age estimation of young cougars in the northern Great Basin. The Journal of Wildlife Management, 849-858.

Manly, B. F. J., McDonald, L. L., Thomas, D. L., McDonald, T. L., \& Erickson, W. P. (2002). Resource selection by animals: statistical analysis and design for field studies. Nordrecht, The Netherlands: Kluwer.

Northrup, J. M., Hooten, M. B., Anderson, C. R., \& Wittemyer, G. (2013). Practical guidance on characterizing availability in resource selection functions under a use-availability design. Ecology, 94(7), 1456-1463.

R Development Core Team (2014). R: A language and environment for statistical computing. $\mathrm{R}$ foundation for statistical computing, Vienna, Austria. http://www.R-project.org/. 
Sappington, J. M., Longshore, K. M., \& Thompson, D. B. (2007). Quantifying landscape ruggedness for animal habitat analysis: a case study using bighorn sheep in the Mojave Desert. Journal of Wildlife Management, 71(5), 1419-1426. 